\title{
T.S-8232-2/55054
}

\section{Molten Nitrate Salt Technology Development Status Report}

\section{c1}

R. W. Carling, C. M. Kramer, R. W. Bradshaw, D. A. Nissen, S. H. Goods, R. W. Mar, J. W. Munford, M. M. Karnowsky, R. N. Biefeld, N. J. Norem

Prepared by Sandia National Laboratories, Albuquerque, New Mexico 87185 and Livermore, California 94550 for the United

States Department of Energy under Contract DE-AC04-76DP00789.

Printed March 1981

\section{Sandia Laboratories energy report}
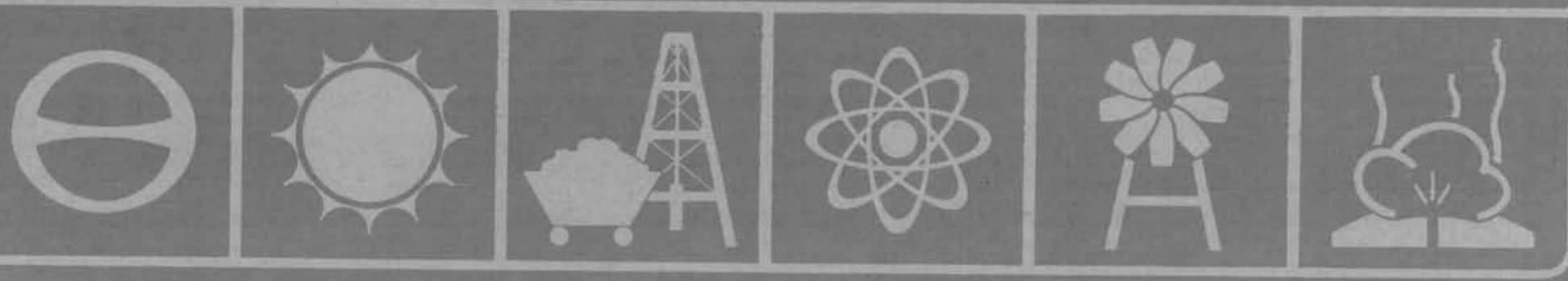
Issued by Sandia National Laboratories, operated for the United States Department of Energy by Sandia Corporation.

\section{NOTICE}

This report was prepared as an account of work sponsored by the United States Government. Neither the United States nor the United States Department of Energy, nor any of their employees, makes any warranty, express or implied, or assumes any legal liability to responsibility for the accuracy, completeness or usefulness of any information, apparatus, product or process disclosed, or represents that its use would not infringe privately owned rights.

Printed in the United States of America

Available from

National Technical Information Service

U.S. Department of Commerce

5285 Port Royal Road

Springfield, VA 22161

Price: Printed Copy $\$ 6.50$; Microfiche $\$ 3.00$ 
SAND80-8052

$U C-62 d$

Unlimited Release

Printed March 1981

MOLTEN NITRATE SALT TECHNOLOGY

DEVELOPMENT STATUS REPORT

R. W. Carling, C. M. Kramer, R. W. Bradshaw, D. A. Nissen, S. H. Goods, and R. W. Mar Sandia National Laboratories, Livermore

J. W. Munford, M. M. Karnowsky,

R. N. Biefeld, and N. J. Norem

Sandia National Laboratories, Albuquerque

ABSTRACT

Recognizing thermal energy storage as potentially critical to the successful commercialization of solar thermal power systems, the Department of Energy (DOE) has established a comprehensive and aggressive thermal energy storage technology development program. Of the fluids proposed for heat transfer and energy storage molten nitrate salts offer significant economic advantages. The nitrate salt of most interest is a binary mixture of $\mathrm{NaNO}_{3}$ and $\mathrm{KNO}_{3}$. Al though nitrate/nitrite mixtures have been used for decades as heat transfer and heat treatment fluids the use has been at temperatures of about $450^{\circ} \mathrm{C}$ and lower. In solar thermal power systems the salts will experience a temperature range of 350 to $600^{\circ} \mathrm{C}$. Because central receiver applications place more rigorous demands and higher temperatures on nitrate salts a comprehensive experimental program has been developed to examine what effects, if any, the new demands and temperatures have on the salts. The experiments include corrosion testing, environmental cracking of containment materials, and determinations of physical properties and decomposition mechanisms. This report details the work done at Sandia National Laboratories in each area listed. In addition, summaries of the experimental programs at Oak Ridge National Laboratory, the University of New York, EIC Laboratories, Inc., and the Norwegian Institute of Technology on molten nitrate salts are given. Also discussed is how the experimental programs will influence the near-term central receiver programs such as utility repowering/industrial retrofit and cogeneration. The report is designed to provide easy access to the latest information and data on molten $\mathrm{NaNO}_{3} / \mathrm{KNO}_{3}$ for the designers and engineers of future central receiver projects. 


\section{CONTENTS}

$\underline{\text { Page }}$

$\begin{array}{lll}1.0 & \text { INTRODUCTION } & 7\end{array}$

2.0 EXPERIMENTAL PROGRAM OVERVIEW 11

$\begin{array}{ll}3.0 & \text { IMMERSION TESTS }\end{array}$

4.0 CORROSION STUDIES USING THERMAL CONVECTION LOOPS 33

5.0 CREEP AND THE EFFECTS OF DEFORMATION ON THE CORROSION 45 CHARACTERISTICS OF INCOLOY 800 IN MOLTEN NITRATE SALTS OF INCOLOY 800

7.0 A SOLID ELECTROLYTE OXIDE ION PROBE FOR MOLTEN NITRATES TO EVALUATE POSSIBLE CORROSION PROBLEMS

9.0 PRESSURE-TEMPERATURE-COMPOSITION RELATIONSHIPS FOR 67 HEATED DRAWSALT SYSTEMS

!0.0 VISCOSITY, SURFACE TENSION, AND DENSITY OF $(\mathrm{K}, \mathrm{Na}) \mathrm{NO}_{3} \quad 79$ FROM 300 TO $600^{\circ} \mathrm{C}$

11.0 HEAT CAPACITIES OF $\mathrm{NaNO}_{3}, \mathrm{KNO}_{3}$, AND $(\mathrm{Na}, \mathrm{K}) \mathrm{NO}_{3} \quad 93$

12.0 PHASE DIAGRAMS OF $\mathrm{NaNO}_{3}-\mathrm{Na}_{2} \mathrm{CO}_{3}$ AND KNO $3-\mathrm{K}_{2} \mathrm{CO}_{3} \quad 101$ 


\subsection{INTRODUCTION}

R. W. Carling

\subsection{Background}

Recognizing thermal energy storage as potentially critical to the successful commercialization of solar thermal power systems, the Department of Energy (DOE) has established a comprehensive and aggressive thermal energy storage technology development program. The overall objective of this program is to develop general solar thermal energy storage technologies that provide: (1) first-generation storage subsystems for those solar thermal applications that presently have no storage subsystems under development, (2) secondgeneration storage subsystems offering cost/performance improvements over the first-generation storage subsystems currently being developed, and (3) a technology base to support storage subsystem development for future solar thermal power applications (Reference 1.1).

Current central receiver solar power systems (e.g., Barstow) employ a water/steam receiver which can either run a turbine directly or charge storage (cf. Figure 1.1). In some second generation storage subsystems the fluid transferring heat from the receiver and that in the storage tank are the same. Therefore, a fluid must be found that is a liquid over the temperature range of interest, i.e., 350 to $600^{\circ} \mathrm{C}$. Ideally, the fluid would be liquid to room temperature for ease of handling. However, to date no fluids that are inexpensive, available, non-toxic, etc., have been identified that are liquid from room temperature to $600^{\circ} \mathrm{C}$. The next best approach is to identify a fluid that has a melting point below $350^{\circ} \mathrm{C}$ and meets the other requirements of cost, availability, and physical properties. The quintessential choices are molten salts and metals. Examples of the former are mixtures of alkali metal nitrates/ nitrites, while alkali metals represent the latter. The data base is large for the alkali metals as a result of their application to the nuclear reactor industry. However, there is a paucity of molten nitrate/nitrite salt data and usage in the upper end $\left(500\right.$ to $\left.600^{\circ} \mathrm{C}\right)$ of the applicable temperature range.

Mixtures of alkali metal nitrates/nitrites are being proposed because they have suitable melting points. The melting points of single, pure alkali metal nitrates or nitrites are too high. Figure 1.2 shows the quaternary phase diagram for $\mathrm{NaNO}_{3}, \mathrm{NaNO}_{2}, \mathrm{KNO}_{3}$, and $\mathrm{KNO}_{2}$ (Reference 1.2). The most common molten salt in industrial use today for heat treating and transfer applications is HITEC or HTS. It has a melting point of $143^{\circ} \mathrm{C}$ and is a mixture of 40 percent $\mathrm{NaNO}_{2}, 7$ percent $\mathrm{NaNO}_{3}$, and 53 percent $\mathrm{KNO}_{3}$ by weight. Another common salt in use is drawsalt, 46 percent $\mathrm{NaNO}_{3}$ and 54 percent $\mathrm{KNO}_{3}$ (by weight), 


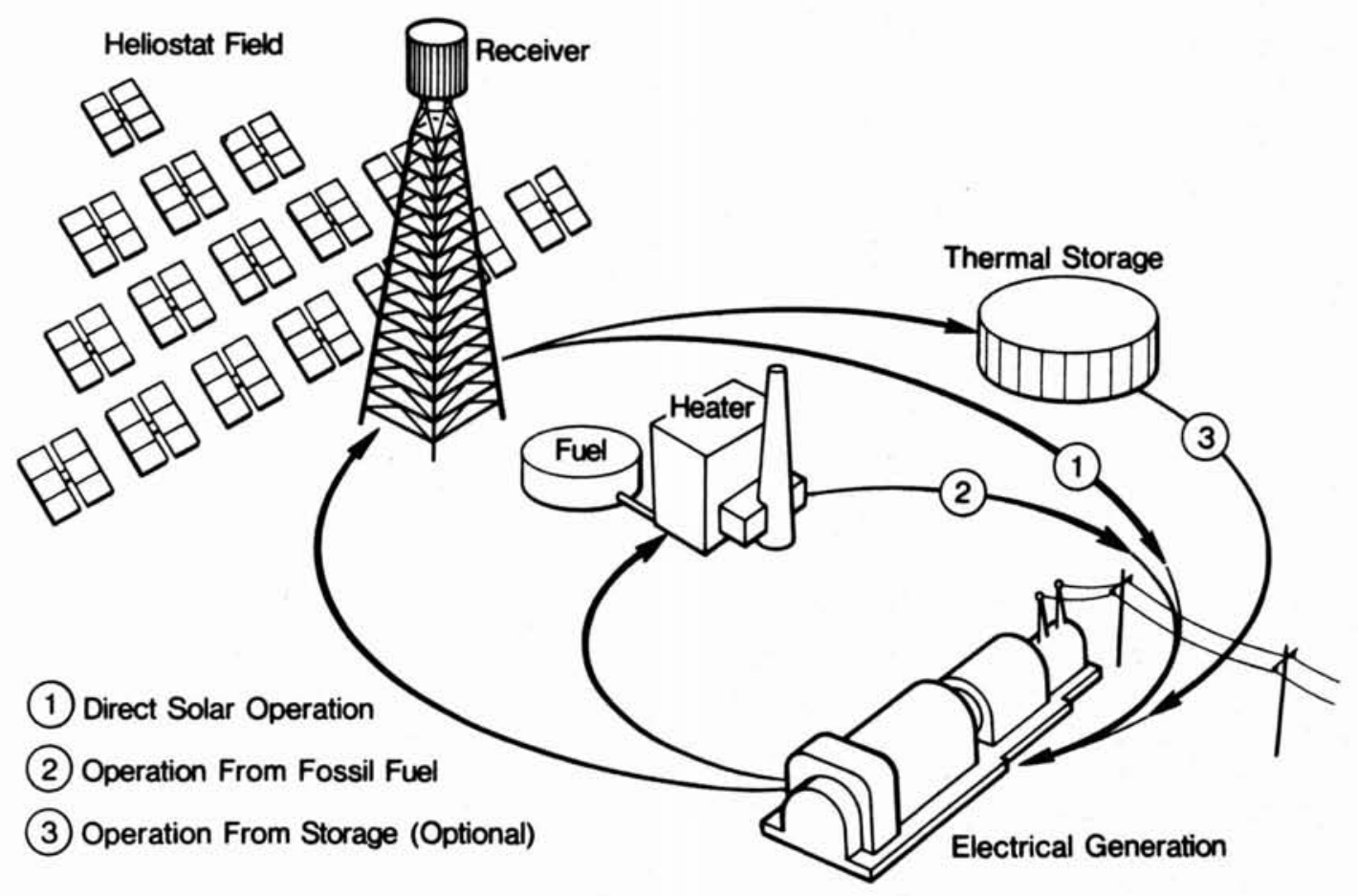

Figure 1.1. Schematic of a "Barstow-Type" Central Receiver Using Different Fluids As the Heat Transfer and Energy Storage Media

which has a melting point of $221^{\circ} \mathrm{C}$. Both salts have acceptable melting points. However, because of the large percentage of $\mathrm{NaNO}_{2}$ in HITEC ( $\mathrm{NaNO}_{2}$ is the most expensive of the three salts in HITEC), HITEC is not economical with respect to drawsalt. Therefore, emphasis for solar thermal power applications has been placed on binary mixtures of $\mathrm{NaNO}_{3}$ and $\mathrm{KNO}_{3}$. The binary phase diagram is shown in Figure 1.3 (Reference 1.3). Since the middle portion of the diagram is relatively flat and the melting point changes relatively slowly in this region it is economical to select a composition rich in $\mathrm{NaNO}_{3}$ because it is less expensive than $\mathrm{KNO}_{3}$ and the overall cost of the salt is then reduced. A composition marketed by Park Chemical Company of Detroit, Michigan under the trade name Partherm 430 is 60 percent $\mathrm{NaNO}_{3}$ and 40 percent $\mathrm{KNO}_{3}$ (by weight) with a melting point of $221^{\circ} \mathrm{C}$. Although a salt mixture has been identified, salt physical properties, chemistry, corrosive behavior, and environmental effects are not well known over the temperature range of interest, 350 to $600^{\circ} \mathrm{C}$. In addition, while molten nitrates have performed satisfactorily for many years as a heat transfer fluid and as a heat treatment bath medium, solar applications place more rigorous demands on the salt. Therefore, many experimental programs have been undertaken to address the uncertainties mentioned above. This report then focuses on the experimental programs on binary mixtures of molten nitrate salts in support of the Thermal Energy and Storage for Solar Thermal Applications (TESSTA) program. The report summarizes: (1) what new information and data are available, (2) how and when the information and data will impact near-term solar thermal power applications, and (3) the experimental work being performed outside Sandia National Laboratories (SNL). 


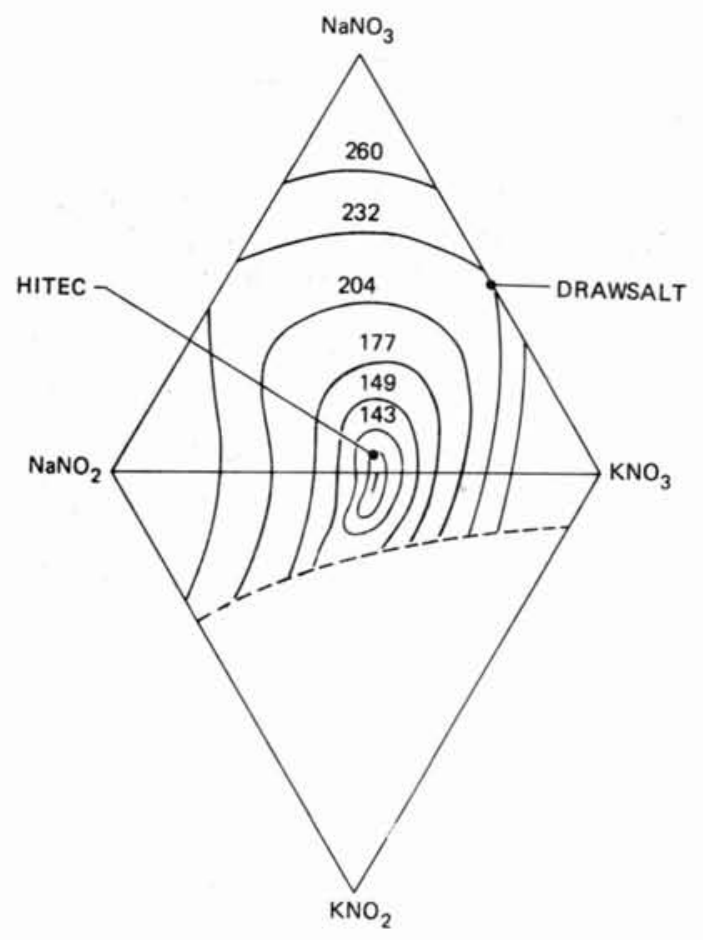

Figure 1.2. Freezing Ponts $\left(\right.$ in ${ }^{\circ} \mathrm{C}$ ) of Alkali Nitrate-Nitrite Mixtures (From Reference 1.2)

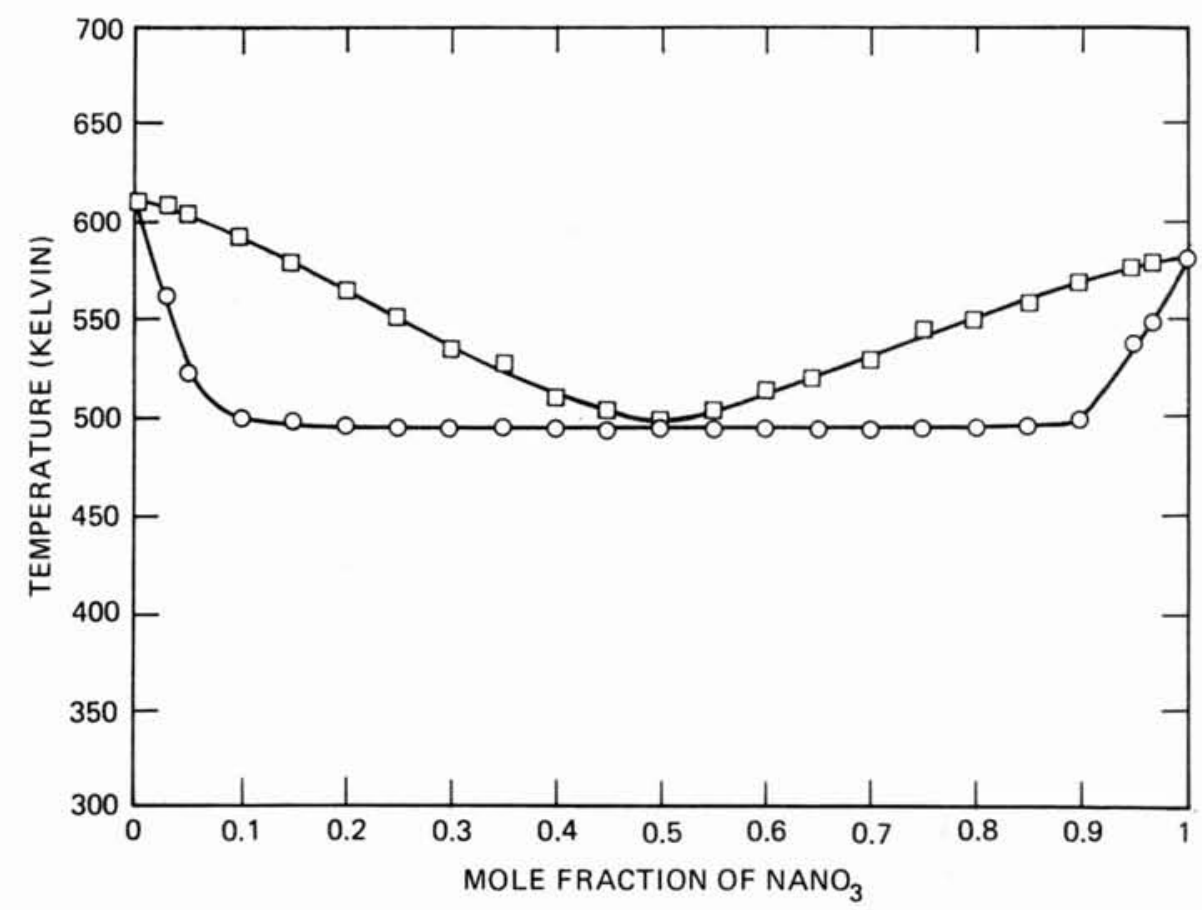

Figure 1.3. Phase Diagram of $\mathrm{NaNO}_{3}$ and $\mathrm{KNO}_{3}$ 


\subsection{References}

1.1 L. G. Radosevich, "Thermal Energy Storage for Solar Thermal Applications Program Progress Report (Oct. 1979 - Mar. 1980)," Sandia National Laboratories, Livermore, SAND80-8218, May 1980.

1.2 J. Alexander, Jr., and S. G. Hindin, Ind. Eng. Chem. 39, 1044 (1947).

1.3 C. M. Kramer and C. J. Wilson, "The Phase Diagram of $\mathrm{NaNO}_{3} / \mathrm{KNO}_{3}$," Sandia National Laboratories, Livermore, SAND80-8502, April 1980. 


\subsection{EXPERIMENTAL PROGRAM OVERVIEW}

R. W. Carling

\subsection{Introduction}

The goal of the program is to provide technical information and data on molten nitrate salt to future designers and engineers of near-term central receiver applications in a timely fashion. To do this a comprehensive program was started to supplement old and generate new information and data on binary mixtures of molten nitrate salts. In-house and external experimental programs are underway to generate the needed information. The external programs are summarized in this section. In addition, details are given of how the experimental programs are intended to impact the development of large power systems. The subsequent sections in this report detail the individual experimental programs within SNL.

\subsection{External Experimental Activities}

There are four contracts with agencies outside of SNL doing experimental work on molten nitrate salts in support of the TESSTA program. They are: Oak Ridge National Laboratory (ORNL), State University of New York at Buffalo (UNYB), EIC Corporation, and the Norwegian Institute of Technology (NIT). A brief contractual summary of each is given in Table 2.I.

TABLE 2.1

SUMMARY OF CONTRACTS FOR MOLTEN NITRATE SALT RESEARCH

\begin{tabular}{|c|c|c|c|c|}
\hline & Contractor & $\begin{array}{l}\text { Principal } \\
\text { Investigator }\end{array}$ & $\begin{array}{c}\text { Contract } \\
\text { Period } \\
\end{array}$ & $\begin{array}{l}\text { Sandia } \\
\text { Technical Manager }\end{array}$ \\
\hline $\begin{array}{l}\text { Closed Thermal } \\
\text { Convection Loops }\end{array}$ & ORNL & J. H. DeVan & $\begin{array}{l}\text { Feb. } 1980-- \\
\text { Feb. } 1981\end{array}$ & R. W. Carling \\
\hline $\begin{array}{l}\text { Electrochemical } \\
\text { Corrosion Studies }\end{array}$ & UNYB & R. A. Osteryoung & $\begin{array}{l}\text { May 1980-- } \\
\text { Sept. } 1981\end{array}$ & R. W. Carling \\
\hline $\begin{array}{l}\mathrm{CO}_{2} \text { and } \mathrm{H}_{2} \mathrm{O} \\
\text { Interactions }\end{array}$ & EIC & S. H. White & $\begin{array}{l}\text { June 1980-- } \\
\text { June } 1981\end{array}$ & R. W. Carling \\
\hline $\begin{array}{l}\text { Thermal } \\
\text { Conductivity }\end{array}$ & NIT & H. A. Oye & $\begin{array}{l}\text { Oct. } 1980-- \\
\text { June } 1982\end{array}$ & R. W. Carling \\
\hline
\end{tabular}




\subsubsection{Oak Ridge National Laboratory}

One of the important criteria when designing a solar thermal power system is long lifetime (typically 30 years). Obviously, understanding the corrosion behavior of the molten nitrate salt and its container material is important when estimating lifetimes. Although there is a large amount of industrial experience with molten nitrate salts, most is at lower temperatures. Therefore, experimental programs at SNLL (cf. Section 4.0) and ORNL were undertaken to address the corrosion behavior of molten nitrate salt with metal alloys that might conceivably be used to contain the salt.

The work at ORNL has involved the construction of three convection loops. Each loop is made out of a different high-strength alloy: Incoloy 800 (I800), 304 stainless steel (304SS), and 316 stainless steel (316SS). Salt is contained within the loop and circulated by natural convection due to the difference in salt density between the hot $\left(595^{\circ} \mathrm{C}\right)$ and cold $\left(360^{\circ} \mathrm{C}\right)$ legs of the loop. An inert cover gas is maintained over the salt. General operating conditions of the loops are given in Table 2.II. A convection loop is shown schematically in Figure 2.1.

TABLE 2.II

OPERATING CONDITIONS OF ORNL THERMAL CONVECTION LOOP

\begin{tabular}{|c|c|c|c|c|}
\hline $\begin{array}{l}\text { Loop } \\
\text { Material } \\
\end{array}$ & $\begin{array}{r}\text { Hours of } \\
\text { Operation } \\
\text { on } 10 / 31 / 80 \\
\end{array}$ & $\begin{array}{l}\text { Weight Changes } \\
\text { at } 600^{\circ} \mathrm{C} \\
\left(\mathrm{mg} / \mathrm{cm}^{2}\right) \\
\end{array}$ & $\begin{array}{l}\text { Nitrate } \\
(\text { wt } \%) \\
\end{array}$ & $\begin{array}{c}\mathrm{Cr} \\
\text { (wt ppm) } \\
\end{array}$ \\
\hline $316 \mathrm{SS}$ & 3000 & -0.06 & 1.9 & 95 \\
\hline $304 S S$ & 2000 & +0.05 & 1.7 & 163 \\
\hline I 800 & 380 & negligible & $N A^{a}$ & $N A^{a}$ \\
\hline
\end{tabular}




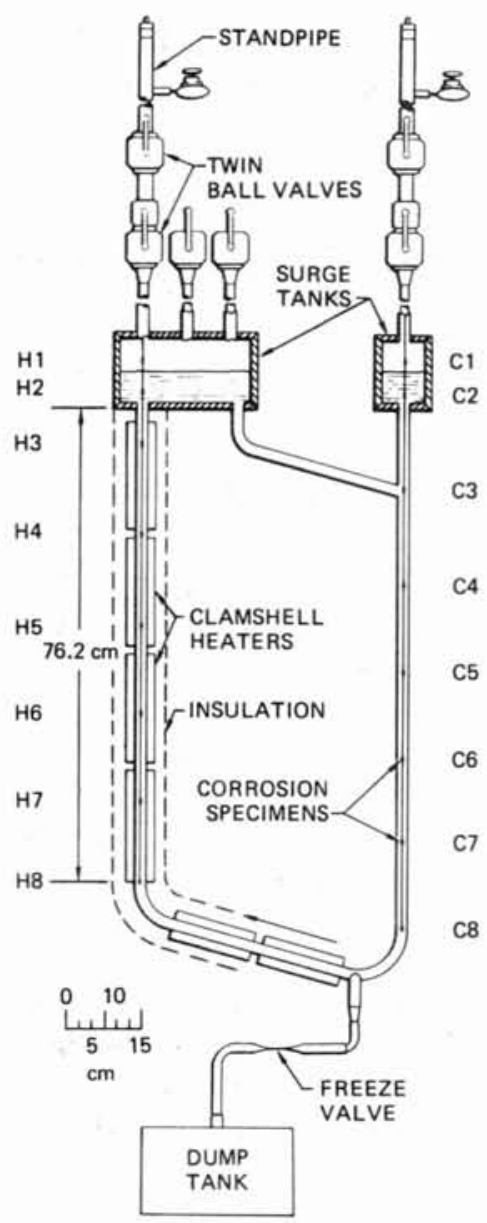

Figure 2.1. Thermal Convection Loop Used at ORNL in $\mathrm{NaNO}_{3}-\mathrm{KNO}_{3}$ Studies

As seen in Figure 2.1 metal coupons have been suspended in each leg. The coupons are approximately $1.9 \times 0.8 \times 0.1 \mathrm{~cm}$. The coupons are withdrawn periodically, cleaned, and weighed. These results indicate that the shorttime corrosion rates of $304 \mathrm{SS}$ and $316 \mathrm{SS}$ are quite small $\left(<4 \mathrm{mg} / \mathrm{m}^{2}-\mathrm{h}\right.$ ) compared to rates measured under similar conditions in HITEC (Reference 2.1). Results from longer time exposures will be used to establish the time dependence of the corrosion process.

In addition to recording weight changes, the corners of some of the coupons are clipped for metallographic analysis. Results show the formation of a duplex oxide layer similar to the layers observed on 304SS and 316SS in the SNLL experiments (Reference 2.2). Scales on the SNLL specimens consisted of an outer layer of $\mathrm{Fe}_{3} \mathrm{O}_{4}$ and an inner spinel layer containing $\mathrm{Cr}$ and $\mathrm{Fe}$.

From the results obtained so far it is apparent that two competing processes are taking place in the loops: oxidation and dissolution. 0xidation is clearly evident from the metallographic analyses, while the occurrence of dissolution is evident from measured weight losses and analysis of the salt. Salt analysis indicates a large increase in chromium in the salt. 
Although the measured weight losses are significant, the weight loss corresponds to a surface recession rate that is less than $4 \mu \mathrm{m} / \mathrm{y}$ (a receiver wall thickness being about $1600 \mu \mathrm{m})$.

Further analyses of the salt within the loops are being done by using controlled potential voltammetry to monitor electrochemical changes. Iridium electrodes have been placed in the hot leg surge tank. The current is measured as a function of impressed voltage between the electrodes. Changes in the salt will result in changes in the shape of the current-voltage curve.

\subsubsection{University of New York at Buffalo}

The objective of this contract is to develop an understanding of the phenomena ascribed to Incoloy 800 that inhibits the corrosion of the metal by molten nitrates. Available experimental evidence indicates that the formation of thin passivating oxide layers is responsible for the negligible corrosion rates of certain structural alloys in molten nitrates. However, nothing is known about the kinetics or mechanism of the formation of this passivating film in molten nitrate, or of the corrosion mechanism in general. The effect of temperature or oxygen partial pressure on these processes is also unknown. Studying these effects is critical because this passivating film will be subjected to disruptive forces developed during the heating and cooling cycles experienced in certain solar energy applications. A thorough understanding of the corrosion mechanism of Incoloy 800 , as a representative structural alloy, and of the mechanism of formation of these passivating films is important so conditions leading to catastrophic failure of this protective layer can be avoided.

In order to understand the corrosion behavior of $\mathrm{Fe}-\mathrm{Cr}$ based alloys, the behavior of metallic iron and chromium and the species that are formed at 350 to $600^{\circ} \mathrm{C}$ in molten $\mathrm{NaNO}_{3}-\mathrm{KNO}_{3}$ will be investigated. The kinetics and mechanism of the formation of the passivating film on Incoloy 800 will be made in molten 50 mole percent $\mathrm{NaNO}_{3}-\mathrm{KNO}_{3}$ over the temperature range 350 to $600^{\circ} \mathrm{C}$. The effect of oxygen partial pressure and the role of impurities, such as $\mathrm{NO}_{-}^{-}$, $\mathrm{OH}^{-}$and $\mathrm{Cl}^{-}$, and the rate and mode for formation of the passivating film wilf" be included in the investigation. The chemical identity of the passivating film will be determined, as well as the dependence of composition upon the conditions of formation.

Current-potential polarization curves will be obtained for each pure metal (i.e., iron, nickel, and chromium) to establish the range of potentials where passivation/dissolution occurs. At the same time information will be obtained about the nature of the species formed during this process (e.g., passivating film, ions in solution, etc.). After establishing the behavior of each metal, studies on 1800 will be conducted. This study includes steady and non-steady electrochemical methods and spectrophoto-metric techniques.

\subsubsection{EIC Corporation}

The objective of this program is to provide an understanding of the interactions of molten potassium nitrate, sodium nitrate, and their binary mixtures with water and carbon dioxide in the air. These studies will 
complement ongoing work at SNLL. The results of these studies will help to determine whether an open, closed or breathing system is needed for salt storage.

The chemical reactivity of the nitrates is of paramount importance particularly since these liquids would be exposed to variable atmospheric conditions. Interactions with atmospheric components are of importance, particularly with respect to the oxygen, water, and carbon dioxide content of the atmosphere. The likelihood of interaction between these atmosphere components and the liquid nitrates is small at lower temperatures $\left(<300^{\circ} \mathrm{C}\right.$ for the binary mixture $(\mathrm{Na}, \mathrm{K}) \mathrm{NO}_{3}$. However, the long-term temperature cycling, the need for higher temperatures $\left(400-600^{\circ} \mathrm{C}\right)$, and the use of metallic containers will lead to decomposition of the nitrate (Reference 2.3). The presence of atmospheric oxygen, carbon dioxide, and water will moderate the reaction pathways available (References 2.4-2.6). Thus, the characterization of the reactions involving water and carbon dioxide with these nitrate melts under atmospheric conditions is of prime importance. A number of anionic species may result from these interactions, for example, $\mathrm{CO}_{3}=\mathrm{OH}^{-}, 0^{2-}, \mathrm{O}_{2}^{2-}, \mathrm{O}_{2}^{-}$, etc.

These species have received particular attention, especially with regard to their electro-oxidative behavior (References 2.7-2.10). Several workers have established half wave potentials, diffusion coefficients, and $n$ values albeit over a limited temperature range. This suggests that electroanalytical techniques could be successfully used to study the formation of these species, as well as the direct behavior of water, carbon dioxide, and oxygen in the nitrate melts.

The low concentrations of water, carbon dioxide, oxygen, etc., suggest that the monitoring of these species and their degradation products might best be achieved by in situ electroanalytical techniques in the molten nitrates. It is clear from previous work that the rotating disc electrode, cyclic voltammetry, and chronopotentiometry offer rapid dynamic means by which the low concentrations of reactants (and products) can be monitored quantitatively as a function of controlled gas pressure/atmosphere and temperature.

The electroanalytical procedures using cyclic voltammetry, chronopotentiometry, and chronoamperometry and differential pulse polarography have been set up using the PAR 174A polarographic analyzer and PAR 175 signal generator. The data is recorded on a PAR 4102 signal processor or the Bascom-Turner 8000 series microprocessor controlled $X-Y$ recorder. Software to process these data is being developed.

A procedure for the purification and characterization of the individual sodium and potassium nitrate melts and their binary mixture involving vacuum drying and treatment with $\mathrm{NO}_{2}$ gas has been developed and is being evaluated using cyclic voltammetry.

Preliminary measurements have been made to obtain information on the behavior of water, carbon dioxide, and potential decomposition products such as nitrite, carbonate, and hydroxide ions in the binary nitrate mixture. The cyclic voltammetric results obtained on the low temperature behavior of water showed a well defined reduction peak (responsive to the presence of different water concentrations) close to the cathodic limit of the solvent. An analysis 
of the peak characteristics show that the reduction is not a simple diffusion controlled process. Nevertheless, from the peak current density it is possible to obtain an activation energy that was $4.4 \mathrm{kcal}$ typical for diffusional processes involving ionic species in molten nitrates. Experiments were carried out at $300^{\circ} \mathrm{C}$ to examine the rate of absorption and desorption of water by the melt. It was observed that argon, carbon dioxide, or oxygen saturated with water at a vapor pressure of $19.6 \mathrm{~mm}$ took approximately 3 minutes to saturate the nitrate melt with the bubbler below the surface of the melt, and 90 minutes when the bubbler was about 2-3 cm above the melt. (The gas flow rate was $\sim 200 \mathrm{ml} \mathrm{min}^{-1}$ and the surface area $\sim 28 \mathrm{~cm}^{2}$.) On the other hand, water was completely removed by bubbling dry argon through the melt for 20 minutes. These results show that water can be reversibly removed from the nitrate melt.

The behavior of nitrite and carbonate ions is less well resolved. For example, the solubility of the carbonate ions is very much less than that of nitrite ions, and the apparent rate of carbonate dissolution is also small. Because the products of electrooxidation of carbonate and nitrite are thought to be gaseous,

$$
\mathrm{NO}_{2}^{-} \rightleftarrows \mathrm{NO}_{2}(\mathrm{~g})+\mathrm{e}^{-}
$$

and

$$
\mathrm{CO}_{3}+\mathrm{CO}_{2}(\mathrm{~g})+\frac{1}{2} \mathrm{O}_{2}(\mathrm{~g})+2 \mathrm{e}^{-}
$$

fast scan voltammetry or high current density chronopotentiometry may be required for electroanalysis. This will prevent disturbance of the diffusion layer, and hence, invalidation of the simple reversible conditions, especially at higher concentrations.

\subsubsection{Norwegian Institute of Technology}

The objective of this study is to measure the thermal conductivity of molten $(\mathrm{Na}, \mathrm{K}) \mathrm{NO}_{3}$ mixtures, to determine the effect of impurities upon the thermal conductivity of these mixtures, and to use the results to construct a predictive model for the thermal conductivity. The thermal conductivity of the following uncontaminated mixtures of molten nitrate salts will be measured over the temperature range, 350 to $600^{\circ} \mathrm{C}$.

$$
\begin{aligned}
& \text { a. } 50 \mathrm{KNO}_{3}-5 \mathrm{ONaNO}_{3} \text { (molar ratio) } \\
& \text { b. } 60 \mathrm{KNO}_{3}-40 \mathrm{NaNO}_{3} \\
& \text { c. } 40 \mathrm{KNO}_{3}-60 \mathrm{NaNO}_{3} \\
& \text { d. } 45 \mathrm{KNO}_{3}-45 \mathrm{NaNO}_{3}-10 \mathrm{KNO}_{2}
\end{aligned}
$$

The effect on the thermal conductivity of small additions of $\mathrm{CO}=$, and $\mathrm{OH}^{-}$ is being determined for each salt listed above. The suggested maximum additions of contaminants are: 

a. $\quad \mathrm{CO}_{3}=(5 \mathrm{wt} \%)$
b. $\mathrm{OH}^{-}(0.1 \mathrm{wt} \%)$

The experiment employs an absolute method for simultaneous determination of the thermal conductivity and diffusivity. The experiment is a transient technique and uses a thin metal foil as the heating element. It is a modification of the "hot-strip" method proposed previously (Reference 2.11). This method is preferred to steady-state types of thermal conductivity experiments because it obtains measurements much faster and thereby significantly reduces thermal radiation losses. Initial work has focused on obtaining a material to cover the thin foil to electrically insulate the molten salt from the foil.

\subsection{Molten Salt Usage in Large Systems}

The information derived from the experiments described in this report will impact decision points set by DOE for the development of thermal storage technologies required for several near-term central receiver applications. These include the repowering/industrial retrofit and cogeneration programs described briefly in Sections 2.3.1 and 2.3.2.

There are also three large-scale experimental programs that address the individual portions of the energy transfer and storage system: the development of an advanced central receiver (ACR), the thermal storage subsystem research experiment (SRE), and the design of a salt/steam heat exchanger. These programs will be described in Sections 2.3.3 to 2.3.5.

\subsubsection{Repowering/Industrial Retrofit}

In March 1979 DOE issued a solicitation for utility repowering/industrial retrofit system conceptual design studies employing solar central receivers. of the twelve responses that were funded, six were for repowering of existing oil or natural gas-fired electric generating plants. The other six were for the first site-specific studies of the use of solar central receiver systems for industrial process heat. Of the six electric utility repowering studies, two proposed molten nitrate salts for heat transport and energy storage. The prime contractors for these studies were Arizona Public Service Company and McDonnell Douglas.

The conceptual design phase of the repowering program has been completed. The designs using molten nitrate salt proposed the salt as the heat transfer and energy storage fluid. The fluid is heated to about $565^{\circ} \mathrm{C}$ in the receiver. The hot molten salt then flows to the thermal storage tank. Salt is withdrawn to generate steam for the turbine. The next stage for repowering is preliminary design with selection of contractors to be made in 1981. The molten salt repowering contracts are summarized in Table 2-III. 
TABLE 2.III

REPOWERING AND COGENERATION CONTRACTORS USING MOLTEN NITRATE SALTS

\begin{tabular}{|c|c|c|c|c|}
\hline $\begin{array}{c}\text { Prime } \\
\text { Contractor }\end{array}$ & Subcontractors & Site Location & Process & Status \\
\hline $\begin{array}{l}\text { Arizona Public } \\
\text { Service Co. }\end{array}$ & $\begin{array}{l}\text { Martin Marietta } \\
\text { Badger Energy } \\
\text { Gibs \& Hill }\end{array}$ & $\begin{array}{l}\text { Saguaro Power } \\
\text { Plant } \\
\text { Tucson, Ariz. }\end{array}$ & $\begin{array}{l}\text { Steam to Produce } \\
\text { Electricity }\end{array}$ & $\begin{array}{l}\text { Conceptual } \\
\text { Design Complete }\end{array}$ \\
\hline McDonnell Douglas & $\begin{array}{l}\text { Sierra Pacific Power } \\
\text { Stearns-Roger } \\
\text { Desert Research Inst. } \\
\text { Foster Wheeler } \\
\text { Univ. Of Houston } \\
\text { Westinghouse }\end{array}$ & $\begin{array}{l}\text { Ft. Churchill } \\
\text { Piant } \\
\text { Yerington, Nev. }\end{array}$ & $\begin{array}{l}\text { Steam to Produce } \\
\text { Electricity }\end{array}$ & $\begin{array}{l}\text { Conceptual } \\
\text { Design Complete }\end{array}$ \\
\hline $\begin{array}{l}\text { Exxon Research } \\
\text { \& Eng. Co. }\end{array}$ & $\begin{array}{l}\text { Martin Marietta } \\
\text { Pacific Gas \& Elec. } \\
\text { Badger Energy }\end{array}$ & $\begin{array}{l}\text { Edison Field } \\
\text { Bakersfield, CA }\end{array}$ & $\begin{array}{l}\text { Steam for } \\
\text { Enhanced } 0 \text { il } \\
\text { Recovery }\end{array}$ & Started \\
\hline McDonnell Douglas & $\begin{array}{l}\text { Stearns-Roger } \\
\text { Univ. of Houston } \\
\text { Ft. Hood Army Base }\end{array}$ & $\begin{array}{l}\text { Fort Hood } \\
\text { Killeen, TX }\end{array}$ & $\begin{array}{l}\text { Steam to Produce } \\
\text { Electricity and } \\
\text { Space Conditioning }\end{array}$ & In Negotiation \\
\hline
\end{tabular}

\subsubsection{Cogeneration}

Seven conceptual design proposals have been selected for the cogeneration of electricity and heat from solar energy. Of the seven, two employ molten nitrate salts as the heat transfer and energy storage fluid: Exxon Research and Engineering Company to provide steam for enhanced oil recovery, and McDonnell Douglas to create steam to produce electricity and space conditioning at Ft. Hood Army Base. The selected proposals are under contract negotiation with DOE. The molten salt cogeneration projects are summarized in Table 2.III.

\subsubsection{Advanced Central Receiver (ACR)}

The ACR program involves design, construction, and testing of a second generation receiver using fluids other than that of the Barstow receiver (water/steam). The prime contractor for the ACR using molten nitrate salt as the fluid is Martin Marietta Corporation.

A schematic of the receiver design is shown in Figure 2.2. The receiver consists of 18 passes of 16 tubes each. The salt is pumped through the receiver in a serpentine fashion. The heat collected is rejected in an air cooler. The receiver experiment is being conducted at the Central Receiver Test Facility (CRTF) in Albuquerque, NM. An illustration of the receiver sitting on top of the tower at the CRTF is shown in Figure 2.3.

Through 0ctober 1980 the receiver has had 225 hours of total solar test time. Of that, 115 hours have been at full power (about 200 heliostats) with 70 hours at full power and design temperatures. The peak power output has been $4.7 \mathrm{MW}_{\mathrm{th}}$. 


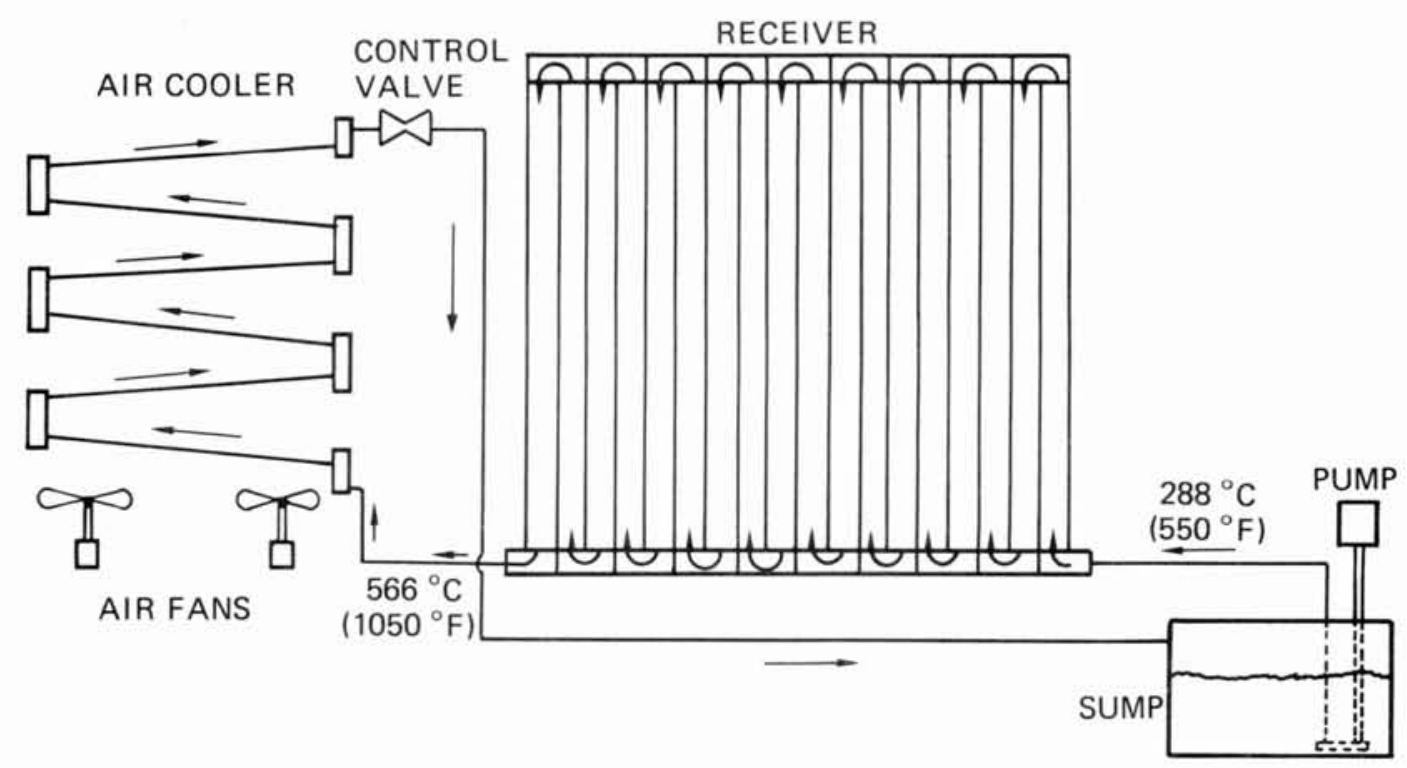

Figure 2.2. Schematic of Martin Marietta Advanced Central Receiver Tested at CRTF in Albuquerque

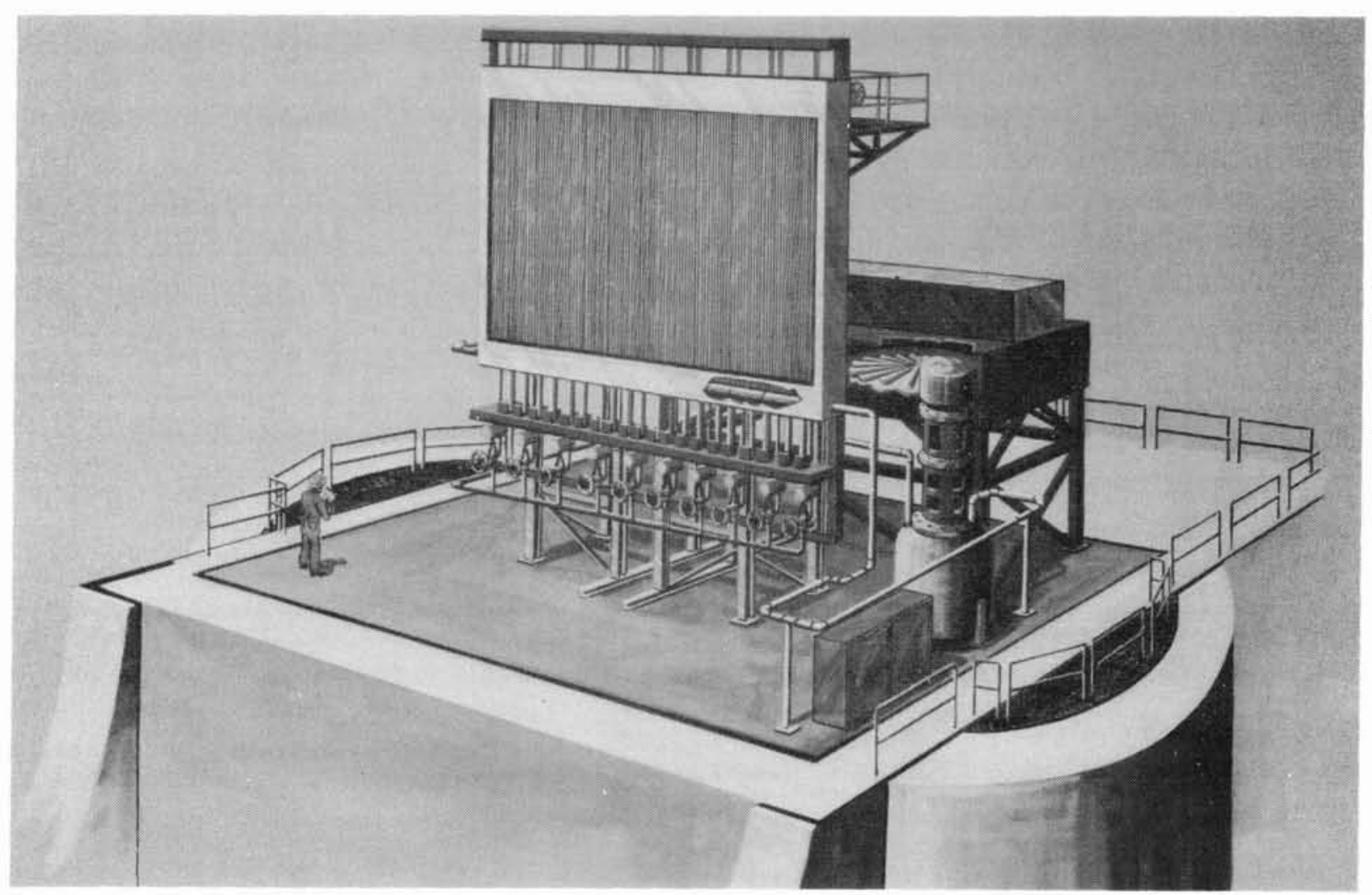

Figure 2.3. Artist Concept of Martin Marietta Advanced Central Receiver in the Exposed Configuration 


\subsubsection{Thermal Storage SRE}

The objective of this effort is to demonstrate a molten nitrate salt storage subsystem using low cost containment techniques. The prime contractor for the SRE is Martin Marietta Corporation. They will design, fabricate and test a subscale research experiment that is scaleable to a full size system. The SRE is a two-tank system. For the hot tank, they propose using an internally insulated tank that employs a thin, waffle-type liner of Incoloy 800 to contain the salt. A drawing of the tank is shown in Figure 2.4. The cold tank will be of carbon steel. The SRE will be built and tested at the CRTF.

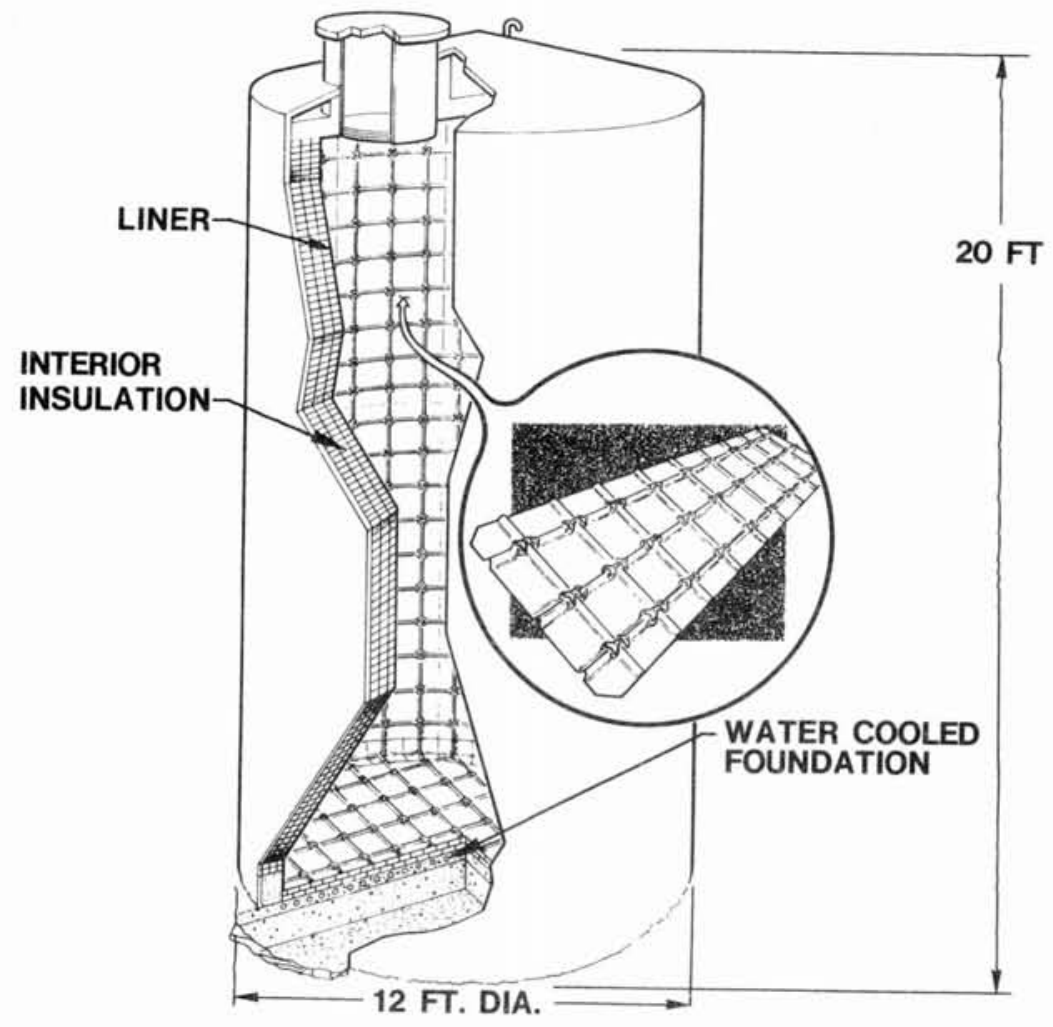

Figure 2.4. Schematic of Martin Marietta Hot Salt Storage Tank for the Subsystem Research Experiment at CRTF in Albuquerque (Insert shows close-up of waffle liner)

\subsubsection{Salt/Steam Heat Exchanger}

Another component of the energy transfer and storage system to be examined is the salt/steam heat exchanger. The proposed work will consist of two phases. The first phase will be a conceptual design study to be awarded to two bidders. At the completion of the initial phase one of the designers will be selected to build a prototype unit. The heat exchanger will be tested at the CRTF. 


\subsection{Summary}

The information derived from the experimental programs discussed in the following sections will impact decision points set by DOE for the development of thermal storage technologies and central receiver applications. The technologies, such as the ACR, SRE, and salt/steam heat exchanger development, are matched to solar thermal power system requirements for near-term central receiver applications. Examples of the applications are the repowering/ industrial retrofit and cogeneration programs. Figures 2.5 and 2.6 detail how the experimental programs fit the needs of the central receiver applications.

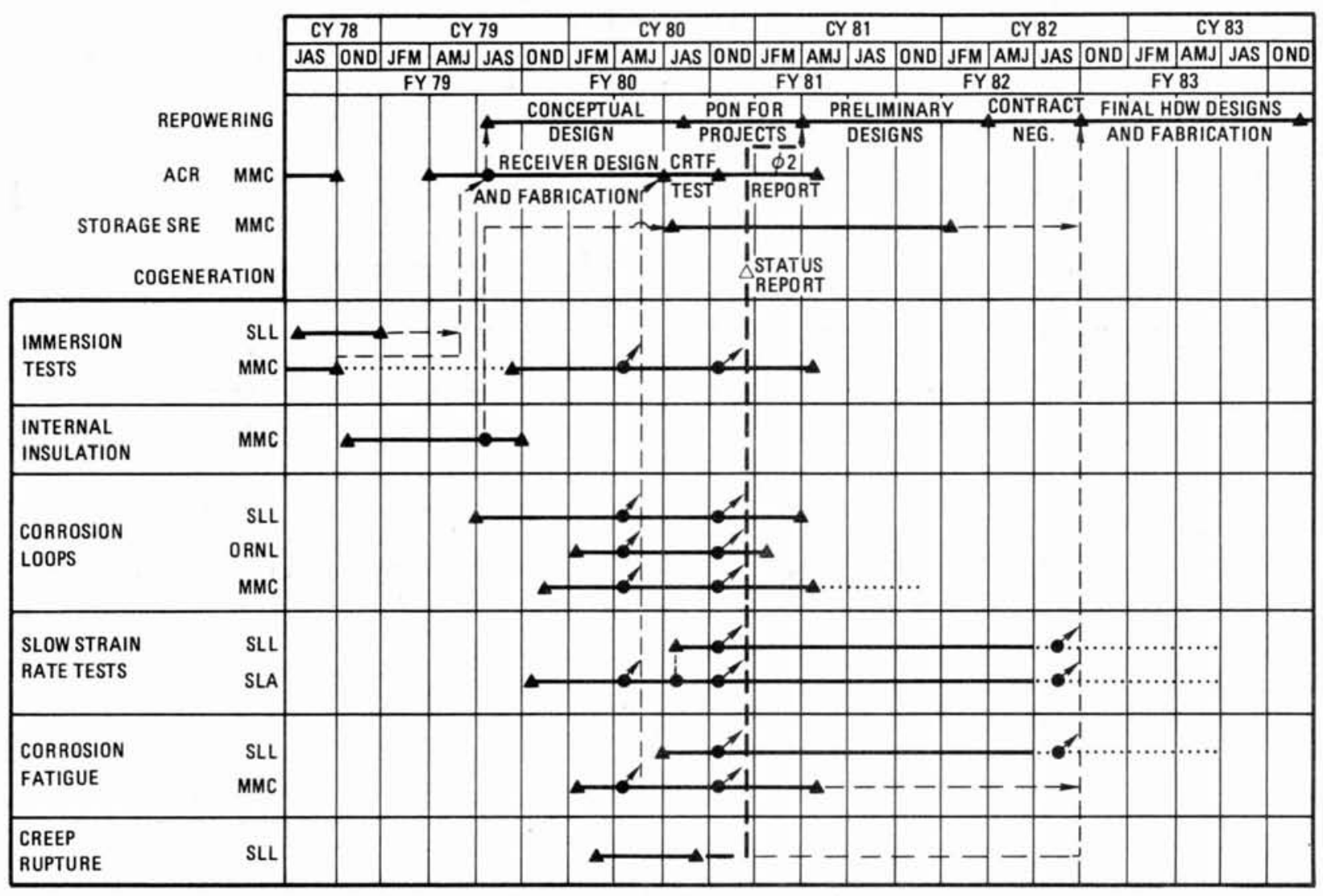

Figure 2.5. Diagram Indicating when Salt Containment Studies Will Impact Near-Term Solar Thermal Applications 


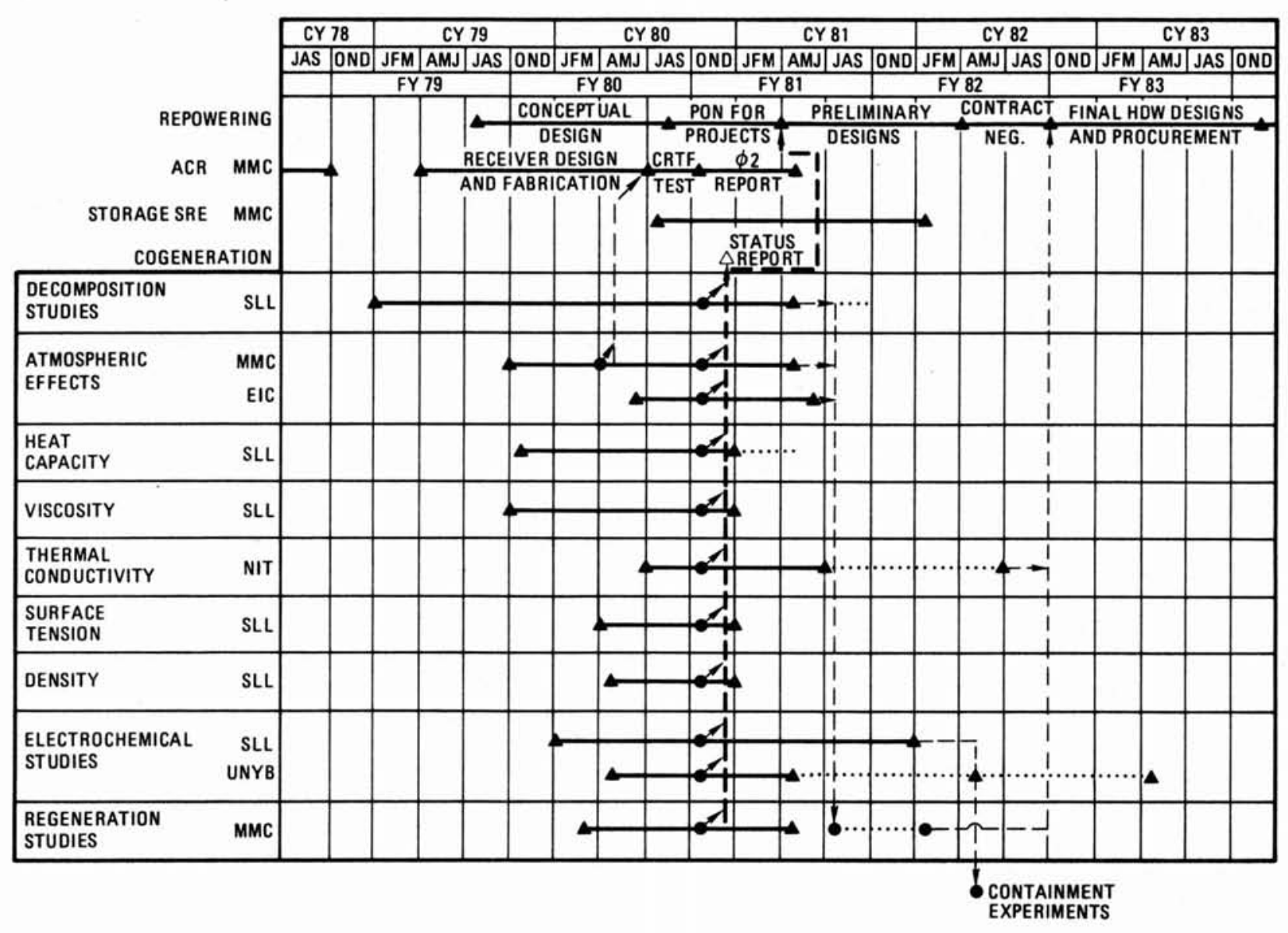

Figure 2.6. Diagram Indicating when Salt Chemistry and Physical Property Studies Will Impact Near-Term Solar Thermal Applications

\subsection{References}

2.1 J. R. Keiser, J. H. DeVan, and E. J. Lawrence, J. Nucl. Mater. 85, 295 (1979).

2.2 W. S. Winters, R. W. Bradshaw, and F. W. Hart, "Design and Operation of Thermal Convection Loops for Corrosion Testing in Molten $\mathrm{NaNO}_{3}-\mathrm{KNO}_{3}$," Sandia National Laboratories, Livermore, SAND80-8212, June 1980.

2.3 B. J. Brough and D. H. Kerridge, Inorg. Chem. 4 , 1353 (1965).

2.4 D. Desimoni, F. Paniccia, and P. G. Zambonin, J. Electroanal. Chem. 33, $373(1972)$.

2.5 P. G. Zambonin, J. Electroanal. Chem. 33, 243 (1971).

2.6 P. G. Zambonin, Anal. Chem. 43, 1571 (1971). 
2.7 L. E. Topol, R. A. Osteryoung, and J. H. Christie, J. Phys. Chem. 70, 2857 (1966).

2.8 P. G. McCormick and H. S. Swofford, Anal. Chem. 41, 146 (1969).

2.9 M. Francini and S. Martini, Electrochim. Acta 13, 851 (1968).

2.10 P. G. Zambonin, Anal. Chem. 44, 763 (1972).

2.11 S. E. Gustafsson, E. Karawachi, and M. N. Kahn, J. Phys. D: Appl. Phys. 12, 1411 (1979). 


\subsection{IMMERSION TESTS}

C. M. Kramer

\subsection{Introduction}

Molten nitrates and nitrites have been proposed for solar central receiver systems as the primary heat transfer fluid or as the thermal storage medium (References 3.1 and 3.2 ). The two salt mixtures that are prime candidates for these applications are drawsalt ( $54 \mathrm{w} / 0 \mathrm{KNO}_{3}-46 \mathrm{w} / 0 \mathrm{NaNO}_{3}$ ) and HTS $\left(53 \mathrm{w} / 0 \mathrm{KNO}_{3}-40 \mathrm{w} / 0 \mathrm{NaNO}_{2}-7 \mathrm{w} / 0 \mathrm{NaNO}_{3}\right.$ ) (References 3.1 and 3.3 ). The latter composition is also called HITEC.

Among the many technical considerations in designing a molten salt solar system is the potential corrosion of containment materials. In solar applications, the operating temperatures may be as high as $600^{\circ} \mathrm{C}$ and a 30 -year required lifetime for the containment materials (References 3.1 and 3.2 ). Although the corrosion of iron, chromium, nickel, cobalt, and some iron alloys in molten nitrates and nitrites has been studied (References 3.4-3.10), these tests have been largely short term (although a few samples have been tested for six weeks). Many of the results are for lower temperatures and not useful for solar central receiver applications. Therefore, a program was initiated to assess the molten alkali nitrate/nitrite salts and metal corrosion problem.

These experiments were designed to assess the suitability of some of the commercially available iron alloys for long term use in molten HTS and to identify possible materials development requirements. Two long term tests were performed. The corrosion behavior of six iron alloys in HTS was evaluated at $550^{\circ} \mathrm{C}$. The alloys were C-steel, three low-alloy chromium-molybdenum steels, and two stainless steels. The corrosion of the three low-alloy chromiummolybdenum steels was also studied in HTS at $450^{\circ} \mathrm{C}$. The extent and the mechanisms of corrosion of each alloy were studied by immersing samples of each alloy in molten salt for periods as long as 223 days. Based on these corrosion results, the suitability of these commercially available alloys was assessed for heat transfer and thermal storage applications. 


\subsection{Experimental}

The immersion bath shown in Figure 3.1 was built for testing the alloys in molten HTS at $550^{\circ} \mathrm{C}$. The immersion bath was modified for the experiments at $450^{\circ} \mathrm{C}$. In the lower temperature experiment the quartz beaker was replaced with an IN600 crucible. Alumina sample racks were used in the HTS at $550^{\circ} \mathrm{C}$. Salt mixtures were prepared from reagent grade compounds, and the salt baths were open to the air. Several salt samples for chemical analysis were also taken during the course of the experiments.

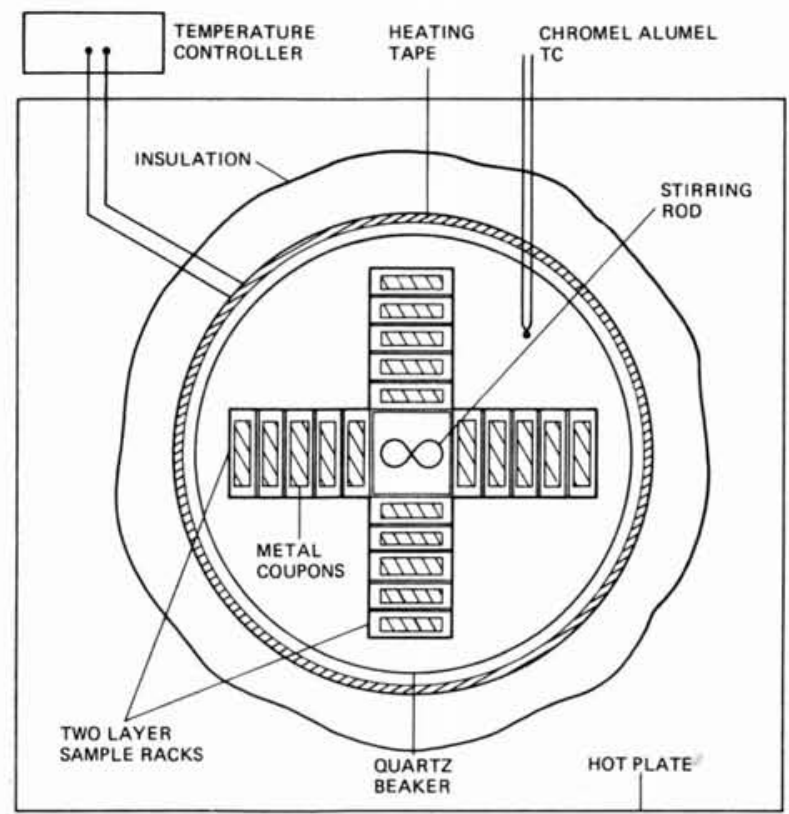

Figure 3.1. Schematic of Molten HITEC Salt Bath for Alloy Immersion Tests

Six coupons of each alloy were polished to 600 grit, stamped for identification, and weighed before being immersed in the bath. The samples were approximately $25 \times 25 \times 7 \mathrm{~mm}$ and had surface areas of approximately $19 \mathrm{~cm}^{2}$. The compositions of each alloy are listed in Table 3.I. Periodically, coupons were withdrawn from the salt baths. The samples were weighed and inspected optically and with the scanning electron microscope for topographical features. Metallographic cross sections were made of each alloy before and after immersion. In addition, electron microprobe studies and $X$-ray diffraction were performed on selected samples. 
TABLE 3.I

CHEMICAL COMPOSITION OF ALLOYS CHOSEN

FOR CORROSION TESTS ( $w t \%$ )

\begin{tabular}{cccccccc}
\hline Alloy & $\mathrm{Cr}$ & $\mathrm{C}$ & $\mathrm{Ni}$ & $\mathrm{Mn}$ & $\mathrm{Mo}$ & $\mathrm{Si}$ & $\mathrm{Fe}$ \\
\hline 1018 Steel & 0. & $0.15-0.2$ & - & $0.6-0.9$ & - & $<0.5$ & balance \\
$\mathrm{Cr}-2$ & $1.9-2.6$ & $<0.15$ & - & $0.3-0.6$ & 0.5 & $<0.5$ & balance \\
$\mathrm{Cr}-5$ & 5.13 & $<0.12$ & - & 0.44 & 0.5 & 0.37 balance \\
$\mathrm{Cr} 9-1 \mathrm{M}$ & $8 .-10$. & $<0.15$ & - & $0.3-0.6$ & $0.9-1.1$ & $<1.0$ & balance \\
316 Stainless & $16 .-18$. & $<0.08$ & $10 .-14$. & $<2.0$ & $2 .-3$. & $<1.0$ & balance \\
310 Stainless & $24 .-26$. & $<0.25$ & $19 .-22$ & $<2.0$ & - & $<1.5$ & bal ance \\
\hline
\end{tabular}

\subsection{Results and Discussion}

The weight change results from these experiments are given in Table 3 .II and illustrated in Figures 3.2 and 3.4. The results of each experiment are discussed separately below.

TABLE 3.11

SUMMARY OF WEIGHT CHANGE DATA

\begin{tabular}{|c|c|c|c|c|c|c|c|c|}
\hline & 1018 & $\begin{array}{c}\left(\mathrm{mg} / \mathrm{cm}^{2}\right) \\
\mathrm{Fe}-21 / 4 \mathrm{Cr} \\
\end{array}$ & $\mathrm{Fe}-5 \mathrm{Cr}$ & $\mathrm{Fe}-9 \mathrm{Cr}-1 \mathrm{Mo}$ & 316 & Stainless & 310 & Stainle \\
\hline \multicolumn{9}{|l|}{ HTS $/ 550^{\circ} \mathrm{C}$} \\
\hline 35 days & 5.7 & $\begin{array}{r}6.8 \\
11.9\end{array}$ & $\begin{array}{l}4.2 \\
4.3 \\
8.0 \\
2.0\end{array}$ & $\begin{array}{l}2.8 \\
2.9\end{array}$ & & $\begin{array}{l}0.49 \\
0.59\end{array}$ & & 0.13 \\
\hline 108 & 6.8 & 17.8 & $\begin{array}{l}4.7 \\
5.6\end{array}$ & 3.6 & & 0.66 & & 0.35 \\
\hline 190 & $\begin{array}{l}6.8 \\
6.9 \\
6.9 \\
7.4\end{array}$ & $\begin{array}{l}6.2 \\
7.2 \\
8.7\end{array}$ & * & $\begin{array}{l}1.8 \\
2.1\end{array}$ & & $\begin{array}{l}0.84 \\
0.85 \\
0.87\end{array}$ & & $\begin{array}{l}0.37 \\
0.42 \\
0.42 \\
0.53\end{array}$ \\
\hline
\end{tabular}

$\begin{array}{llll}\text { HTS } / 450^{\circ} \mathrm{C} & & & \\ 60 & 2.3 & 1.9 & 1.2 \\ & 2.5 & 1.9 & 1.3 \\ 98 & 3.6 & 2.5 & 1.9 \\ 138 & 4.1 & 2.8 & 2.0 \\ 187 & 4.8 & 3.3 & 2.4 \\ 223 & 5.4 & 3.7 & 2.5\end{array}$

*No sample available. 


\subsubsection{HTS at $550^{\circ} \mathrm{C}$}

All six alloys showed a weight gain due to oxide formation. The 1018 and stainless steel alloys gained weight continuously over 190 days. In contrast, the $\mathrm{Fe}-2 \mathrm{1} / 4 \mathrm{Cr}$, Fe-5Cr and $\mathrm{Fe}-9 \mathrm{Cr}-1 \mathrm{Mo}$ alloys gained weight initially but then no more. The scatter in data was caused by spalling of the oxide scale.

Regions of locally adherent and well bonded oxide were observed on every alloy. Only the stainless coupons had oxide layers that were adherent throughout. Intergranular corrosion and internal oxidation was not observed. X-ray diffraction of the scales of $\mathrm{Fe}-21 / 4 \mathrm{Cr}$, Fe-5Cr and $\mathrm{Fe}-9 \mathrm{Cr}-1 \mathrm{Mo}$ samples showed that both $\mathrm{Fe}_{3} \mathrm{O}_{4}$ and $\mathrm{Fe}_{2} \mathrm{O}_{3}$ were present. The oxides of the other coupons were too thin for X-ray analysis. These results are consistent with previous studies. Passivation of iron in molten nitrate salts has been observed, and attributed to the formation of a mixed oxide film that is primarily $\mathrm{Fe}_{3} \mathrm{O}_{4}$ (References $3.6,3.7,3.9$ ). Continuous, adherent, blue-black films were found on iron in less than 100 minutes when submerged in $\mathrm{NaNO}_{3}$, $\mathrm{NaNO}_{2}$, and an equimolar mixture of $\mathrm{NaNO}_{3}$ and $\mathrm{KNO}_{3}$ (Reference 3.7). Dissolution of iron has not been observed in mixed molten $\mathrm{NaNO}_{3}-\mathrm{KNO}_{3}$ (Reference 3.6). However, dissolution was seen in another case of mixed nitrates

(Reference 3.11), and intergranular attack was observed with 330 stainless steel (Reference 3.6). Mixed oxide scales were al so found on Fe oxidized in air (References 3.12-3.18).

The effect of chromium is shown in Figure 3.2 where the oxidation of each alloy is plotted versus the chromium content of the alloy. The beneficial effects of chromium on hindering corrosion in molten HTS are clear. The

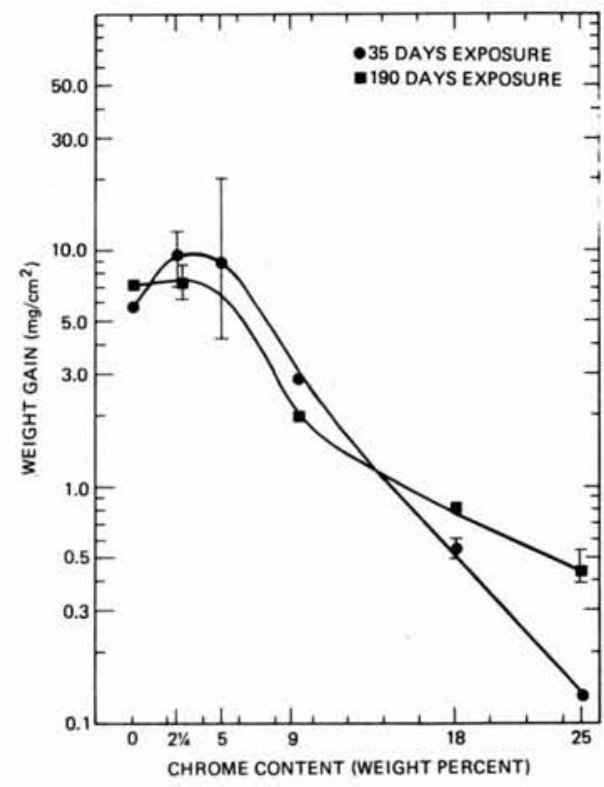

Figure 3.2. Plot of Oxidation of Fe Alloys vs Chromium Content. Spalling of oxide may have contributed to spurious results in the low-Cr alloys where the apparent oxidation is less after 135 days than after 35 days. 
variation in the amount of oxidation spans two orders of magnitude. In other oxidation experiments (Reference 3.13) molybdenum enhanced oxidation resistance. This implies molybdenum may have contributed to the improved behavior of the $\mathrm{Fe}-9 \mathrm{Cr}$-1Mo compared to the lower $\mathrm{Cr}$ alloys.

Visual inspection showed that the $\mathrm{Cr}-2$ performed the poorest. Spalling and orange-colored blisters were present on all the $\mathrm{Cr}-2$ samples. Some craters were also observed on the $1018, \mathrm{Fe}-5 \mathrm{Cr}$, and $\mathrm{Fe}-9 \mathrm{Cr}-1 \mathrm{Mo}$ samples. The stainless steel samples did not spall or blister. All the metal coupons turned very dark grey in the salt.

Topographical scanning electron microscope (SEM) photographs of the oxide scales on the metal coupons revealed some interesting characteristics of the oxide scales. The stainless steel coupons had small ( $<5 \mu \mathrm{m})$, equiaxed, dense crystals on the surface. The lower chromium alloys had slightly larger grains, and many of the grains were split into laminar plates. If these cracks were present at $550^{\circ} \mathrm{C}$, and not introduced in the scale during cooling to room temperature, they could account for the fact low chromium alloys corroded faster than the stainless steels. Cracks between the laminar plates may be paths for diffusion of $\mathrm{Fe}$ or oxygen. The amount of cracking was increased by exposure to moist air and chloride ions.

An automated electron microprobe X-ray diffractometer was used to determine the chemical composition of the corrosion layers of a five percent $\mathrm{Cr}$ sample. The microprobe was programmed to collect elemental X-rays from 1600 points in an $80 \times 80$ um matrix centered on the metal-oxide interface of a polished metallographic cross-section. The X-ray intensities of each point in the matrix were corrected for X-ray absorption, fluorescence, and atomic number. The corrected X-ray intensities were used to produce a computergenerated map of each element of interest. Figure 3.3 is a series of computer images from the $\mathrm{Cr}-5$ alloy that displays the relative elemental distribution of the $\mathrm{Fe}, \mathrm{Cr}$, and oxygen. The outermost half $(\sim 20 \mu \mathrm{m})$ of the oxide layer is entirely Fe-oxide.

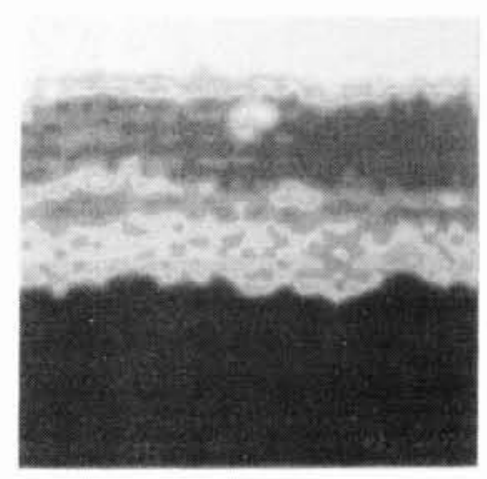

$\mathrm{Fe}$

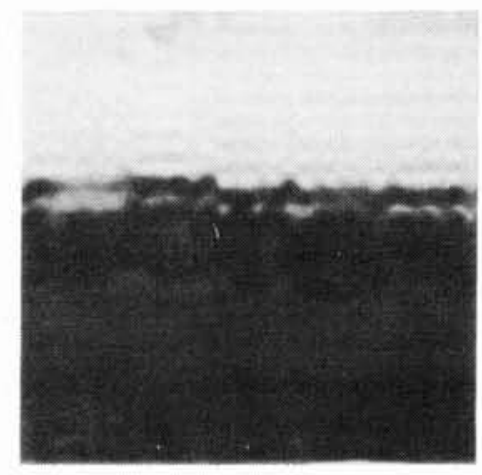

$\mathrm{Cr}$

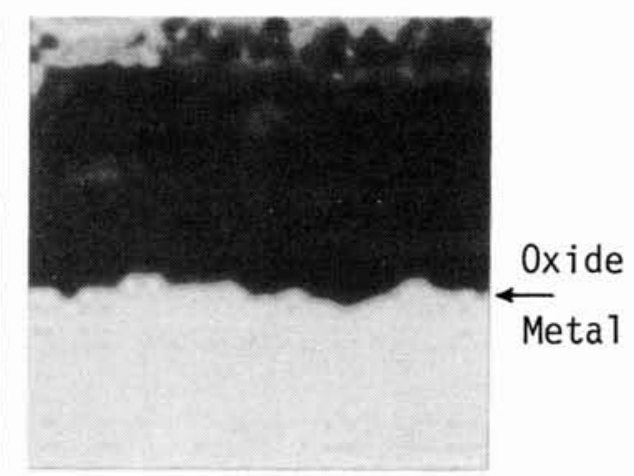

0

Figure 3.3. Computer-Generated Images Mapping the Intensity of $\mathrm{Fe}, \mathrm{Cr}$, and 0xygen Over the Same Area of Metal-0xide Interface. Darker color indicates greater concentration. 
The microprobe was also used to study a 316 stainless steel metal-oxide interface. There were problems in locating the oxide metal interface because the oxide was very thin. However, there was evidence that the outermost oxide was entirely $\mathrm{Fe}$-oxide and the inner layer enriched with $\mathrm{Cr}, \mathrm{Ni}$, and perhaps Mo. A chromium-rich inner layer has also been observed in the oxidation of $\mathrm{Fe}$ alloys (Reference 3.19). Oxidation protection is initially by $\mathrm{Cr}_{2} \mathrm{O}_{3}$ or an $\mathrm{Fe}-\mathrm{Cr}-0$ spinel formation that subsequently breaks down and forms an Fe-rich oxide outer layer (Reference 3.17 ).

The salt composition changed over the six months of the experiments. The amount of nitrite $\left(\mathrm{NO}_{2}\right)$ decreased significantly. A carbonate analysis of the salt sample taken after 190 days at $550^{\circ} \mathrm{C}$ showed that the HTS was reacting with the $\mathrm{CO}_{2}$ of the atmosphere to form $\sim 0.2$ percent carbonate. The etching of the glass equipment also reflected the strong basic nature of the melt. The changes in composition may not have altered the corrosion process significantly since $\mathrm{NaNO}_{2}$ behaved similarly to $\mathrm{NaNO}_{3}$ in other corrosion tests with iron (Reference 3.7 ). The concentration of other metals did not change during the experiment. The presence of oxygen, water, acids, or bases in molten nitrate melts have been shown to have minimal effect on the corrosion behavior of iron (References 3.6 and 3.7).

\section{3 .2 HTS at $450^{\circ} \mathrm{C}$}

The oxidation behavior of the three Fe-Cr alloys at $450^{\circ} \mathrm{C}$ is shown in Figure 3.4. The weight gains over a time period of 60-223 days are linear for each alloy. Because the rates of oxidation are constant, oxidation may be controlled by the rate at which the salt can penetrate to the metal surface via cracks in the outer oxide layer. Higher chromium content in the alloys reduced the corrosion rates. The rates for the 2-1/4, 5, and 7 percent chromium alloys at $450^{\circ} \mathrm{C}$ are $0.019,0.011$, and $0.0071 \mathrm{mg} \mathrm{cm}-2$ day-1, respectively. The amount of oxidation was approximately half the amount observed at $550^{\circ} \mathrm{C}$. The $\mathrm{Fe}-21 / 4 \mathrm{Cr}$ alloys did not have orange blisters as it did at $550^{\circ} \mathrm{C}$.

Metallographic cross-sections were made of these $\mathrm{Fe}-\mathrm{Cr}$ corrosion coupons. The oxides formed were identical in morphology and composition to those observed at $550^{\circ} \mathrm{C}$.

\subsection{Future Recommendations}

All of the alloys tested showed reasonable resistance to the molten salt. From chemical corrosion considerations only, the stainless alloys are good candidates for the highest temperatures of a solar central receiver. The $\mathrm{Fe}-2$ $1 / 4 \mathrm{Cr}$ alloy is not an acceptable choice for use with molten HTS at $550^{\circ} \mathrm{C}$ due to its oxidation, spalling and blistering. The $1018, \mathrm{Fe}-5 \mathrm{Cr}$ and $\mathrm{Fe}-9 \mathrm{Cr}-1 \mathrm{Mo}$ are candidate materials that are worthwhile investigating for lower temperature applications, especially where cost is a critical consideration (as in large storage tanks). 


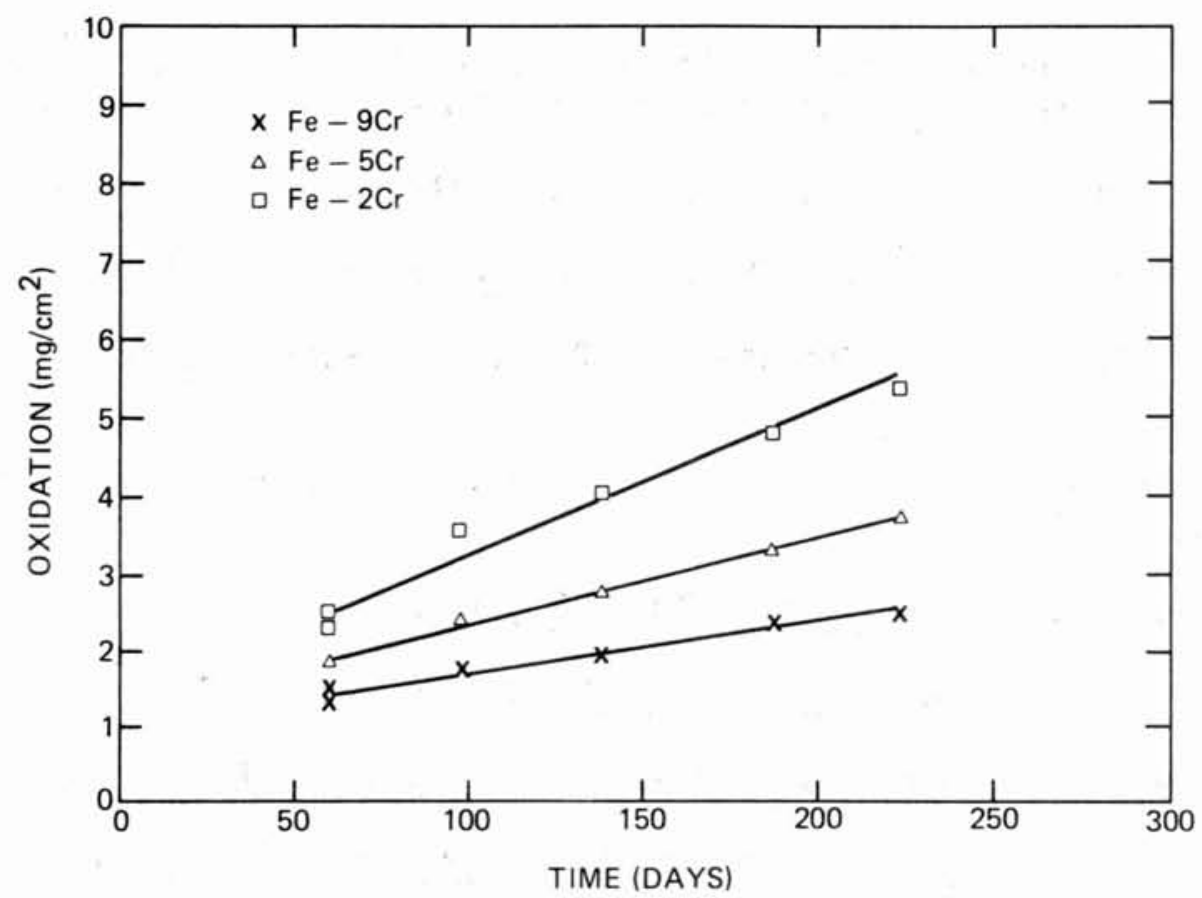

Figure 3.4. Oxidation of Alloys in HITEC at $450^{\circ} \mathrm{C}$

\subsection{References}

3.1 A. L. G. Radosevich, "Thermal Energy Storage for Advanced Solar Central Receiver Power Systems," Sandia Laboratories, Livermore, SAND78-8221, August 1978.

B. T. D. Brumleve, "A High-Temperature Solar Energy System," Sandia Laboratories, Livermore, SAND74-8008, July 1974.

C. A. C. Skinrood, T. D. Brumleve, C. T. Schafer, C. T. Yokomizo, and C. M. Leonard, "Status Report on a High Temperature Solar Energy System," Sandia Laboratories, Livermore, SAND74-8017, September 1974.

D. T. D. Brumleve, "Status Report on the Direct Absorption Receiver," Sandia Laboratories, Livermore, SAND78-8702, July 1978.

E. V. P. Burolla and J. J. Bartel, "The High Temperature Compatibility of Nitrate Salt, Granite Rock, and Pelletized Iron Ore," Sandia Laboratories, Livermore, SAND79-8634, August 1979.

F. L. N. Tallerico, "A Description and Assessment of Large Solar Power Systems Technology," Sandia Laboratories, Livermore, SAND79-8015, August 1979.

3.2 A. C. Skinrood, Solar Age $\underline{5}$ (8), 84 (1980). 
3.3 M. D. Silverman and J. R. Engel, "Survey of Technology for Storage of Thermal Energy in Heat Transfer Salt," ORNL/TM-5682, January 1977.

3.4 W. E. Kirst, W. M. Nagle, and J. B. Castnen, AIChE Trans 36, 371 (1941).

3.5 T. Notoya, and R. Midorikawa, Denki Kagaku 39 (12), 930 (1971).

3.6 A. J. Arvia, J. J. Podesta, and R. C. V. Piatti, Electrochem Acta 17, 33 (1972).

3.7 A. Baraka, A. I. Abdel Rohman, and A. A. El Hosary, Brit. Corros. J. 11 (1), 44 (1976).

3.8 E. I. Gurovich, Zh. Prikl. Khim. 29, 1358 (1956).

3.9 I. D. Dirmeik, Corrosion NACE 25 (4), 180 (1969).

3.10 S. L. Marchiano and A. J. Arvia, Electrochem. Acta 17, 861 (1972).

3.11 Encyclopedia of Electrochemistry of the Elements, 10, J. A. Plambeck, ed. A. J. Bard (Marcel Dekker Inc., NY, 1976).

3.12 D. Caplan, et al., Oxidation of Metals 12 (1), 67 (1978).

3.13 L. B. Pfeil, J. Iron \& Steel Inst. 123, 237 (1931).

3.14 U. R. Evans and Edward Arnold, Corrosion and Oxidation of Metals (London,1960).

3.150 . Kubaschewski and B. E. Hopkins, Oxidation of Metals and Alloys, 2nd ed. (Butterworth \& Co., London, 1962).

3.16 D. Inman and N. S. Wrench, Brit. Corros. J. 1, 246 (1966).

3.17 Corrosion, V.1., ed. L. L. Shreir (Newnes-Butterworths, London, 1976).

3.18 Corrosion Resistance of Metals and Alloys, 2nd ed., ed. F. L. Laque TReinhold Pub. Co., NY, 1963).

3.19 L. A. Morris, Met. Eng. Qtrly, 30, May 1968. 


\subsection{CORROSION STUDIES USING THERMAL CONVECTION LOOPS}

R. W. Bradshaw

\subsection{Introduction}

Central solar receivers will operate in the $300-600^{\circ} \mathrm{C}$ temperature range. In addition to corrosion of the containment alloys by the molten salt, other possible corrosion mechanisms are (1) depletion of alloying elements into the salt as soluble products, and (2) thermal gradient mass transfer caused by reduced solubility in the minimum temperature portion of the system. Thermal convection loops provide a relatively simple experimental means to study these forms of corrosion in a system where the temperature range can be matched to that in receivers and where circulating flow can be established from hot to cold regions.

Although corrosion in thermal convection loops has been studied in depth in liquid metals and molten halides (Reference 4.1 ), no work with $\mathrm{NaNO}_{3}-\mathrm{KNO}_{3}$ is evident in the literature. A study of 316 stainless in a thermal convection loop containing $44 \mathrm{KNO}_{3}-49 \mathrm{NaNO}_{2}-7 \mathrm{NaNO}_{3}$ (molar) demonstrated rapid corrosion and dissolution of the alloy at a temperature of $550^{\circ} \mathrm{C}$ (Reference 4.2 ).

\subsection{Experimental}

A brief summary of the experimental system and procedures is given here. Details are available el sewhere (Reference 4.3). Three thermal convection loops were constructed for this study using the alloys, 304SS, 316SS and I800. An illustration of one of the loops is shown in Figure 4.1. The tubing used was $2.54 \mathrm{~cm}$ (1 in.) $0 . D$. by $2.1 \mathrm{~cm}(0.81 \mathrm{in.})$ I.D. in all cases. The operating temperature ranges were 350 to $600^{\circ} \mathrm{C}$ for the $304 \mathrm{SS} 100 \mathrm{p}$ and 360 to $630^{\circ} \mathrm{C}$ for the other loops. Experiments were conducted at higher temperatures to establish temperature limits of alloy compatibility with molten nitrates and to accelerate the testing process. The loops were filled with a commercial drawsalt composition, $60 \mathrm{w} / 0 \mathrm{NaNO}_{3}-40 \mathrm{w} / 0 \mathrm{KNO}_{3}$ (Partherm 430 , Park Chemical Co.). The loops were open to the atmosphere and free to absorb water vapor and carbon dioxide. No additions or treatments were made to the salt throughout the tests, which lasted up to 8500 hours. 


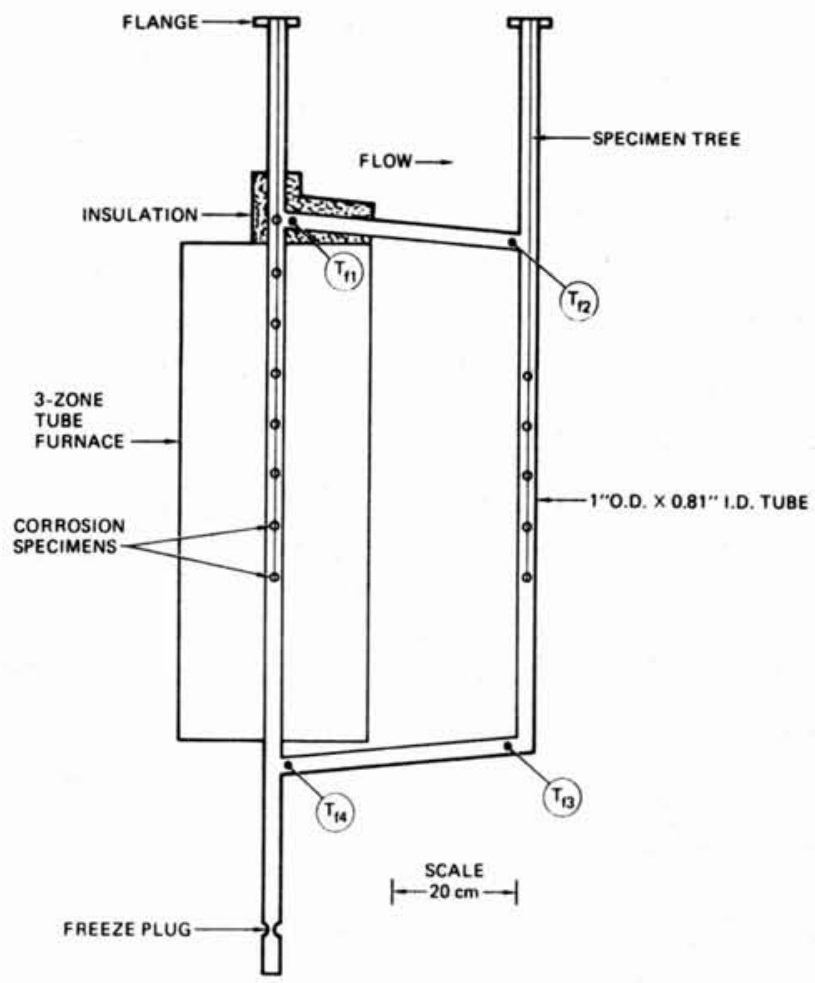

Figure 4.1. Schematic Diagram of 304SS Thermal Convection Loop

Rectangular coupons were suspended from removable trees in both the hot and cold legs of each loop so that samples could be periodically removed for weighing and metallographic analysis. In addition to wrought stock of each alloy type, autogeneous weldments were inserted. Several coupons of 321SS were inserted in the 304SS 100p and several 347SS samples were placed in the 316SS loop to observe the behavior of the stabilized stainless steels. Alloy coupons were prepared by grinding with 180 grit SiC paper. At the conclusion of the experiments, the loops were sectioned and samples of tubing from various parts were analyzed. Samples of molten salt were withdrawn periodically for analysis of metallic content $(\mathrm{Cr}, \mathrm{Fe}, \mathrm{Ni})$, and nitrite and carbonate content. Metallic content was determined by atomic absorption spectroscopy, and nitrite and carbonate by a mixed-indicator acid-base titration (Reference 4.4). No hydroxide was detected in the salt samples.

\subsection{Results and Discussion}

The corrosion behavior of 304 SS, 316 SS and I800 observed in thermal convection loop experiments is summarized here. Emphasized are those results that concern alloy performance and choice of operating conditions for receivers. Generally, corrosion occurred by oxidation to produce scales composed primarily of iron oxides. Chromium was depleted from the alloys in all cases and dissolved in the salt. However, thermal gradient mass transport was not 
observed. A significant result of these experiments is that the limiting temperature found compatible with long-term operation is approximately $600^{\circ} \mathrm{C}$. The following discussion is divided into two sections, corresponding to behavior at temperatures up to $600^{\circ} \mathrm{C}$ and those above $600^{\circ} \mathrm{C}$.

\subsubsection{Results Below $600^{\circ} \mathrm{C}$}

The results with the 304SS loop illustrate behavior at temperatures up to $600^{\circ} \mathrm{C}$. Most of the discussion will concern temperatures close to $600^{\circ} \mathrm{C}$ since negligible corrosion occurs at appreciably lower temperatures. The basic corrosion morphology observed in 304SS coupons is depicted in Figure 4-2 where a photomicrograph of a cross-sectioned specimen exposed for 4200 hours at a temperature of $595^{\circ} \mathrm{C}$ is shown. The results of oxide analysis by X-ray diffraction and EDAX are indicated. The corrosion products consist of the iron oxide magnetite, $\mathrm{Fe}_{3} \mathrm{O}_{4}$, which forms the outer layer and a mixed oxide spinel $(\mathrm{Fe}, \mathrm{Cr})_{304}$. The spinel is not enriched with $\mathrm{Cr}$ compared to the alloy. The total amount of scaling is about $12 \mu \mathrm{m}(0.5 \mathrm{mil})$ after 4200 hours. The net weight change of the coupon corresponding to Figure $4-2$ was $-0.1 \mathrm{mg} / \mathrm{cm}^{2}$, however, and the scale layer seemed to be generally adherent.

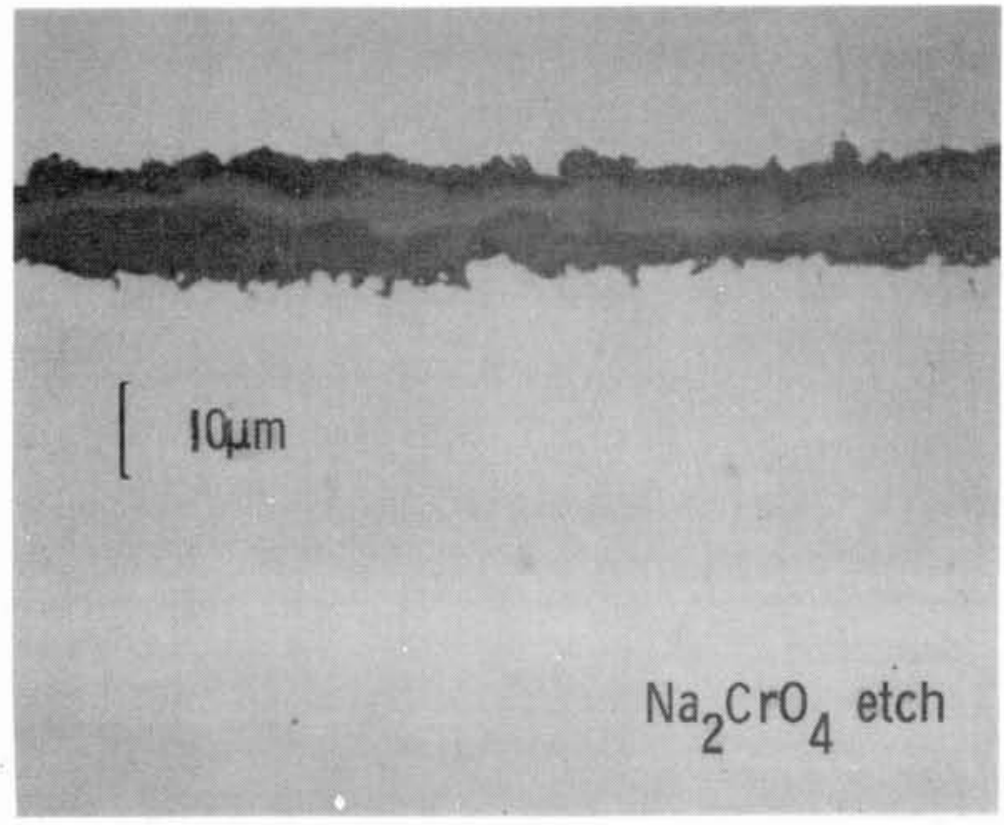

Figure 4.2. Oxide Structure on 304 SS after 4200 Hours at $595^{\circ} \mathrm{C}$ 
Examination of the walls of the 304 tubing used to construct the loops reveals similar scale structures, although some differences exist since the tube surfaces were not polished as were the inserted coupons. Effects of surface finish on corrosion of stainless steels at similar temperatures in steam have been discussed el sewhere (Reference 4.5). The corrosion behavior observed on tube walls at the higher temperatures in the loop are typified by Figure 4.3. This oxide layer, which varies in thickness from 8-12 $\mu \mathrm{m}$, was formed after 8500 hours at a temperature of $550^{\circ} \mathrm{C}$ in the heated section of the 10op. Both $\mathrm{Fe}_{3} \mathrm{O}_{4}$ and $(\mathrm{Fe}, \mathrm{Cr})_{3} \mathrm{O}_{4}$ were detected by X-ray diffraction, although the ordered duplex scale structure observed on polished coupons has been replaced by a less differentiated scale. The outer region of this scale is still solely $\mathrm{Fe}_{3} \mathrm{O}_{4}$ however. The specimen shown in Figure 4.3 was electrolytically etched with oxalic acid to reveal carbides at the grain boundaries. Intergranular chromium carbides are much less prevalent in the region immediately beneath the scale layer indicating depletion of $\mathrm{Cr}$ from the alloy. Chromium depletion will be discussed in more detail later.

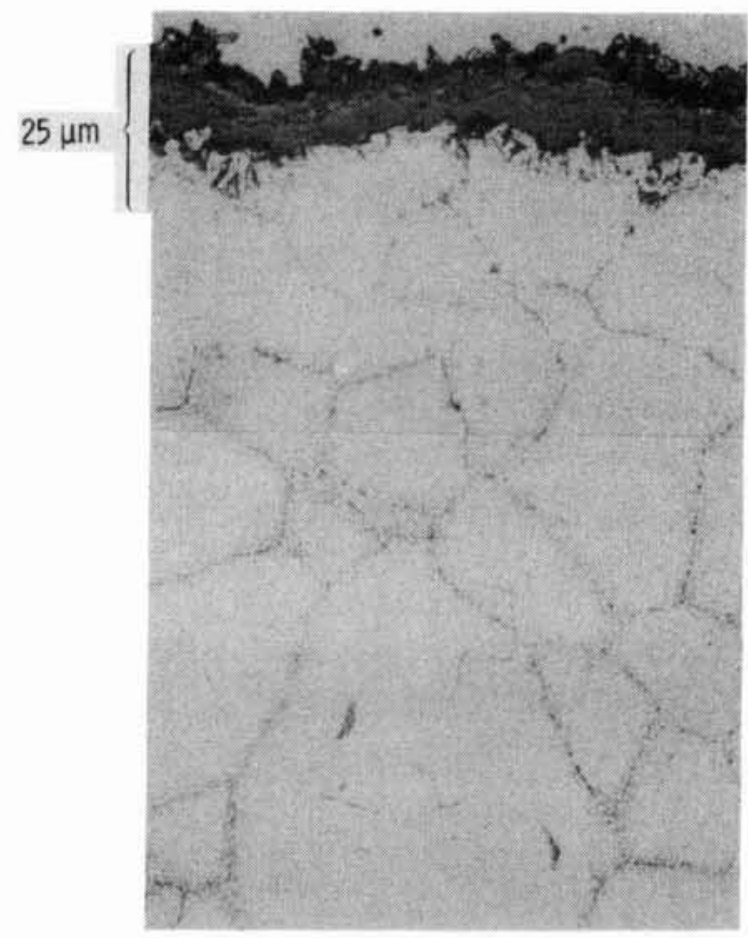

Figure 4.3. Microstructure of Tube Section from 304 SS Loop Showing Scaling and Carbide Precipitation $\left(580^{\circ} \mathrm{C}, 8500 \mathrm{hr}\right.$, oxalic acid etch)

The effect of temperature on scaling of 304SS is shown in Table 4.I where data are derived from tube sections cut from the hot leg of the loop. At the maximum salt temperature obtained, $600^{\circ} \mathrm{C}$, scaling amounted to about $25.4 \mu \mathrm{m}$ (1 mil) after 8500 hours of isothermal operation. A considerable variation in scale thickness was measured at all temperatures. 
TABLE 4.I

SCALING OF 304 SS TUBING AFTER 8500 HOURS

\begin{tabular}{|c|c|c|}
\hline \multirow{2}{*}{$\begin{array}{c}\text { Salt Temp } \\
\left({ }^{\circ} \mathrm{C}\right)\end{array}$} & \multicolumn{2}{|c|}{ Scale Thickness } \\
\hline & Mean & Range \\
\hline 600 & 16 & $9-25$ \\
\hline 575 & 11 & $6-15$ \\
\hline 550 & 9 & $5-13$ \\
\hline
\end{tabular}

In addition to wrought 304SS, weldments of $304 S S$ and the Ti-stabilized version, 321SS, were included in the test. The weight change curves of inserted coupons of these materials are plotted in Figures 4.4, 4.5, and 4.6, respectively. The weight changes observed were quite small, although several trends are evident. Superficially, weldments and parent alloy appear similar and oxide scales, viewed in cross-section, are comparable, but the weldments appear to lose weight with respect to parent material, although the difference

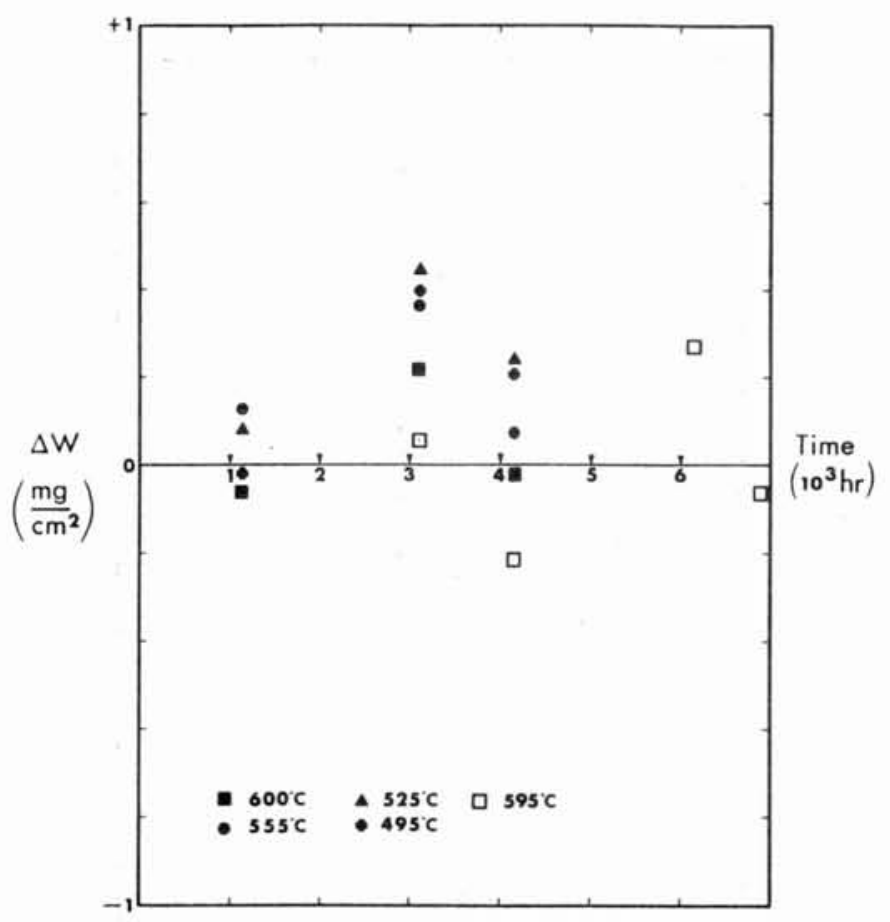

Figure 4.4. Weight Changes of 304 SS vs Time for Several Temperatures 


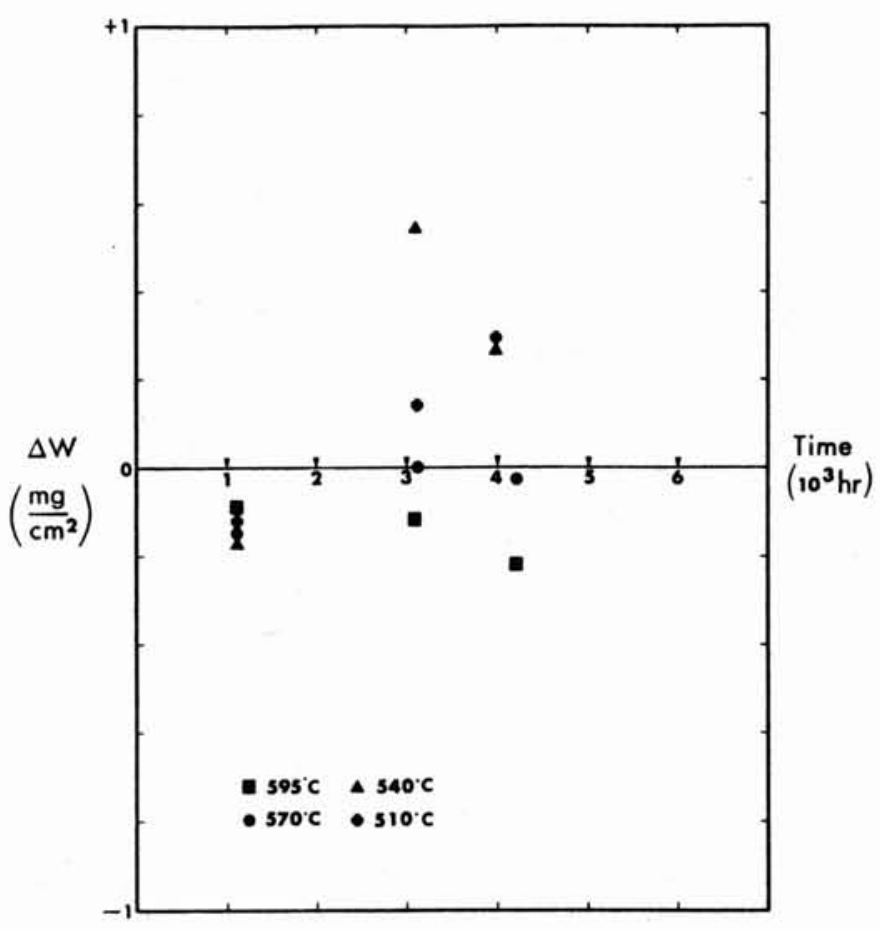

Figure 4.5. Weight Changes of 304 SS Weldments vs Time for Several Temperatures

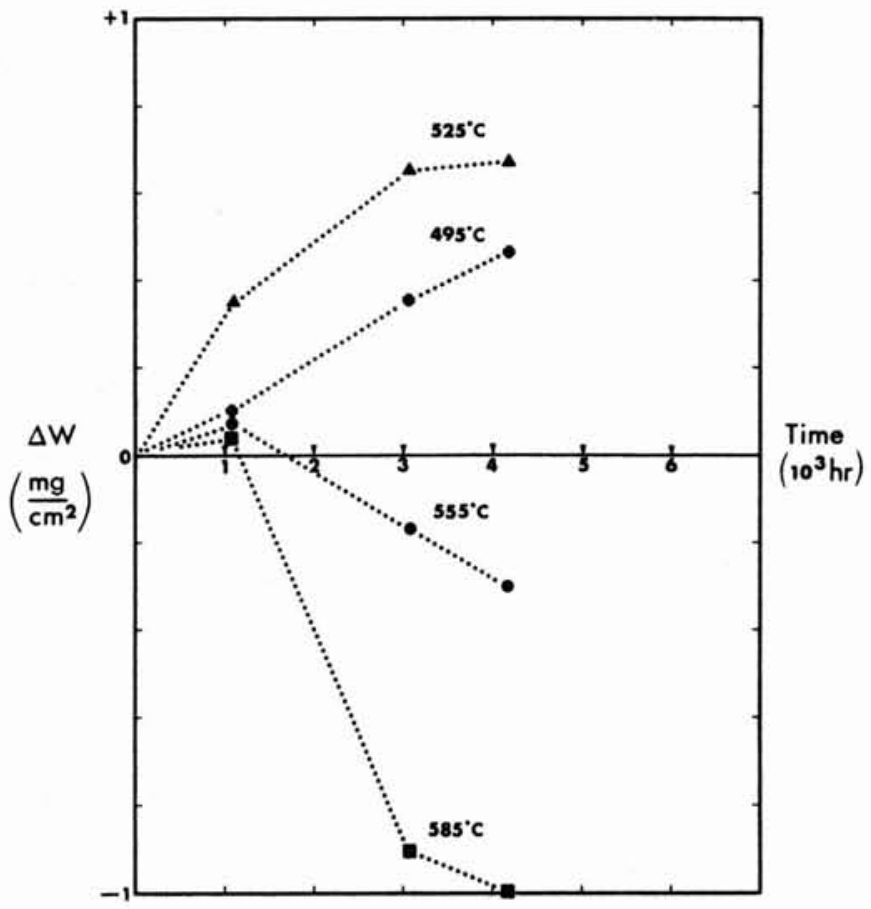

Figure 4.6. Weight Changes of 304 SS vs Time for Several Temperatures 
is not significant. This relative loss may be caused by spalling of surface scales on weldments, although both types behave similarly from visual inspection. The weight change curves of $321 \mathrm{SS}$, where increasingly negative weight changes are observed, was influenced most strongly by spalling of surface scales. Despite the fact that scales are similar to 304 SS when examined in cross-section, coupons of 321 SS revealed a substantial loss of surface layers.

\subsubsection{Results Above $600^{\circ} \mathrm{C}$}

The corrosion behavior of $316 \mathrm{SS}$ and I 800 demonstrate several effects that occur in the temperature range from $600^{\circ} \mathrm{C}$ to $630^{\circ} \mathrm{C}$. These effects are much faster corrosion rates and a change in the composition and morphology of surface scales. Most of the results are derived from the 316SS loop since experimental difficulties were encountered with the I800 loop.

Figures 4.7 and 4.8 illustrate the weight change behavior of 316 SS and I800, respectively, at several temperatures obtained in the hottest parts of the loops. The general trends are the same for both alloys. Weight gains are experienced at $600^{\circ} \mathrm{C}$ during periods of several thousand hours. At higher temperatures, weight is initially gained as oxide scales form, but thereafter, increasing weight losses occur that grow with both time and temperature. The weight loss can be attributed to loss of scales by spalling and to chromium loss from the alloys, a phenomenon that will be discussed in detail later.

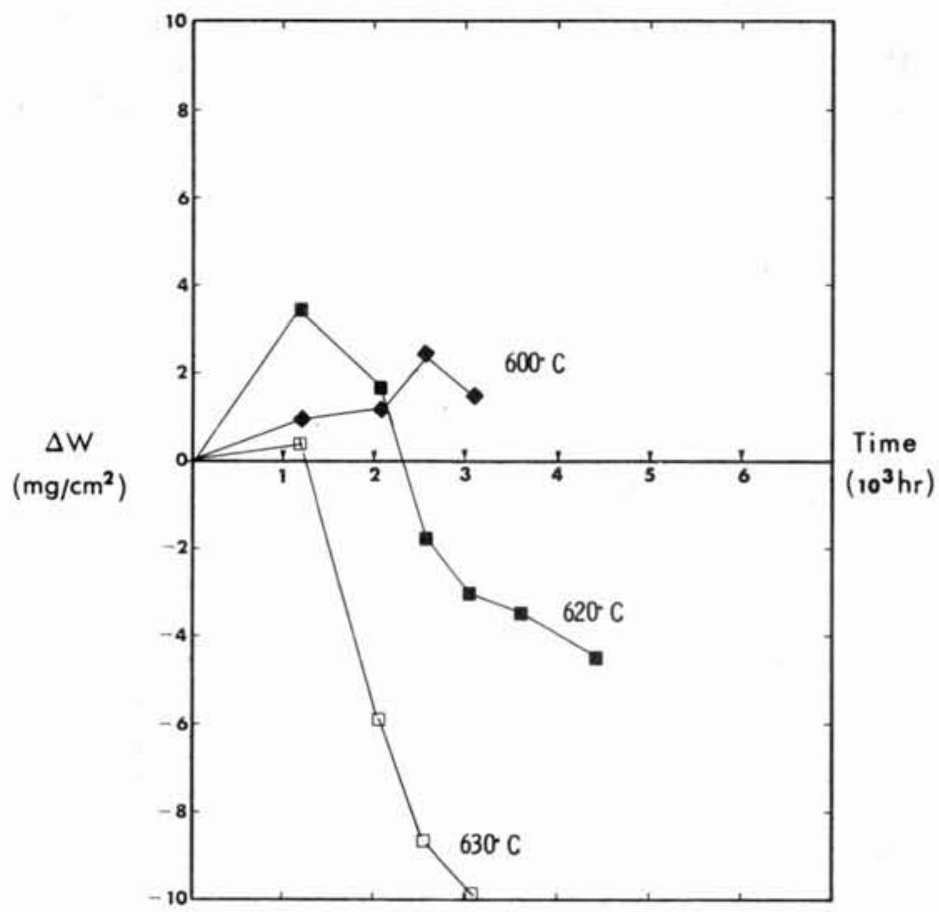

Figure 4.7. Weight Changes of 316 SS at Several Temperatures 


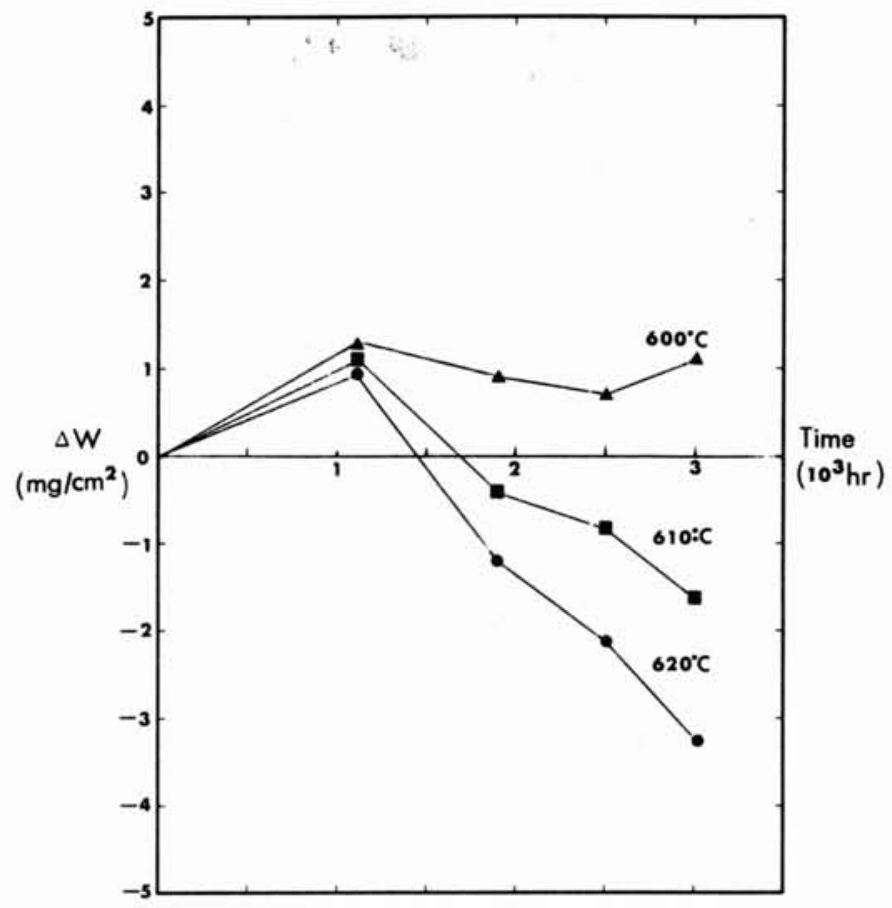

Figure 4.8. Weight Changes of 1800 at Several Temperatures

A comparison of the corrosion behavior of $316 \mathrm{SS}$ and the Nb-stabilized steel, 347SS, is made in Figure 4.9 where weight change data are plotted versus time. Stainless 347 displays much greater loss of weight than $316 \mathrm{SS}$ (cf. Figure 4.7) at a similar temperature. In this case, spalling of surface scales was quite obvious on $347 \mathrm{SS}$ and appears to be responsible for much of the weight loss.

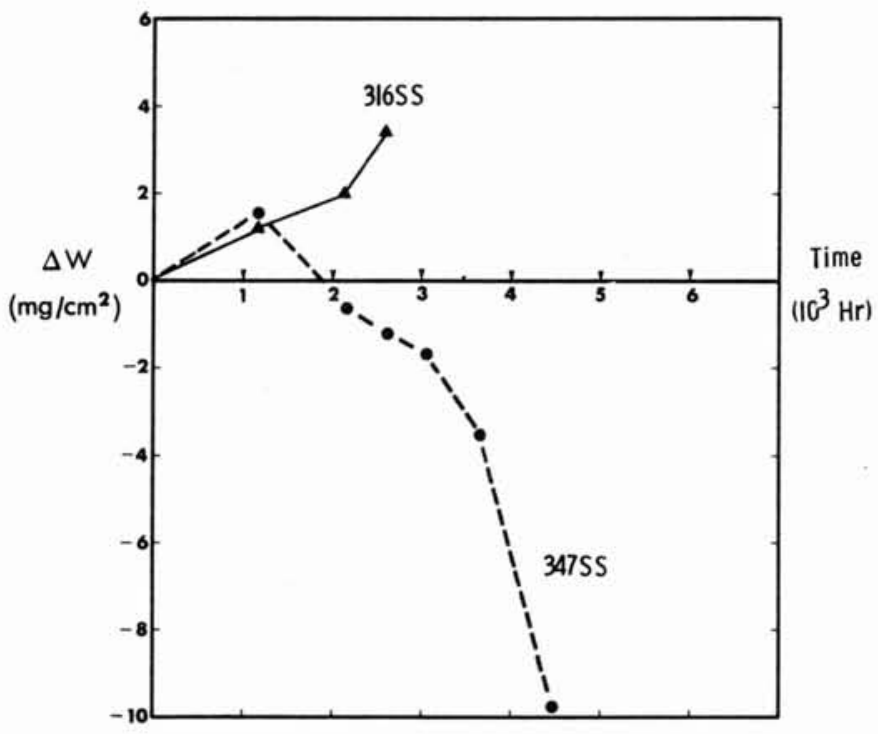

Figure 4.9. A Comparison of Weight Changes of 316 SS and 347 SS at $610^{\circ} \mathrm{C}$ 
The microstructure of $316 \mathrm{SS}$ after 2090 hours at $620^{\circ} \mathrm{C}$ is shown in Figure $4.10(\mathrm{a})$. This figure is typical of the range $610^{\circ} \mathrm{C}$ to $630^{\circ} \mathrm{C}$. A duplex oxide layer is present as before; however, the roughly equivalent thicknesses of each layer observed below $600^{\circ} \mathrm{C}$ have changed such that the magnetite layer (outer) is much thicker than the inner $(\mathrm{Fe}, \mathrm{Cr})_{3} \mathrm{O}_{4}$ layer.

(a)

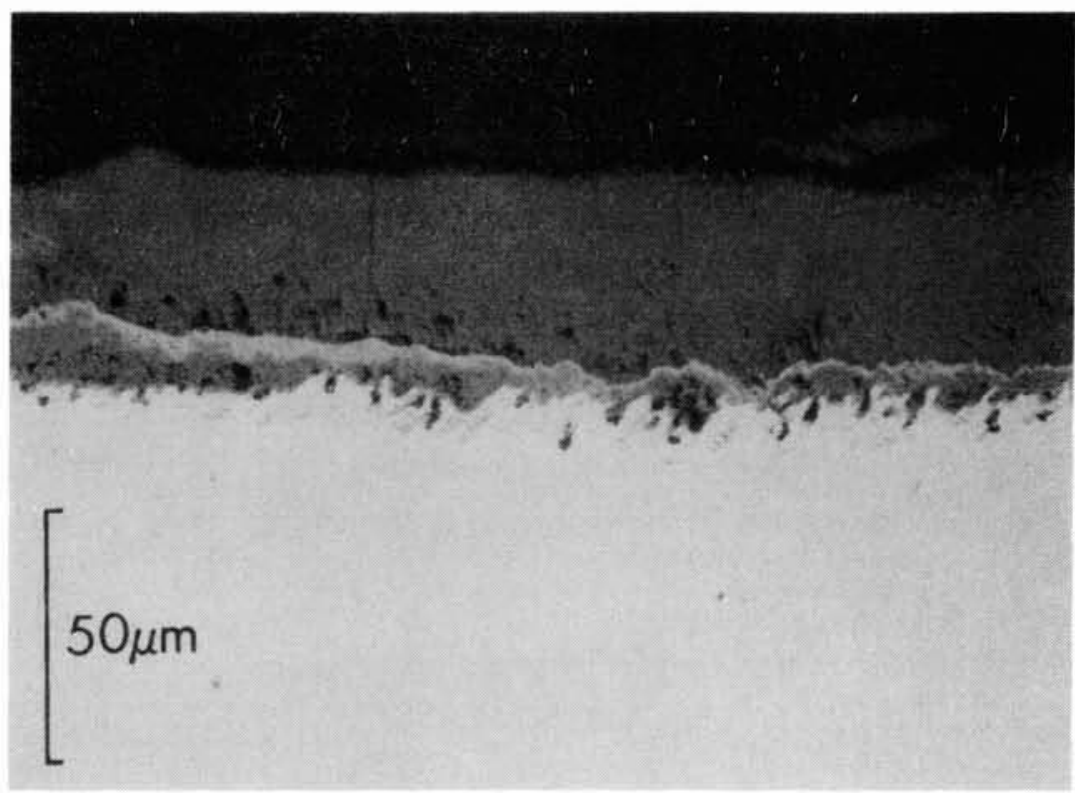

(b)

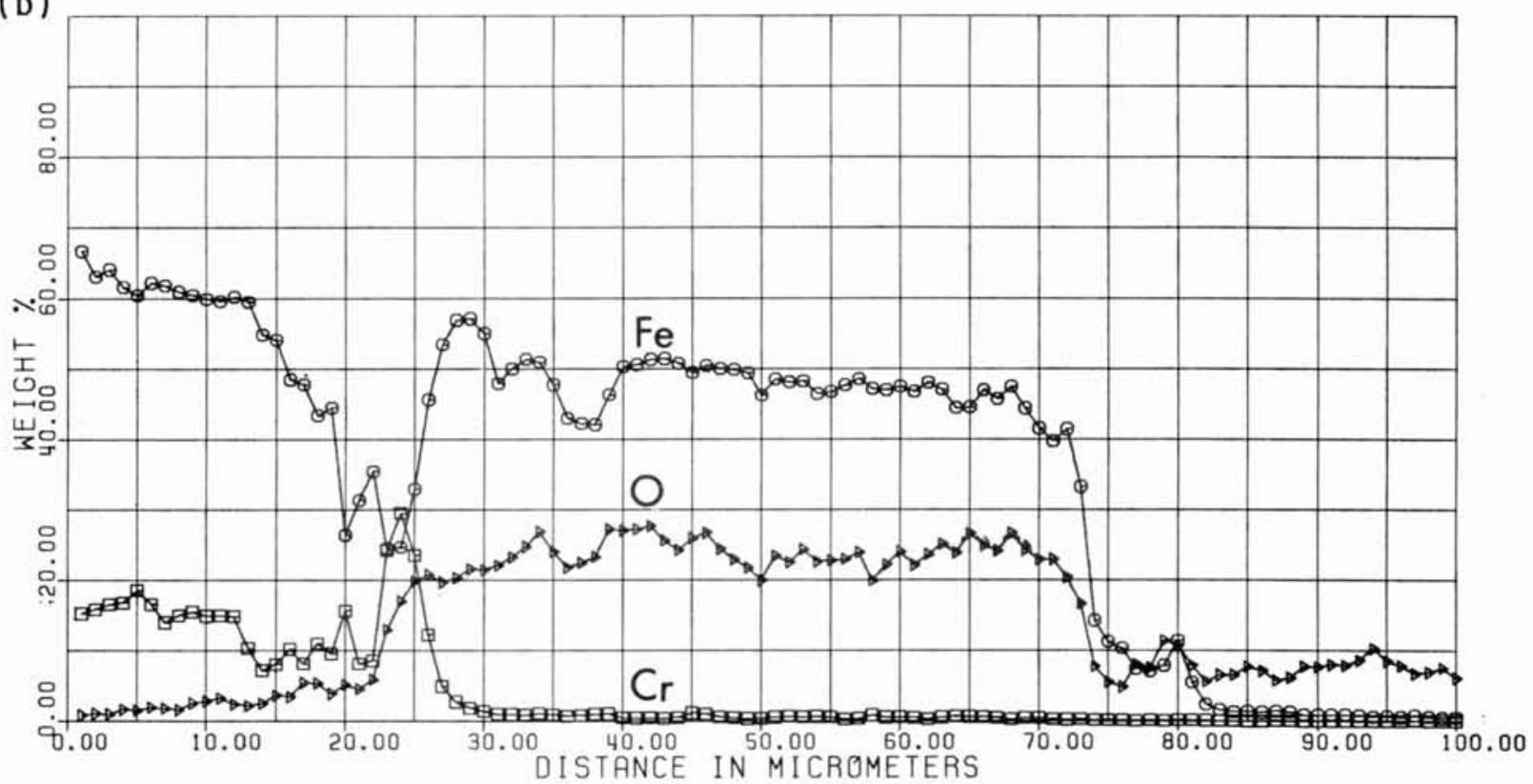

Figure 4.10. (a) Corrosion Microstructure of $316 \mathrm{SS}$ after $1000 \mathrm{hr}$ at $630^{\circ} \mathrm{C}$;

(b) An Electron Microprobe Analysis of Iron, Chromium, and 0xygen Concentrations in the 0xide Scale on 316 SS after $1000 \mathrm{hr}$ at $630^{\circ} \mathrm{C}$ 
An electron microprobe analysis taken across the scale is shown in Figure 4.10(b). Although the results do not sum to 100 percent in the oxide layer zones because of a lack of calibration standards, the trends in the data are accurate. The curve for $\mathrm{Cr}$ concentration clearly shows the virtual absence of $\mathrm{Cr}$ in the outer oxide layer. Depletion regions beneath the scale, with respect to both $\mathrm{Cr}$ and $\mathrm{Fe}$, are evident. The relatively thin spinel layer is identified by the peak in $\mathrm{Cr}$ concentration that occurs at $24 \mu \mathrm{m}$ on the beam traverse scale.

The dependence of scaling on temperature is further indicated in Figure 4.11 where the total scale thickness on a group of $316 S S$ specimens removed from the loop after 1000 hours has been plotted on an Arrhenius-type plot. The error bar shown for the lowest point is indicative of the uncertainties for all points and arises from the variations in loop temperatures during operating, and the presence of a temperature gradient of about $3^{\circ} \mathrm{C} / \mathrm{cm}$ in the hot leg where the samples were located. As much as $50 \mu \mathrm{m}$ ( 2 mils) of scaling were observed during the 1000 hours of exposure. Obviously, such a corrosion rate is not acceptable in a thin-walled receiver tube.

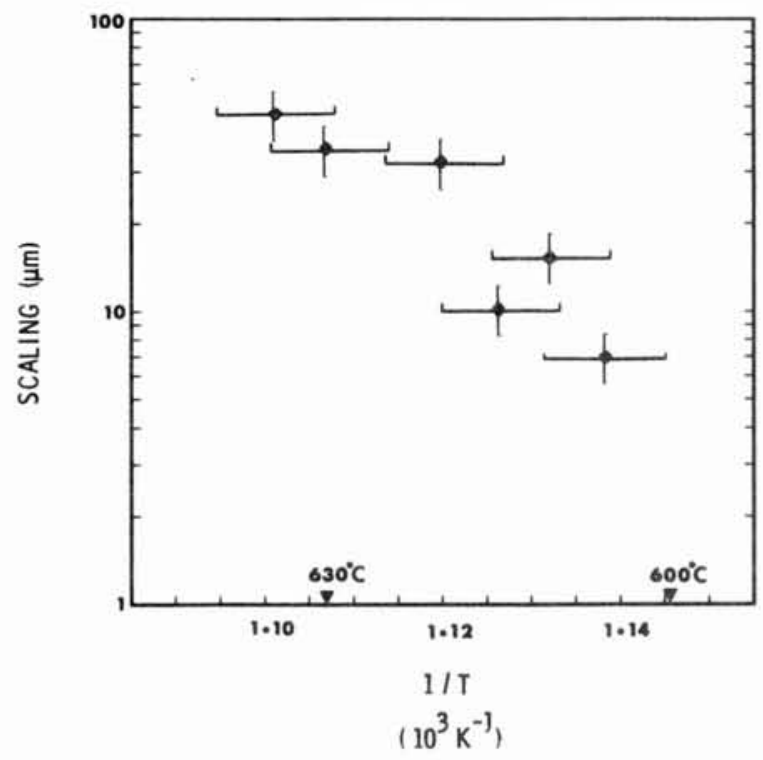

Figure 4.11. Arrhenius Plot of Scaling of 316 SS As a Function of Temperature in Molten $\mathrm{NaNO}_{3} / \mathrm{KNO}_{3}$

0ccurring simultaneously with oxide scaling is the phenomenon of $\mathrm{Cr}$ depletion. Depletion of $\mathrm{Cr}$ is undesirable since it will lead to microstructural changes and degradation of mechanical properties. The direct evidence of $\mathrm{Cr}$ depletion from the alloys studied was its appearance as a soluble component in the salt circulating in the loops. Salt samples were periodically withdrawn from the loops, quenched, dissolved in water, and analyzed by atomic absorption spectroscopy for metallic content. Negligible amounts of iron and nickel were detected but appreciable amounts of chromium were found. The 
concentration of $\mathrm{Cr}$ in the salt from the 304SS and 316SS loops are plotted in $\log -\log$ coordinates in Figure 4.12 as functions of time. The slope of the straight line was determined by a least-squares fit. In both cases, the slope is about 0.5 suggesting that diffusion controls depletion kinetics. Either diffusion in the alloy matrix or surface scales might control $\mathrm{Cr}$ loss. The total $\mathrm{Cr}$ loss in the 316SS loop, which operated at temperatures as high as $630^{\circ} \mathrm{C}$, was approximately five times that of the 304SS 100p. This indicates that temperatures exceeding $600^{\circ} \mathrm{C}$ rapidly accelerate $\mathrm{Cr}$ depletion as well as corrosion.

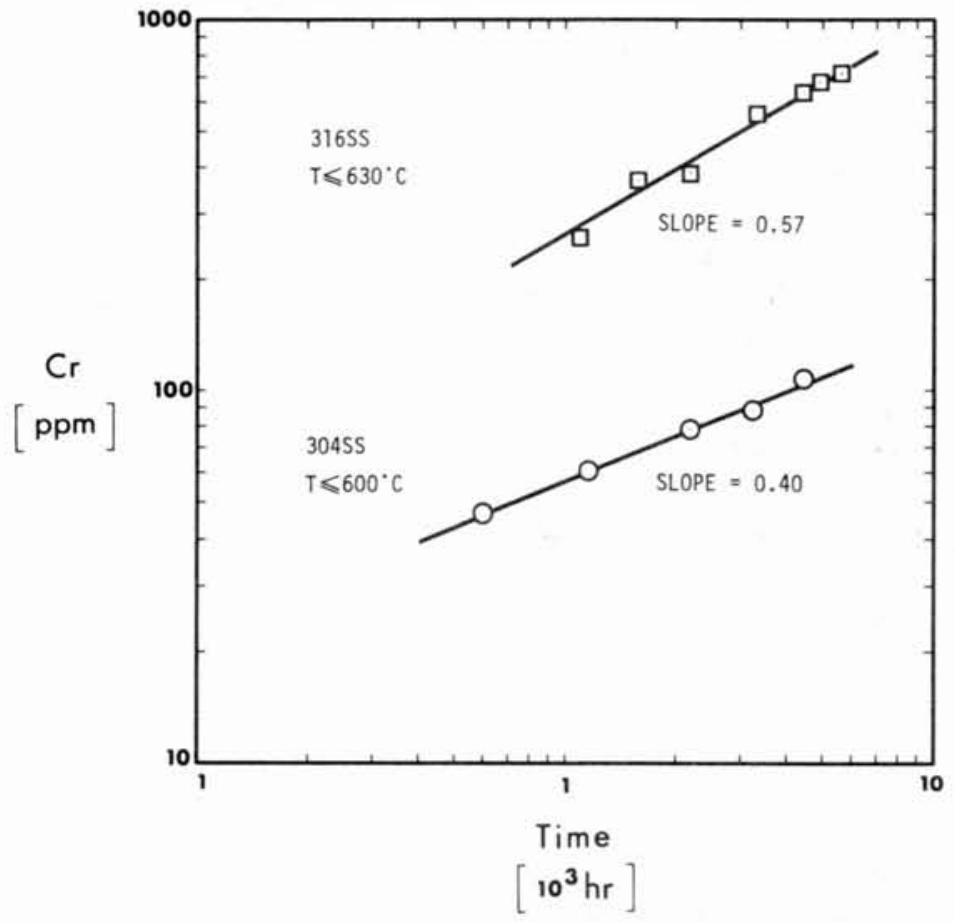

Figure 4.12. Chromium Concentration As a Function of Time in the Circulating Salt in Loops at Different Maximum Temperatures

An analysis of tube surfaces obtained from the coldest $\left(360^{\circ} \mathrm{C}\right)$ sections of the loops did not reveal evidence of thermal gradient mass transport. Tube surfaces were examined by scanning Auger electron spectroscopy since the surface layers were extremely thin. In addition to iron and chromium, $\mathrm{Ca}, \mathrm{Mg}$, $\mathrm{Si}$ and $\mathrm{C}$ were detected in appreciable mass fractions. These elements are impurities in the commercial grade salt and are probably precipitated on the cold parts of the system as alkaline earth silicates and carbonates. Since the impurity levels are on the order of $0.1 \mathrm{w} / \mathrm{o}$ in commercial salt, these deposits will be limited. 


\subsection{Conclusions and Recommendations}

The results presented here reveal several significant factors that must be recognized in designing and operating molten nitrate systems at high temperature. The corrosion behavior of stainless steels and Incoloy 800 is strongly influenced by temperature in the range $600^{\circ} \mathrm{C}$ to $630^{\circ} \mathrm{C}$. Operation at temperatures exceeding $600^{\circ} \mathrm{C}$ for long periods of time is not recommended and temperatures in the range of $630^{\circ} \mathrm{C}$ drastically shortens the life of metals. From a corrosion viewpoint, a marked difference between I800 and 316SS was not evident.

The influence of thermal cycling, a variable not studied here, will be to increase corrosion rates, particularly at the highest temperatures where scale layers are thickest and most susceptible to spalling. While the three primary alloys formed generally adherent scales, the stabilized steels, 321SS and $347 \mathrm{SS}$, experienced spalling, which would disqualify them from thermal cycling service in molten nitrates.

Surface finish affects corrosion behavior of the alloys studied here. Unpolished surfaces corrode less uniformly than abrasively polished surfaces and tend to corrode more rapidly. The corrosion behavior of electropolished surfaces should be investigated since it might provide an economical method of improving corrosion resistance in tube bundles.

Depletion of chromium from the alloy matrix is an additional mode of deterioration in molten nitrates. Chromium, in the form of a soluble chromate, increases in concentration in the melt with time, apparently according to diffusion-limited kinetics. No thermal gradient mass transfer was observed. Iron and nickel do not appear to be extracted from the alloy nor are they appreciably soluble in the melt.

\subsection{References}

4.1 J. W. Koger, Handbook of Stainless Steels, D. Pickner and I. M. Bernstein, editors (McGraw-HilT, 1977).

4.2 J. R. Keiser, J. H. DeVan, and E. J. Lawrence, J. Nucl. Mater. 85, 275 (1979).

4.3 W. S. Winters, R. W. Bradshaw, and F. W. Hart, "Design and Operation of Thermal Convection Loops for Corrosion Testing in Molten $\mathrm{NaNO}_{3}-\mathrm{KNO}_{3}$," Sandia National Laboratories, Livermore, SAND80-8212, June 1980.

4.4 D. M. Meeker and D. A. Nissen, report in preparation, Sandia National Laboratories, Livermore.

4.5 F. Eberle and J. H. Kitterman, Behavior of Superheater Alloys in HighTemperature, High-Pressure Steam, G. E. Lien, editor, ASME (1968). 


\title{
5.0 CREEP AND THE EFFECTS OF DEFORMATION ON THE CORROSION CHARACTERISTICS OF INCOLOY 800 IN MOLTEN NITRATE SALTS
}

\author{
S. H. Goods
}

\subsection{Introduction}

Incoloy 800 ( 1800 ) has been proposed for use in the receiver tube panel arrays in a number of advanced solar central receiver (SCR) designs. Among these are designs that require the use of molten sodium and potassium nitrate salt mixtures to act as the heat transfer and energy storage fluid. While there is some industrial experience with the storage and handling of these salts in molten form (References $5.1,5.2$ ), the experience involves temperatures substantially below those proposed for SCR operation (temperature near $600^{\circ} \mathrm{C}$ ). It becomes important therefore to examine the corrosion compatibility of the fluid containment alloy with nitrate-based salts at temperatures more representative of the operating conditions of these facilities.

During sunlight hours, complex thermal stresses will develop in the receiver tube panels due to their one-sided heating by the redirected sunlight. Diurnal cycling, as well as intermittent cloud cover, will result in the receiver tubes being subjected to a low cycle, high strain amplitude fatigue with hours-long hold periods at maximum temperature. At peak stress levels, the temperature will be well into the creep regime of 1800 . Thus superimposed upon the fatigue cycle will be creep or plastic relaxation processes. The effects of the resulting creep-fatigue interactions on the mechanical behavior and lifetime of this alloy (and other austenitic stainless steels) is a subject of much study (References 5.3,5.4) and will not be addressed here. Rather, a simple screening test has been devised to examine both the effects of exposure to the molten salt on the creep lifetime of 1800 as well as to study the effects, if any, of continuous deformation on the structure of the surface oxides (the corrosion products) formed and the adherency of these oxides to the base metal.

The corrosion that may occur can develop in one of two ways. First, if oxidation occurs via a general surface attack, a uniform surface oxide structure would be expected to form. Creep deformation (either grain boundary sliding or bulk deformation) could result in oxide cracking leading to the exposure of fresh base metal. This in turn could result in an increased rate of oxide growth. This type of corrosion is generally a slow process, so in thick-section specimens, short-time creep tests would reveal little degradation in creep rupture lifetimes or in loss of ductility. However, if corrosion occurs preferentially along grain boundaries, reduced rupture lifetime and loss of creep ductility would be expected even in relatively short-time creep tests. 


\subsection{Experimental}

Tensile creep tests have been performed on tube stock supplied by the Pacific Tube Company. The tubing had an $0 . D$. of $1.27 \mathrm{~cm}$ and $0.29 \mathrm{~cm}$ wall thickness. The alloy composition is given below in weight percent.

$$
\begin{array}{cccccccccc}
\mathrm{Cr} & \mathrm{Ni} & \mathrm{Fe} & \mathrm{C} & \mathrm{Ti} & \mathrm{Al} & \mathrm{Cu} & \mathrm{Si} & \mathrm{Mn} & \mathrm{S} \\
21.15 & 32.81 & \frac{\mathrm{Cl}}{43.35} & \frac{.04}{.47} & \frac{.52}{.52} & \frac{.21}{1.02} & \frac{.002}{.21}
\end{array}
$$

The as-received stock was solution-annealed at $1050^{\circ} \mathrm{C}$, resulting in an ASTM grain size of 7 . Optical microscopy revealed a microstructure essentially free of carbides $\left(\mathrm{M}_{23} \mathrm{C}_{6}\right)$ but containing a few large $(\sim 5 \mathrm{~m})$ titanium carbonitride particles.

Test specimens were fabricated from $30-\mathrm{cm}$ lengths of this stock by machining 2.54-cm gage sections $(0.127 \mathrm{~cm}$ wall thickness) near one end of each length (Figure 5.1). An I800 plug was then welded in the end of the specimen. The tube was filled with the powdered salt ( 60 percent $\mathrm{NaNO}_{3}, 40$ percent $\mathrm{KNO}_{3}$ by weight) and mounted into a constant-load tension creep frame. This specimen geometry was necessary to contain the salt in a molten state since the unique surface tension properties of the salt result in its creeping up the walls and out of any open container at elevated temperatures. Deformation was measured by means of a linear variable differential transformer (LVDT) attached to a high-temperature extensometer gage. Temperature was maintained by using a three-zone resistance heated tube furnace controlled by a Research Incorporated Furnace Controller and Power Supply. Temperatures could be held to within $1^{\circ} \mathrm{C}$ of the set point throughout the duration of each test. All tests were conducted between 600 and $670^{\circ} \mathrm{C}$. Scanning electron microscopy (SEM) was used to observe both fracture surfaces and surface oxide morphology.

The thick wall regions outside of the gage section did not deform plastically. Thus, the structure of the surface oxides that formed on the plastically deforming gage section could be compared to those formed on the elastically deformed sidewalls. In addition, the exterior or air-exposed surfaces could be examined and compared to the salt exposed inner surfaces, as shown in Figure 5.1 .

\subsection{Results and Discussion}

\subsubsection{Creep Behavior}

Figure 5.2 is a typical creep curve for 1800 tested in the as-received condition at $600^{\circ} \mathrm{C}$ and at an initial stress of $317.25 \mathrm{MPa}$ in air (that is, the tube specimen was not salt-filled). For this test the specimen was held at the test temperature for 24 hours prior to mechanical loading. Upon loading, a small amount of instantaneous plastic strain ( 0.6 percent) occurred but 


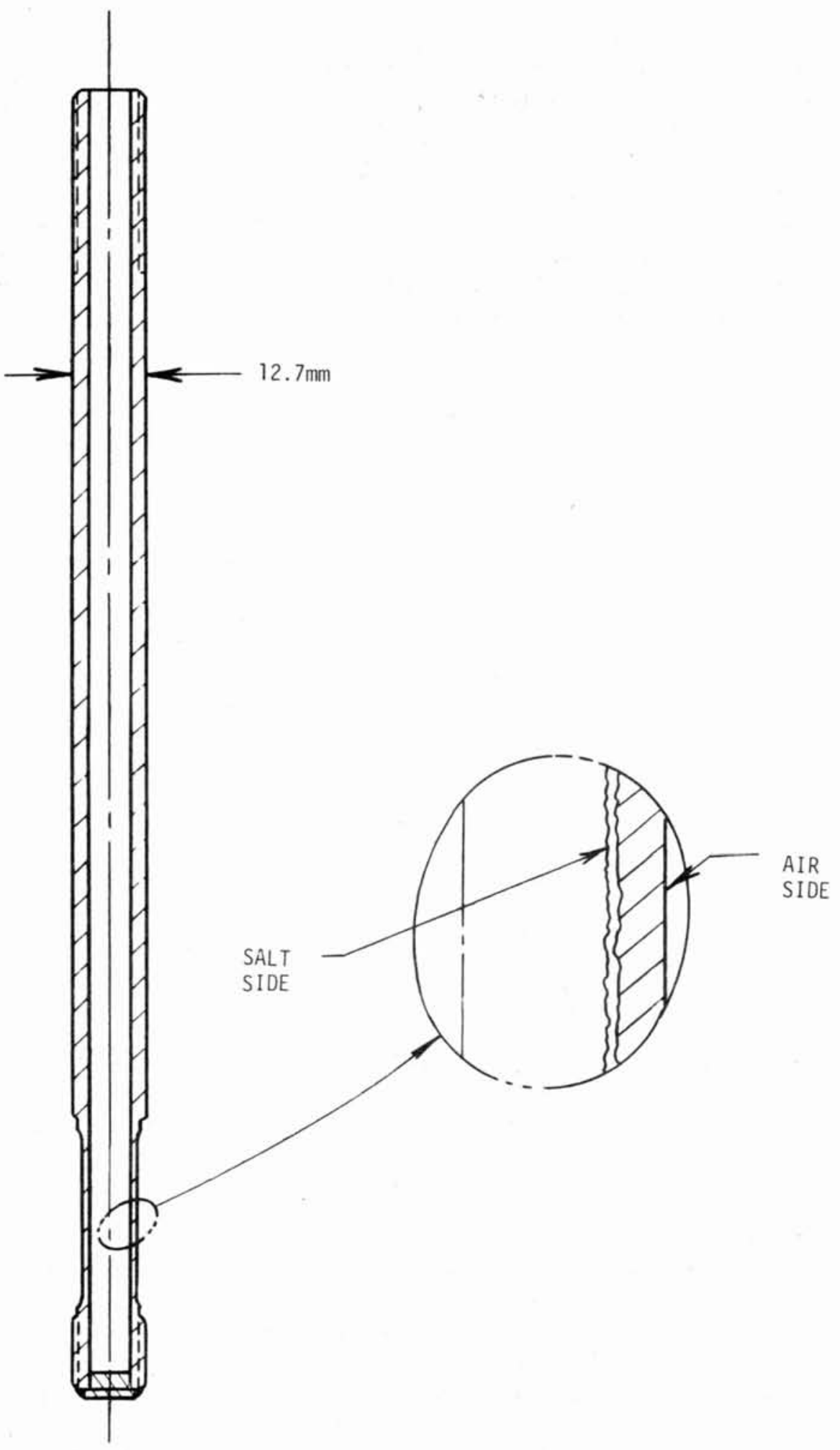

5.1. Creep Specimen. The molten salt is contained within the hollow tube by an 1800 plug welded into the bottom end. The long length of tubing above the gage section exits through the top of the furnace chamber. The resulting temperature gradient aids in containing the salt. 
little or no primary creep was observed. The particular heat treatment described previously resulted in an extended tertiary creep regime at all temperatures and stresses of testing. In other tests at $600^{\circ} \mathrm{C}$, when the load was applied immediately upon reaching the test temperature a different type of creep behavior was observed (refer to Figure 5.3). Here, both the test temperature and the initial stress were the same as for the test represented by Figure 5.2 . However, the instantaneous plastic strain ( $~ 6.5$ percent) was much greater than that induced in the as-received tube. The primary creep region was also greatly exaggerated over the earlier test with the creep rate decreasing rapidly after several hours.*

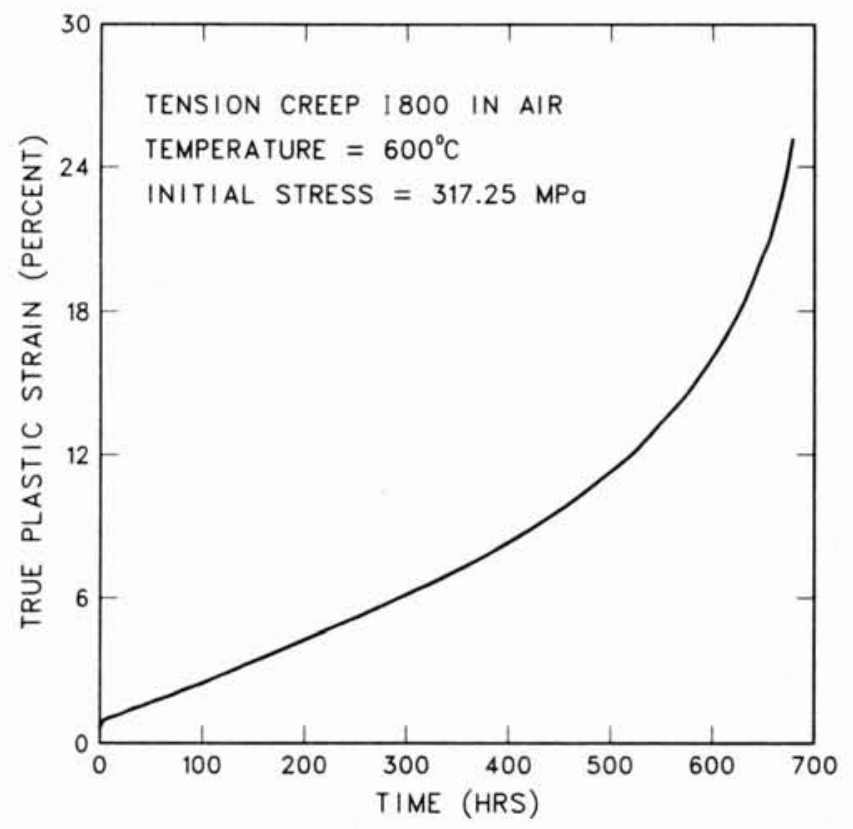

5.2. Constant load creep curve for Alloy 800 tested at $600^{\circ} \mathrm{C}$ and at an initial stress of $317.25 \mathrm{MPa}$. Prior to mechanical loading the specimen was brought to the test temperature and held there for 24 hours.

The difference in initial creep behavior between the two tests can be attributed to the difference in carbide microstructure. At $600^{\circ} \mathrm{C} \mathrm{M}_{23} \mathrm{C}_{6} \mathrm{car}$ bides form after several hours. Thus, the 24-hour hold at the test temperature prior to mechanical loading for the specimen shown in Figure 5.2 represents a carbide forming and stabilizing heat treatment. The carbides that form result in a microstructure that is strengthened against plastic deformation. For the specimen shown in Figure 5.3, the strengthening microstructure has not yet formed prior to loading, resulting in a greater initial offset. As the carbides precipitate, the specimen becomes more resistant to deformation and

*That the test shown in Figure 5.3 was conducted on a salt-filled specimen, while the specimen represented by Figure 5.2 was unfilled should have little bearing on initial creep behavior. Thus, the comparisons drawn between these two tests at the same temperature and initial stress remains valid. 


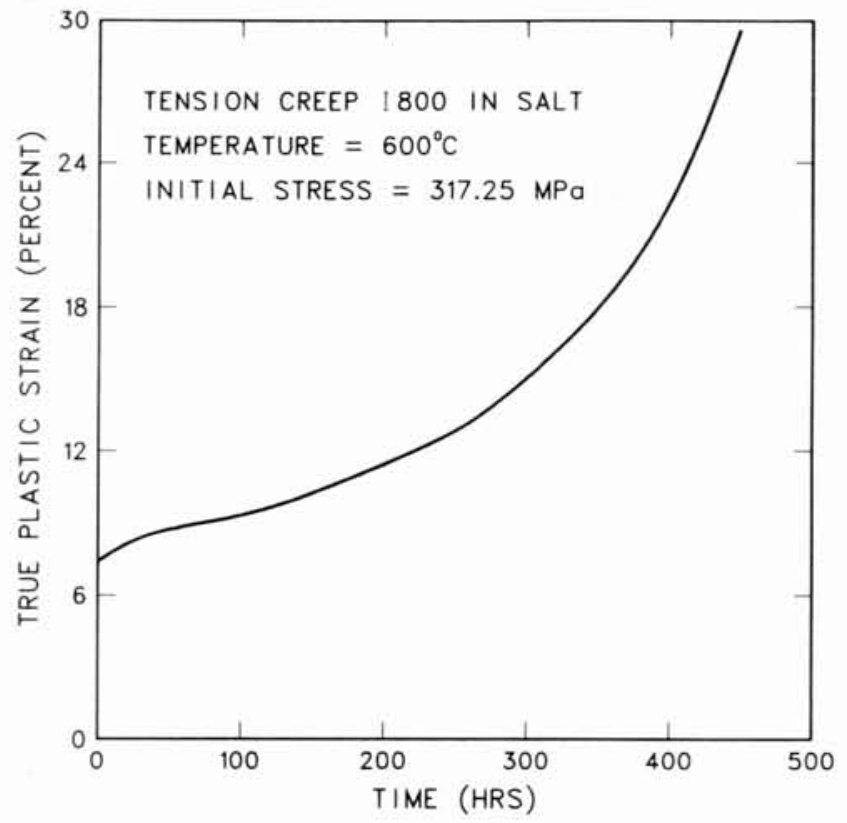

5.3. Constant Load Creep Curve for Salt-Exposed Alloy 800 Tested at $600^{\circ} \mathrm{C}$ and Initial Stress of $317.25 \mathrm{MPa}$. The specimen was mechanically loaded immediately upon reaching the test temperature.
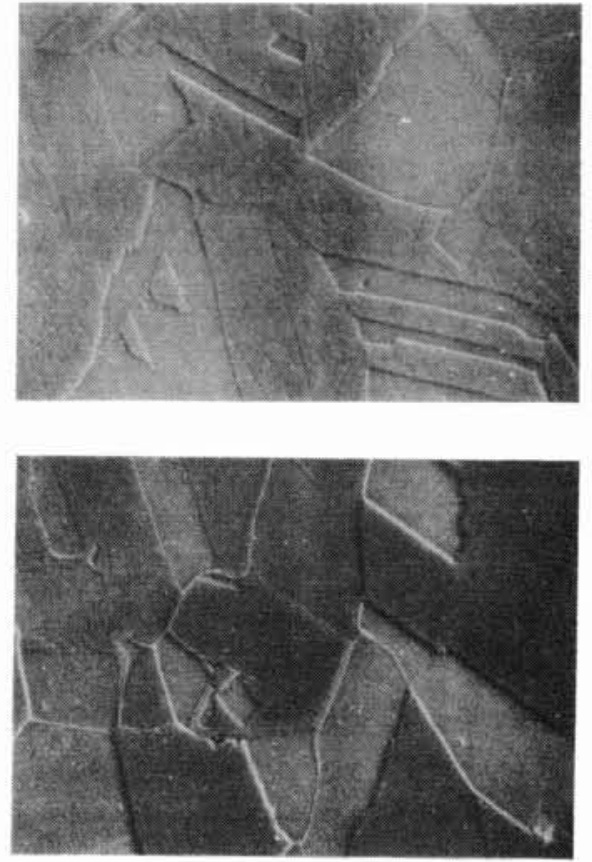

a

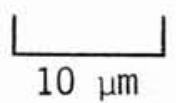

b c

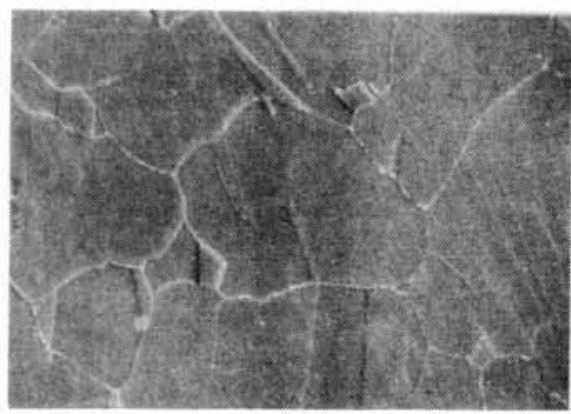

d

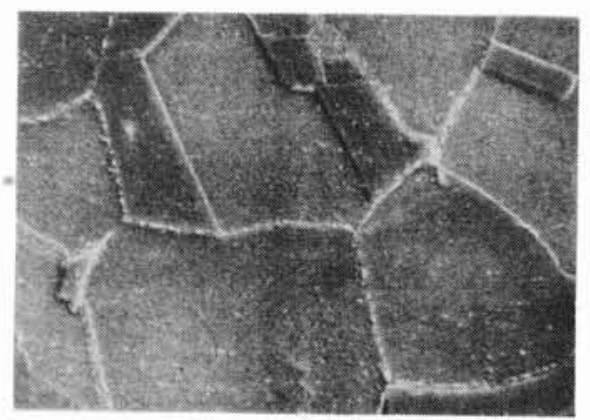

5.4. Optical Micrographs (Scanning Electron Microscopy) of Polished and Etched Cross Sections of I800 Tubing Showing the Evolution of the Microstructure As a Function of Annealing Time at $600^{\circ} \mathrm{C}$. Annealing time: (a) 1 hour, (b) 5 hours, (c) 8 hours, (d) 12 hours. 
the creep rate falls off dramatically. The evolution of the carbide strengthened microstructure is shown in Figure 5.4 and correlates quite well with the creep behavior shown in Figure 5.3.

While the salt-exposed creep specimen exhibits a shorter creep rupture lifetime than the air-exposed specimen, the difference more likely results from test to test variation rather than to an environmental effect. Figure 5.5 compares the effect of salt and air exposure on creep behavior of the alloy at $630^{\circ} \mathrm{C}$ and an initial stress of $275.85 \mathrm{MPa}$. The longer life of the test in salt is opposite to the results at $600^{\circ} \mathrm{C}$. Comparison at other temperatures showed no clear trend with regard to salt-induced degradation in the mechanical properties of 1800 . Observation of the fracture surfaces of all specimens tested reveal mixed mode failure with regions of transgranular fracture adjacent to intergranular fracture. The presence of salt within the tube during testing does not significantly influence the fracture surface morphology in these creep tests, however a slower strain rate test might well display a fracture mode change.

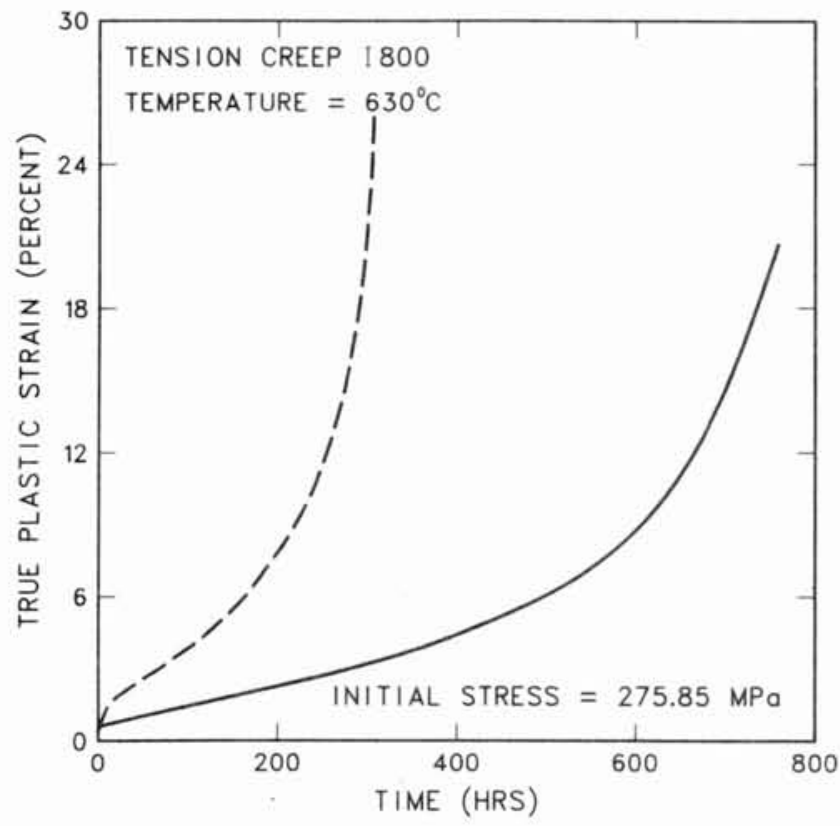

5.5. Constant Load Creep Curves for $I 800$ at $630^{\circ} \mathrm{C}$ and at an Initial Stress of $275.85 \mathrm{MPa}$, Comparing Creep Lifetimes and Ductility for Specimens Tested in Salt (-) and in Air (---)

\subsubsection{0xide Structure}

While mechanical testing alone did not reveal the presence of environmental attack, metallographic observations of the salt-exposed tensile specimen clearly showed salt-induced corrosion. Figure 5.6 shows polished cross sections of three different regions of an 1800 tensile specimen creep 
tested at $650^{\circ} \mathrm{C}$ for 550 hours to 10 percent strain. The air-exposed exterior sidewall (Figure 5-6C) shows only a very thin layer of surface oxide. Exposure to the salt at this temperature on the undeformed sidewall surface resulted in a much thicker $(\sim 10 \mu \mathrm{m})$ uniform and adherent oxide. The saltexposed gage section exhibited a still thicker oxide layer $(\sim 25 \mu \mathrm{m})$. The oxide was seen to penetrate down grain boundary cracks formed during deformation. In addition, the oxide itself exhibited a greater degree of porosity and cracking than that formed on undeformed sidewall sections. Increasing the amount of deformation resulted in an oxide which was more extensively cracked and more porous.

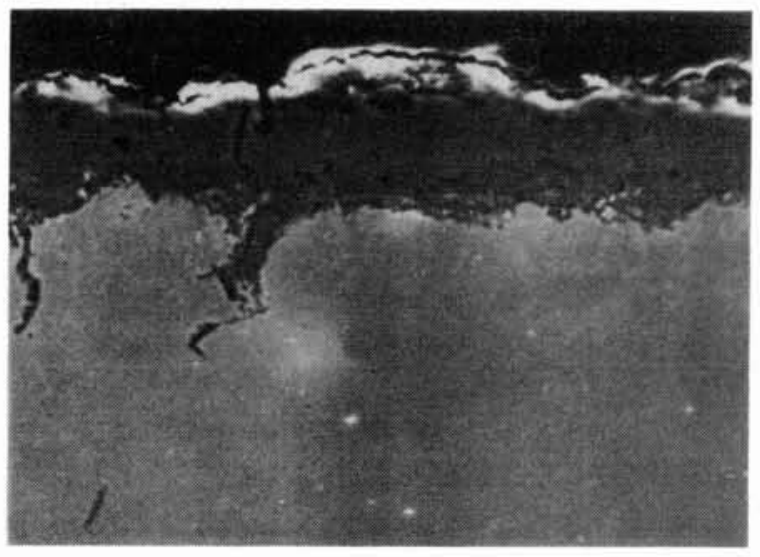

a

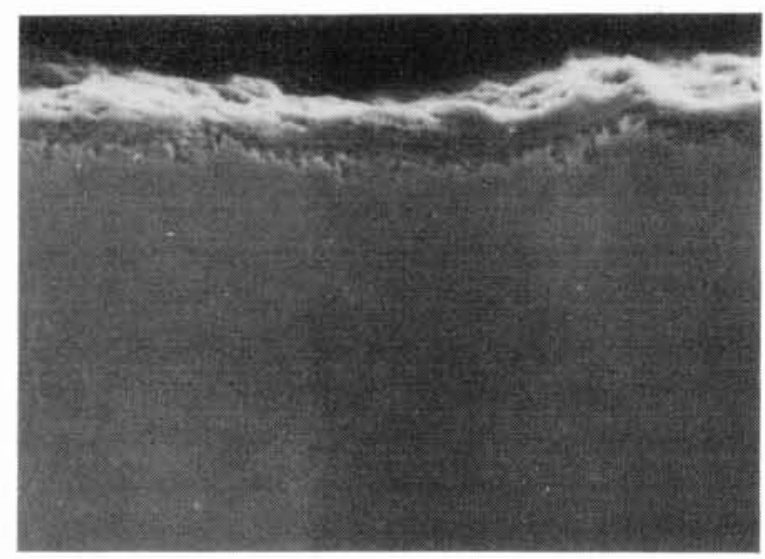

b

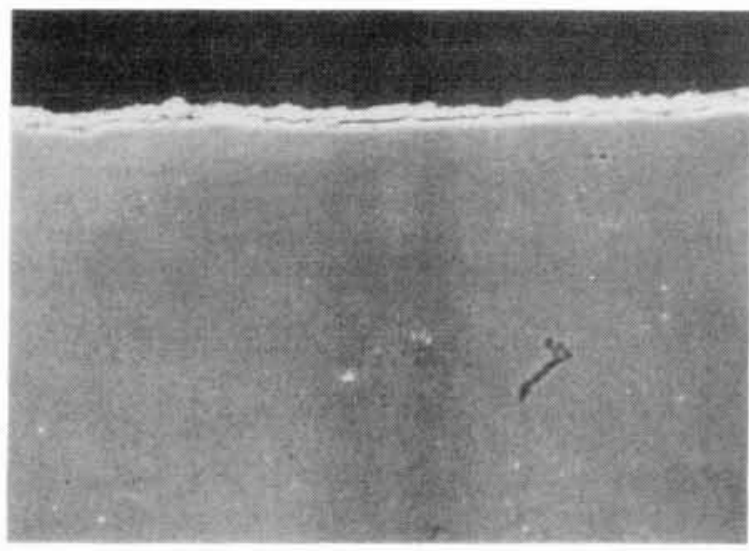

C

5.6. Surface 0xide Structure Formed during Exposure of I800 to Molten Nitrate Salt (Scanning Electron Microscopy). Oxide structure formed (a) on saltexposed gage surface (deformed inner tube wall) and (b) on salt-exposed, nondeforming sidewall. (c) Air-exposed sidewall surface. Deformation resulted in a thicker, more porous oxide when compared to the nondeformed, salt-exposed sidewall. 
The surface oxides that formed were multiphase (refer to Figure 5.7). EDAX analysis was used in a qualitative manner to map iron and chromium concentration in the oxide and substrate. The spot density from these patterns revealed that the near-surface oxide was iron-rich and poor in chromium. Beneath this surface layer was a $\mathrm{Cr}$ oxide-rich region. Crystal structure determination indicated the presence of $\mathrm{NaFeO}_{2}, \alpha-\mathrm{Fe}_{2} \mathrm{O}_{3}$, and $\gamma-\mathrm{Fe}_{2} \mathrm{O}_{3}$ in the surface scale. The presence of sodium was confirmed by electron microprobe analysis.

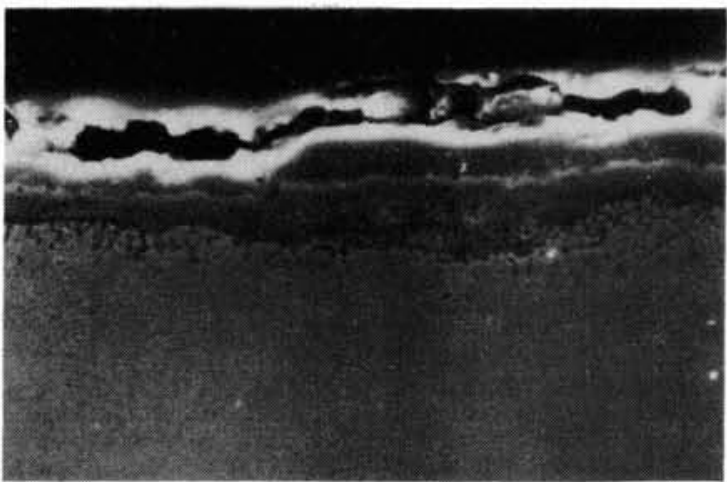

a
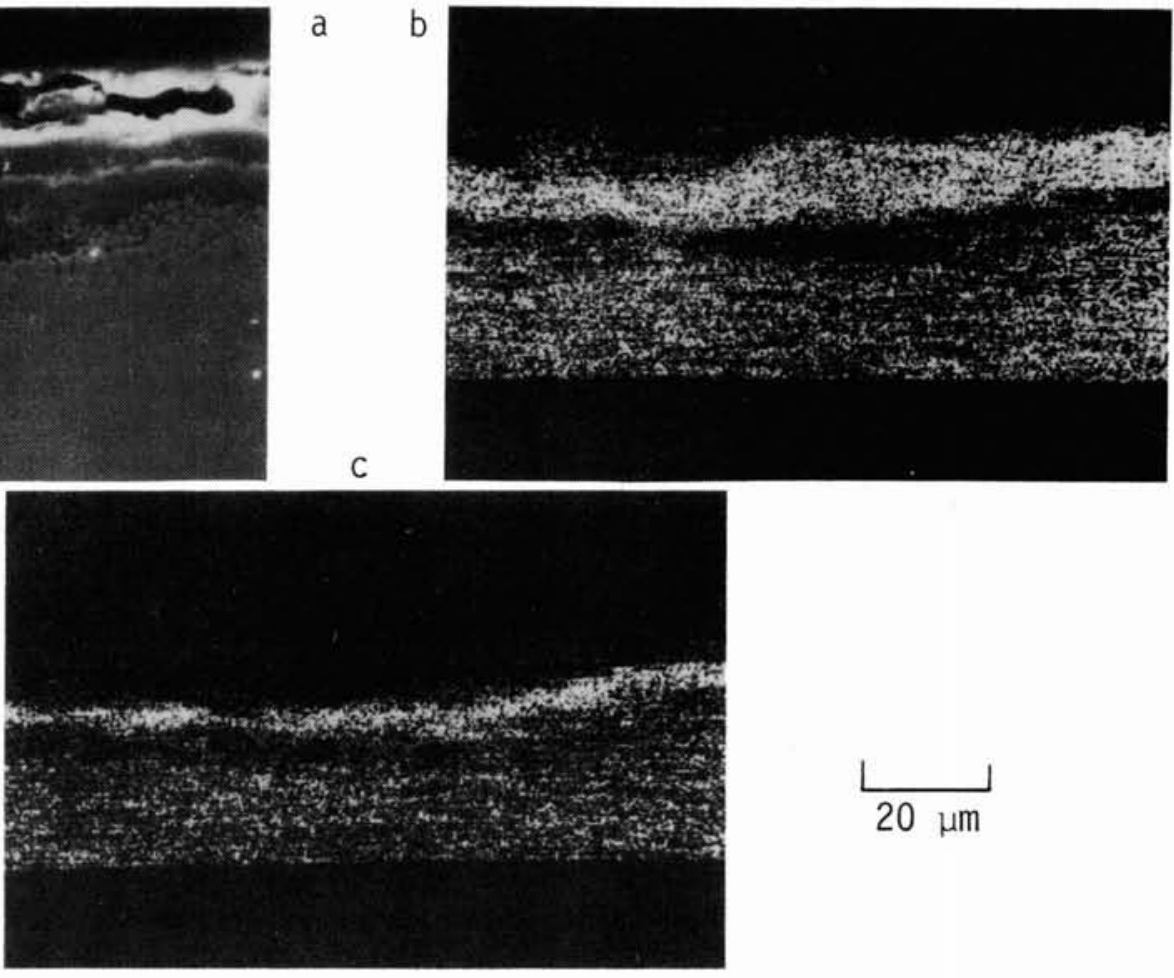

5.7. (a) Scanning electron microscopy of the salt-exposed sidewall in an I 800 tube at $670^{\circ} \mathrm{C}$. The interface running through the oxide corresponds to the original metal interface. The flaring and irregular features above the oxide in the micrograph are an artifact resulting from the mounting material pulling away from the specimen during polishing. (b) and (c) reveal the duplex nature of the oxide, with an iron-rich surface layer above a chromium-rich under layer.

Deformation also resulted in the intrusion of these oxides along grain boundaries in the tube sidewall (refer to Figure 5-8). This SEM montage shows the oxide structure developed on the salt-exposed sidewall of a specimen tested at $630^{\circ} \mathrm{C}$ for $\sim 760$ hours $\left(\sigma_{0}=275.85 \mathrm{MPa}\right)$. The extensive grain boundary cracking has resulted in oxide penetration in excess of 75 um below the tube sidewall surface. While this penetration is certainly enhanced by the large imposed strain, it nonetheless indicates the potential for severe surface corrosion in relatively short times. 


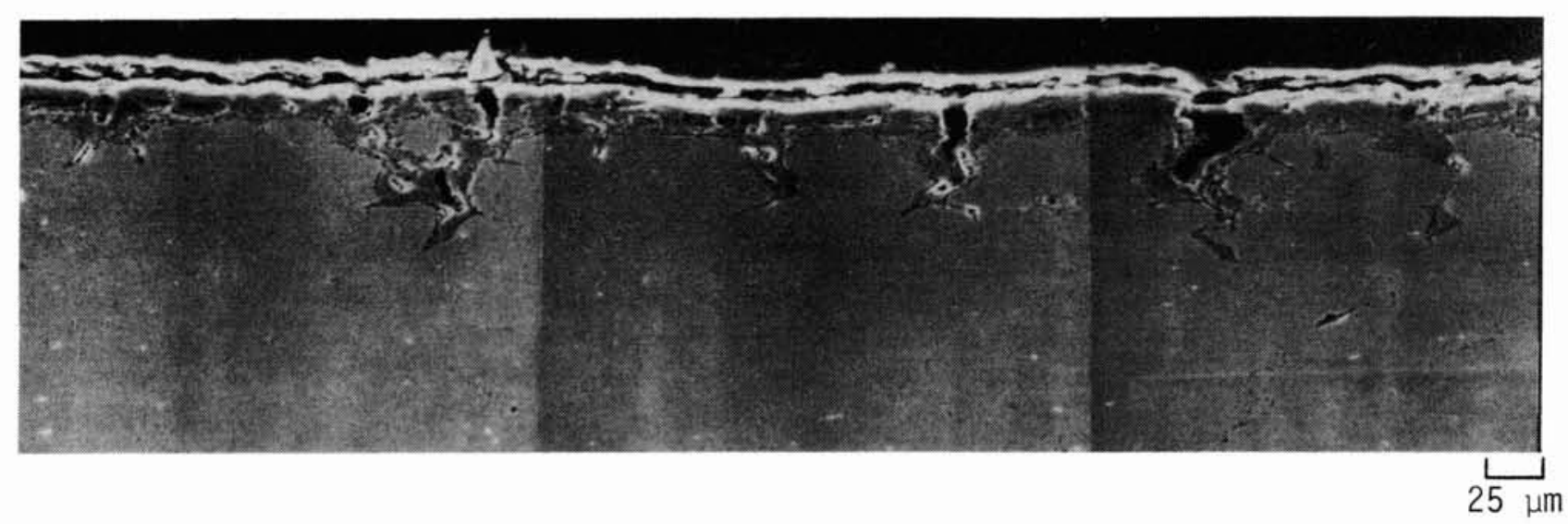

5.8. SEM Montage of the Salt-Exposed Gage Section of an I800 Tube Creep Tested at $630^{\circ} \mathrm{C}$ ( see Figure 5.4 ). Deformation-induced cracking results in deep intrusions of oxide down along grain boundaries.

\subsection{Conclusion}

The results of this work indicate that in the high temperature region of the SCR tube panel $\left(\sim 600-630^{\circ} \mathrm{C}\right)$ I 800 tubing in the solution-annealed condition will be microstructurally unstable. $\mathrm{M}_{23} \mathrm{C}_{6}$ carbides precipitate rapidly along grain boundaries resulting in a probable loss of solution strengthening and an increased resistance to grain boundary sliding. While these instabilities do not preclude the use of this alloy in receiver tube panel applications, appropriate stabilizing heat treatments may be necessary as design parameters.

The results of the mechanical testing alone do not reveal a degradation in structural properties. Deformation does not change the mode of corrosive attack. That is, it remains a general surface corrosion problem. The grain boundary penetration is the result of deformation-induced grain boundary cracking that exposes fresh base metal to the molten salt. The presence of thicker, more porous oxides on deformed sidewall sections, compared to the oxides formed on undeformed surfaces, suggests that these oxides are brittle and crack as a result of the imposed creep strain. This cracking results in the exposure of fresh base metal to the molten salt, with the net effect being an acceleration in the overall corrosion rate and a further reduction in potential service lifetime.

The high alloy content of 1800 does not guarantee resistance to corrosion in molten nitrate salt environments. The increased chromium content of the salt after exposure (refer to Section 4.0) suggests an oxidation process that is controlled by $\mathrm{Cr}$ dissolution into the salt. At temperatures below $630^{\circ} \mathrm{C}$ the oxide-metal interface is well defined. At higher temperatures the interface is diffuse and irregular with penetration of the oxide into the metal and some very small, isolated metal fragments in the oxide. 
The formation of oxides greater than $20 \mu \mathrm{m}$ thick in these relatively short-exposure times indicates the potential for severe surface corrosion. The large, monotonic strains imposed on the specimens as described above are not representative of those experienced by a central receiver panel. Longer exposure times, with both mechanical and thermal cycling representative of actual service conditions between this candidate SCR material and the molten salt environment is warranted.

The author wishes to acknowledge T. J. Sage for his assistance in all aspects of the experimental program.

\subsection{References}

5.1 "Molten Salt Safety Study Final Report," MCR-80-1305, Martin Marietta Co., 1980.

5.2 H. P. Vosnick and U. W. Uhl, Chem. Engr., p. 129 (May 29, 1963).

5.3 S. Majumdar, "Biaxial Creep-Fatigue Behavior of Materials for Solar Thermal Systems," ANL-80-34, 1980.

5.4 S. Majumdar, "Biaxial Creep-Fatigue Behavior of Type $316 \mathrm{H}$ Stainless Steel Tube," ANL-79-33, 1979. 


\title{
6.0 EVALUATION OF THE STRESS CORROSION CRACKING SUSCEPTIBILITY OF INCOLOY 800
}

\author{
J. W. Munford
}

\subsection{Introduction}

A slow strain rate test technique has been used to measure the stress corrosion cracking susceptibility of Incoloy 800 (I800) in molten nitrate salt. This testing procedure yields semi-quantitative data that permit, by comparing relative ductility measurements (i.e., elongation, reduction in area), a good measure of the stress corrosion susceptibility of the alloys tested. A metallographic and fractographic analysis, when combined with the above data, quantifies the mechanical measurements by assuring that no significant changes in the fracture morphology have occurred for the various test conditions.

\subsection{Experimental}

Tensile specimens were machined from 0.070 -inch thick sheet, cleaned, and tested in the as-received condition. The chemistry of the I800 sheet was (wt \%):

$$
\begin{aligned}
& \mathrm{Ni} \quad \mathrm{Cr} \quad \mathrm{Mn} \quad \mathrm{Cu} \quad \mathrm{Al} \quad \mathrm{Ti} \quad \mathrm{Co} \quad \mathrm{P} \quad \mathrm{S} \quad \mathrm{C} \\
& \begin{array}{llllllllll}
31.2 & 21.2 & 0.92 & 0.71 & 0.34 & 0.33 & 0.10 & 0.019 & 0.010 & 0.074
\end{array}
\end{aligned}
$$

The alloy had an ASTM grain size of 7-8. The salt used for this study was a $\mathrm{KNO}_{3} / \mathrm{NaNO}_{3}$ mixture.

In addition to evaluating the as-received sheet, a series of tests were conducted on TIG weldments (In 82 filler wire). The weld specimens were tested in the as-welded condition with the weldment located at the center of the test specimen transverse to the load axis.

The 1800 samples were tested in air at 25 and $250^{\circ} \mathrm{C}$ (as baseline data), and molten nitrate salt at temperatures from 300 to $630^{\circ} \mathrm{C}$. Strain rates varied from $10^{-4}$ to $10^{-7} \mathrm{sec}^{-1}$. The reduced area values were selected as being the most sensitive to environmental degradation. 


\subsection{Results and Discussion}

The results listed in Table 6 .I show the reduction in area (RA) values for all the test conditions. These results do not show any indication of stress corrosion cracking for either I800 parent metal or weldments. In addition, the metallographic and fractographic analyses have shown no significant changes in fracture morphology between air and molten salt tests. Further examinations are still in progress.

TABLE 6.I

SUMMARY OF ALLOY 800 SLOW STRAIN RATE TESTS

\begin{tabular}{ccccc}
\hline Specimen & Environment & $\begin{array}{c}\text { Temperature } \\
\left({ }^{\circ} \text { C) }\right.\end{array}$ & $\begin{array}{c}\text { Strain Rate } \\
(\text { sec-1) }\end{array}$ & $\begin{array}{c}\text { RA } \\
(\text { \%) }\end{array}$ \\
\hline \hline 101 & Air & 25 & $10^{-4}$ & 71 \\
102 & Air & 25 & $10^{-5}$ & 70 \\
103 & Air & 25 & $10^{-6}$ & 72 \\
104 & Air & 250 & $10^{-4}$ & 61 \\
105 & Air & 250 & $10^{-5}$ & 53 \\
106 & Air & 250 & $10^{-6}$ & 58 \\
107 & Salt & 300 & $10^{-4}$ & 60 \\
108 & Salt & 300 & $10^{-5}$ & 52 \\
109 & Salt & 300 & $10^{-6}$ & 57 \\
110 & Salt & 400 & $10^{-4}$ & 61 \\
111 & Salt & 400 & $10^{-5}$ & 56 \\
112 & Salt & 400 & $10^{-6}$ & - \\
113 & Salt & 500 & $10^{-4}$ & 57 \\
114 & Salt & 500 & $10^{-5}$ & 55 \\
115 & Salt & 500 & $10^{-6}$ & - \\
116 & Salt & 600 & $10^{-4}$ & - \\
117 & Salt & 600 & $10^{-5}$ & 53 \\
118 & Salt & 600 & $10^{-6}$ & 60 \\
119 & Salt & 630 & $10^{-4}$ & 59 \\
120 & Salt & 630 & $10^{-6}$ & 56 \\
121 & Salt & 630 & $10^{-5}$ & 55 \\
122 & Salt & 600 & $2 \times 10^{-6}$ & 54 \\
123 & Salt & 600 & $2 \times 10^{-5}$ & 55 \\
201 & Salt & 600 & $10^{-4}$ & 64 \\
202 & Salt & 600 & $10^{-5}$ & 63 \\
203 & Salt & 600 & $10^{-6}$ & 65 \\
204 & Salt & 500 & $10^{-7}$ & 65
\end{tabular}

Alloy 800 Weldments, TIG, In 82 Filler Wire

\begin{tabular}{llrrl}
313 & Air & 25 & $10^{-6}$ & 68 \\
314 & Air & 25 & $10^{-4}$ & 69 \\
315 & Air & 25 & $10^{-5}$ & 67 \\
307 & Salt & 500 & $10^{-6}$ & 70 \\
308 & Salt & 500 & $10^{-5}$ & 67 \\
309 & Salt & 500 & $10^{-6}$ & 68 \\
310 & Salt & 500 & $10^{-6}$ & 65 \\
311 & Salt & 500 & $10^{-5}$ & 69 \\
312 & Salt & 500 & $10^{-5}$ & 68 \\
301 & Salt & 600 & $10^{-5}$ & 66 \\
302 & Salt & 600 & $10^{-4}$ & 67 \\
303 & Salt & 600 & $10^{-6}$ & 71 \\
304 & Salt & 600 & $10^{-4}$ & 68 \\
305 & Salt & 600 & $10^{-5}$ & 68 \\
306 & Salt & 600 & $10^{-6}$ & 70 \\
\hline
\end{tabular}




\title{
7.0 A SOLID ELECTROLYTE OXIDE ION PROBE FOR MOLTEN NITRATES TO EVALUATE POSSIBLE CORROSION PROBLEMS
}

\author{
D. A. Nissen
}

\subsection{Introduction}

There is a large and growing interest on the part of the solar energy community in the use of molten salts as the heat transfer fluid in central receiver applications. This interest is presently focused on molten nitrate $\left(\mathrm{NaNO}_{3}-\mathrm{KNO}_{3}\right)$ and nitrate-nitrite $\left(\mathrm{NaNO}_{3}-\mathrm{KNO}_{3}-\mathrm{NaNO}_{2}\right)$ mixtures because of their suitable thermal properties, as well as a history of satisfactory industrial experience. However, there is essentially no corrosion data available for temperatures above $450^{\circ} \mathrm{C}$ and the potential for serious corrosion problems is a major concern.

To evaluate possible corrosion problems it is desirable to be able to predict conditions under which structural alloys will exhibit passivity. Potential/p $=$ diagrams, analogous to those developed by Pourbaix (Reference 7.1), have been constructed for molten salts from published thermodynamic data (Reference $7 \cdot 2,7 \cdot 3$ ). Considerable caution must be used in applying these diagrams to real systems because the data used to construct these diagrams is for the pure liquid or solid compounds and, more importantly, because of the controversy surrounding the existence of the oxide ion in nitrate melts (Reference 7.4). This work reports on the construction and testing of an oxide ion-sensitive electrode of the type $\mathrm{M}, \mathrm{MO} / \mathrm{ZrO}_{2}\left(\mathrm{Y}_{2} \mathrm{O}_{3}\right)$ or $\mathrm{ThO}_{2}\left(\mathrm{Y}_{2} \mathrm{O}_{3}\right)$ for use in molten nitrates. These electrodes proved to be sensitive to oxide ion concentrations within the $10^{-4}$ to $5 \times 10^{-1}$ molal range in molten $\mathrm{NaNO}_{3}-\mathrm{KNO}_{3}$.

\subsection{Experimental}

Either $\mathrm{ZrO}_{2}\left(\mathrm{Y}_{2} \mathrm{O}_{3}\right)$ or $\mathrm{ThO}_{2}$ was used to contain the metal, metal oxide phase and separate it from the nitrate melt. Both ceramics worked equally well, and except for an asymmetry potential difference of a few millivolts, gave identical results. The couple $\mathrm{Pb}, \mathrm{Pb} 0$ was chosen for the electrode because it has been well characterized (Reference 7.5), and by operating the electrode at temperatures above the melting point of $\mathrm{Pb}\left(327^{\circ} \mathrm{C}\right)$ the response was significantly improved. The temperature dependence of this electrode was linear over the range 325 to $425^{\circ} \mathrm{C}$ and equal to $5.8 \times 10^{-4} \mathrm{~V} /{ }^{\circ} \mathrm{C}$. 
By varying the concentration ratio of the acid-base pair $\mathrm{Cr}_{2} \mathrm{O}_{7}=/ \mathrm{CrO}_{4}=$ it was possible to change the concentration of oxide ion in the $\mathrm{NaNO}_{3}-\mathrm{KNO}_{3}$ melt

$$
2 \mathrm{CrO}_{4}=+\mathrm{Cr}_{2} \mathrm{O}_{7}=+0=\text {. }
$$

The same result was also obtained by titrating $\mathrm{Cr}_{2} \mathrm{O}_{7}=$ with $\mathrm{CO}_{3}$

$$
\mathrm{Cr}_{2} \mathrm{O}_{7}=+\mathrm{CO}_{3}=+2 \mathrm{CrO}_{4}=+\mathrm{CO}_{2}
$$

in which case the electrode was used to detect the endpoint.

Except for the lowest oxide ion concentration, $<10^{-3} \mathrm{molal}$, the response of this electrode to changes in the oxide ion concentration was very rapid, and once the equilibrium potential had been reached $(\sim 5-10 \mathrm{~min})$ it remained very stable $( \pm 0.0005 \mathrm{~V})$ for as long as 48 hours. At the lower oxide ion concentrations about one hour was required for the potential to stabilize.

To reduce the influence of impurities and possible side reactions to a minimum, the experiments were done in an all gold apparatus under argon that had been carefully treated to remove traces of $\mathrm{O}_{2}, \mathrm{H}_{2} \mathrm{O}$, and $\mathrm{CO}_{2}$. The reference electrode for these studies was $\mathrm{Ag} / \mathrm{AgNO}_{3}(0.1 \mathrm{~m}), \mathrm{NaNO}_{3}-\mathrm{KNO}_{3}$ contained in a thin Pyrex membrane.

For oxide ion concentrations greater than $3 \times 10^{-3}$ molal the $\mathrm{Pb}, \mathrm{PbO}$ electrode potential was linearly dependent upon $\log \left[0^{=}\right]$and $\mathrm{dE} / \mathrm{d} \log \left[0^{=}\right]$ corresponded to a two-electron process. For oxide ion concentrations less than $3 \times 10^{-3}$ molal the potential was also linearly dependent upon $\log \left[0^{\circ}\right]$; however, $\mathrm{dE} / \mathrm{d} \log \left[\mathrm{0}^{\mathrm{C}}\right]$ corresponded to a one-electron process.

\subsection{References}

7.1 M. Pourbaix, Thermodynamics of Dilute Aqueous Solutions (Edward Arnold, London, 1949).

7.2 S. L. Marchiano and A. J. Arvia, Electrochemica Acta 17, 25 (1972).

7.3 R. Littlewood, J. Electrochem. Soc. 109, 525 (1962).

7.4 J. A. Plambeck, Encyclopedia of Electrochemistry of the Element, Vol. X, A. J. Bard, ed. (Marcel Dekker, New York, 1976), p. 1972.

7.5 C. B. Alcock and T. N. Belford, Trans. Faraday Soc. 60, 822 (1964). 


\title{
8.0 THERMAL STABILITY OF NITRATES
}

\author{
C. M. Kramer
}

\subsection{Introduction}

Solar power plants use thermal energy from the sun to produce steam for turbines that generate electricity. In one type of solar power plant the sun's rays are focused by a field of heliostats (sun-tracking mirrors). The heliostats focus the sunlight onto an elevated receiver, through which a heat transfer fluid is pumped to absorb the focused energy. The hot fluid then flows to a heat exchanger to generate steam to turn a turbine (Reference 8.1).

Economic use of solar insolation for electrical power generation necessitates energy storage. Ideally, the heat transfer fluid would also be a sensible heat thermal storage medium (References 8.1,8.2). The criteria for a single heat transfer and thermal energy storage fluid are: melting point less than $350^{\circ} \mathrm{C}$, thermal stability to $600^{\circ} \mathrm{C}$, high specific heat, low vapor pressure, compatibility with structural materials, and low cost. Satisfying these criteria are certain molten salts and molten metals (References 8.3-8.5). Examples of the former are mixtures of $\mathrm{NaNO}_{3}$ and $\mathrm{KNO}_{3}$. Examples of the latter are alkali metals. An important characteristic of sodium and potassium nitrate is their chemical stability in air (Reference 8.6 ) which can greatly simplify the design of the solar power plant.

In a few industrial applications the molten nitrates have been heated to as high as $600^{\circ} \mathrm{C}$, the exact temperature depending on the duration of use and economic factors (Reference 8.6). However, industrial experience has shown that degradation of the salts may occur when heated to high temperatures. Therefore, a study has been conducted to investigate decomposition mechanisms of nitrates and nitrites.

\subsection{Experimental}

Because gases may evolve from the salts weight losses may occur due to the following reactions

$$
\mathrm{NaNO}_{3}+\mathrm{NaNO}_{2}+\frac{1}{2} \mathrm{O}_{2}
$$




$$
\begin{aligned}
& 2 \mathrm{NaNO}_{3}+\mathrm{Na}_{2} \mathrm{O}+\frac{5}{2} \mathrm{O}_{2}+\mathrm{N}_{2} \\
& \mathrm{NaNO}_{3}(\ell)+\mathrm{NaNO}_{3}(\mathrm{~g})
\end{aligned}
$$

A combined experimental system was assembled that included a mass spectrometer and a microbalance to gain more insight into the reactions. The essential elements of the thermogravimetry and mass spectrometry (TG/MS) system are: the microbalance, the furnace, the gas inlet system, the mass spectrometer, the vacuum system, and the data acquisition system. The TG/MS apparatus is shown in Figure 8.1.

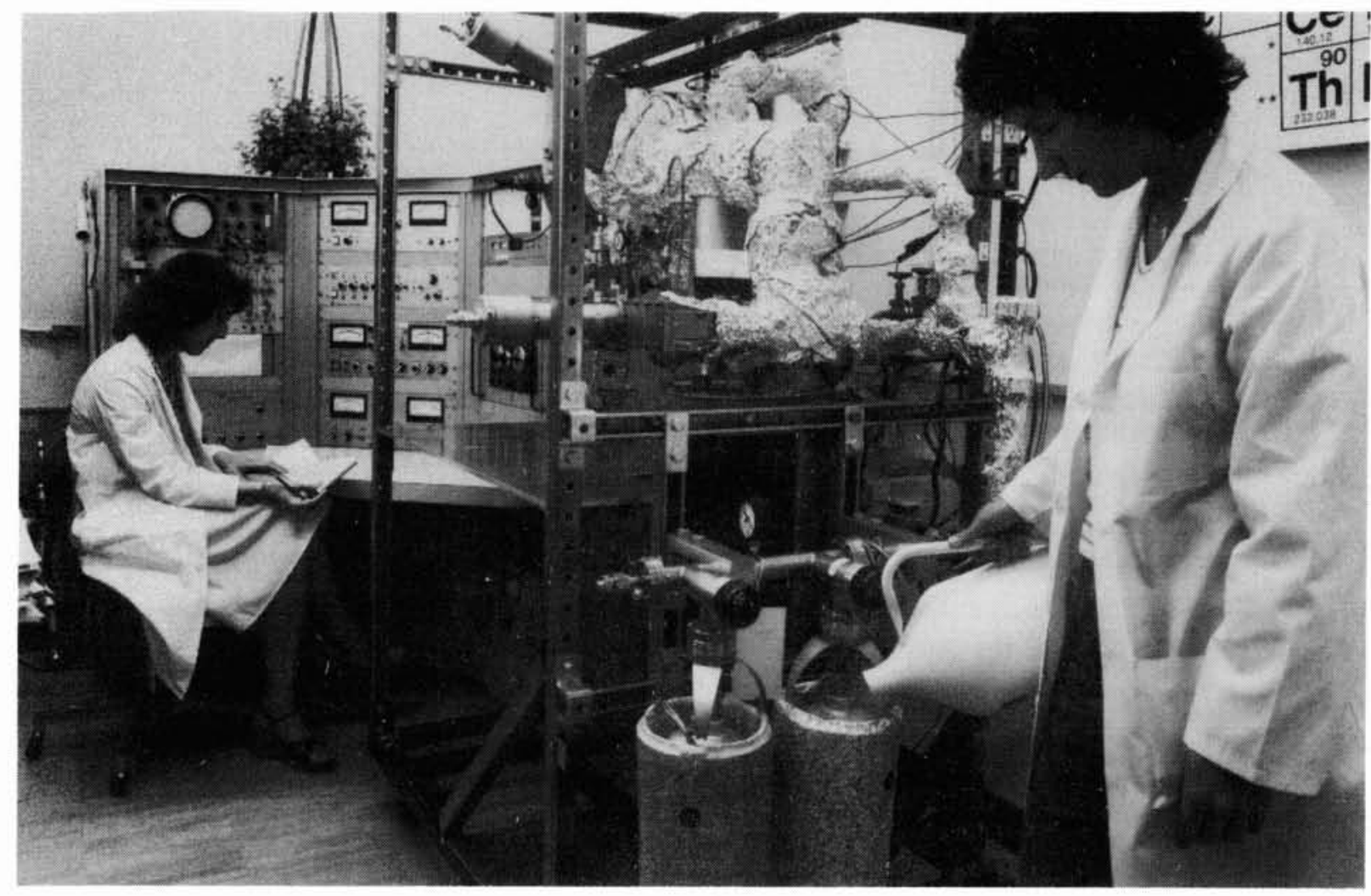

Figure 8.1. Photograph of TG/MS System

A Cahn $\mathrm{R}-\mathrm{H}$ microbalance was used that has a minimum detectable weight change of $10 \mu \mathrm{g}$ and a maximum weight limit of $10 \mathrm{~g}$. The furnace is a $1.9-\mathrm{cm}$ diameter stainless steel tube that is heated externally by a kanthal heater. The furnace can be operated as high as $1000^{\circ} \mathrm{C}$.

A gas sampling system was constructed to couple the vacuum chamber of the mass spectrometer (which was kept at less than $10^{-4}$ torr) to the sample chamber that may be at 760 torr. To achieve this pressure drop, a small tube in the furnace wall at the upper edge of the sample crucible was connected to 
a shutoff valve and a leak valve. The leak valve provided a variable, but reproducible, gas flow into the mass spectrometer. This system allowed timeresolved detection of decomposition processes that had not been applied to the nitrate salts before. A disadvantage of this gas sampling arrangement was that vapor species that are condensible at room temperature could not be detected. These vapors condense on the circuitous and relatively cold route the gases must take to the mass spectrometer; therefore species from nitrate or nitrite vaporization (i.e., Reaction 8.3) were not studied by mass spectrometry in this work.

The mass spectrometer is an Extranuclear Laboratories quadrupole mass spectrometer and has an axial ionizer and a $\mathrm{Cu}-\mathrm{Be}$ detector. To facilitate comparisons of experiments, the electron optics were adjusted so the ion intensities were insensitive to small changes in the lenses and all experiments were performed with identical mass spectrometer settings.

The TG/MS system is housed in a stainless steel vacuum system having an ion pump and a Ti-sublimation pump.

A data acquisition system was incorporated into the TG/MS system for ease of collecting thermogravimetric data. In the system, the balance output voltage is fed into a digital voltmeter. A microprocessor unit reads the digital voltmeter and two digital chromel-alumel thermocouples. The thermocouple readings and the voltmeter output are read into the CDC 6600 computer so that kinetic analysis may be performed.

A computer program was used that performed a least squares analysis for the weight per unit surface area (wt/sa) as a function of time, $t$. The equation to which the thermogravimetric data were fit was:

$$
\frac{w t}{s a}=a+b t+c t^{2}
$$

The computer program calculated the best values of the constants a, b, and $c$ for each experiment. The initial rate of decomposition is b. The rate constants were assumed to have an Arrhenius temperature dependence, i.e.,

$$
b=\exp \left(\Delta S^{\star} / R\right) \exp \left(-\Delta H^{\star} / R T\right)
$$

where $\Delta S^{\star}$ and $\Delta H^{*}$ are the entropy and enthalpy of activation for a reaction. The computer program also least squares fitted $\ln (b)$ versus $1 / T$ and determined $\Delta S^{\star}$ and $\Delta H^{*}$ for a given series of experiments.

Three salts have been studied with the TG/MS apparatus: $\mathrm{NaNO}_{3}, \mathrm{KNO}_{3}$, and $\mathrm{NaNO}_{2}$. The experiments were isothermal decomposition experiments in a vacuum over a temperature range of 340 to $460^{\circ} \mathrm{C}$.

Small (< $10 \mathrm{mg}$ ) samples of salt were precipitated from salt water solutions onto gold "flags." The flags were suspended in the furnace by thin gold wires welded to the flags. When melted, the salt samples covered the entire flag surface. Since the samples of salt were small, they did not form pendant drops on the flag. Therefore, the salt thickness was assumed to be 
uniform over the surface of the flag. The precipitated salt samples were submitted to infrared absorption analysis to verify that the salts were unchanged by this procedure.

The heating schedule for the experiments was as follows: the furnace was heated from room temperature to $60^{\circ} \mathrm{C}$ and held for 180 minutes; the furnace was then heated at 25 degrees per minute to the isothermal test temperature and held at that temperature for 360 minutes; the furnace was then turned off to cool.

A unique method of comparing the evolved gases was employed. From preliminary experiments masses 28,30 , and $32\left(\mathrm{~N}_{2}, \mathrm{NO}\right.$, and $\left.\mathrm{O}_{2}\right)$ were the only gases evolved from $\mathrm{NaNO}_{2}, \mathrm{NaNO}_{3}$, and $\mathrm{KNO}_{3}$. To compare the amounts of each gas that were evolved the mass range 27-33 was quickly and repeatedly scanned with the mass spectrometer. The mass spectra was recorded on a strip chart recorder. The resulting record gave discrete peaks that formed an envelope for each mass. After the experiment was finished, a planimeter was used to measure the area under each envelope for each mass. The kinetic analyses of the weight changes and the evolved gases are given in Tables 8.I, 8.II, and 8.III and illustrated in Figure 8.2.

TABLE 8.I

KINETIC THERMOGRAVIMETRY DATA FOR $\mathrm{NaNO}_{3}$ IN VACUUM

\begin{tabular}{|c|c|c|}
\hline $\begin{array}{c}T \\
(K) \\
\end{array}$ & $\begin{array}{c}\mathrm{b}^{\star} \\
\text { (mg } \mathrm{cm}^{-2} \mathrm{~min}^{-1} \\
\end{array}$ & $\begin{array}{c}\mathrm{c}^{\star} \\
\left(\mathrm{mg} \mathrm{cm} \mathrm{cm}^{-2} \mathrm{~min}^{-2}\right) \\
\end{array}$ \\
\hline $\begin{array}{l}677 \\
716 \\
737 \\
723 \\
726 \\
774 \\
726 \\
784 \\
655\end{array}$ & $\begin{array}{l}-1.883\left(10^{-2}\right) \\
-1.082\left(10^{-1}\right) \\
-1.798\left(10^{-1}\right) \\
-7.957\left(10^{-2}\right) \\
-9.342\left(10^{-2}\right) \\
-4.010\left(10^{-1}\right) \\
-6.620\left(10^{-2}\right) \\
-3.116\left(10^{-1}\right) \\
-7.203\left(10^{-3}\right)\end{array}$ & $\begin{array}{l}2.332\left(10^{-5}\right) \\
1.787\left(10^{-4}\right) \\
1.181\left(10^{-3}\right) \\
2.548\left(10^{-5}\right) \\
1.710\left(10^{-4}\right) \\
3.019\left(10^{-3}\right) \\
6.503\left(10^{-5}\right) \\
4.078\left(10^{-3}\right) \\
1.426\left(10^{-6}\right)\end{array}$ \\
\hline $\begin{array}{l}752 \\
745 \\
744\end{array}$ & $\begin{array}{l}-1.628\left(10^{-1}\right) \\
-1.171\left(10^{-1}\right) \\
-1.198\left(10^{-1}\right)\end{array}$ & $\begin{array}{r}-6.263\left(10^{-4}\right) \\
3.608\left(10^{-4}\right) \\
3.692\left(10^{-4}\right)\end{array}$ \\
\hline $\begin{array}{l}636 \\
627 \\
631\end{array}$ & $\begin{array}{l}-1.105\left(10^{-3}\right) \\
-1.765\left(10^{-3}\right) \\
-1.721\left(10^{-3}\right)\end{array}$ & $\begin{array}{r}-3.282\left(10^{-8}\right) \\
4.182\left(10^{-7}\right) \\
4.350\left(10^{-7}\right)\end{array}$ \\
\hline $\begin{array}{l}676 \\
650 \\
715\end{array}$ & $\begin{array}{l}-5.572\left(10^{-3}\right) \\
-2.884\left(10^{-3}\right) \\
-3.045\left(10^{-2}\right)\end{array}$ & $\begin{array}{l}6.79\left(10^{-8}\right) \\
5.823\left(10^{-7}\right) \\
4.104\left(10^{-5}\right)\end{array}$ \\
\hline
\end{tabular}


TABLE 8.II

KINETIC THERMOGRAVIMETRY DATA FOR $\mathrm{NaNO}_{2}$ IN VACUUM

\begin{tabular}{lcc}
\hline $\begin{array}{c}T \\
(\mathrm{~K})\end{array}$ & $\begin{array}{c}\mathrm{b}^{\star} \\
\left(\mathrm{mg} \mathrm{cm} \mathrm{min}^{-1}\right.\end{array}$ & $\begin{array}{c}\mathrm{c}^{\star} \\
\left(\mathrm{mg} \mathrm{cm}-2 \mathrm{~min}^{-2}\right)\end{array}$ \\
\hline \hline 745 & $-7.118\left(10^{-1}\right)$ & $1.279\left(10^{-2}\right)$ \\
743 & $-4.307\left(10^{-1}\right)$ & $2.998\left(10^{-3}\right)$ \\
753 & $-4.868\left(10^{-1}\right)$ & $5.397\left(10^{-3}\right)$ \\
627 & $-9.646\left(10^{-3}\right)$ & $1.303\left(10^{-5}\right)$ \\
623 & $-6.818\left(10^{-3}\right)$ & $3.103\left(10^{-6}\right)$ \\
627 & $-7.329\left(10^{-3}\right)$ & $5.662\left(10^{-6}\right)$ \\
671 & $-2.994\left(10^{-2}\right)$ & $3.331\left(10^{-5}\right)$ \\
717 & $-1.024\left(10^{-1}\right)$ & $3.513\left(10^{-4}\right)$ \\
663 & $-1.327\left(10^{-2}\right)$ & $1.050\left(10^{-5}\right)$ \\
& & \\
*Sample weight/surface area $=$ a + bt + ct2 & \\
surface area $=1.489 \mathrm{~cm}^{2}$ for every experiment. \\
\hline
\end{tabular}

TABLE 8.III

KINETIC THERMOGRAVIMETRY DATA FOR $\mathrm{KNO}_{3}$ IN VACUUM

\begin{tabular}{ccc}
\hline $\begin{array}{c}T \\
(\mathrm{~K})\end{array}$ & $\begin{array}{c}b^{*} \\
\left(\mathrm{mg} \mathrm{cm}-2 \mathrm{~min}^{-1}\right.\end{array}$ & $\begin{array}{c}\mathrm{c}^{*} \\
\left(\mathrm{mg} \mathrm{cm}-2 \mathrm{~min}^{-2}\right)\end{array}$ \\
\hline \hline 747 & $-1.938\left(10^{-1}\right)$ & $9.845\left(10^{-4}\right)$ \\
743 & $-1.924\left(10^{-1}\right)$ & $9.438\left(10^{-4}\right)$ \\
737 & $-1.908\left(10^{-1}\right)$ & $1.006\left(10^{-3}\right)$ \\
717 & $-3.994\left(10^{-2}\right)$ & $7.699\left(10^{-5}\right)$ \\
671 & $-9.742\left(10^{-3}\right)$ & $2.236\left(10^{-6}\right)$ \\
741 & $\left.-2.381710^{-1}\right)$ & $1.349\left(10^{-3}\right)$ \\
650 & $-4.981\left(10^{-3}\right)$ & $2.074\left(10^{-6}\right)$ \\
624 & $-1.950\left(10^{-3}\right)$ & $8.724\left(10^{-7}\right)$ \\
623 & $-1.863\left(10^{-3}\right)$ & $9.152\left(10^{-7}\right)$ \\
621 & $-2.455\left(10^{-3}\right)$ & $2.231\left(10^{-6}\right)$
\end{tabular}

*Rate of sample weight change per unit surface area: rate $=b+c t$. 


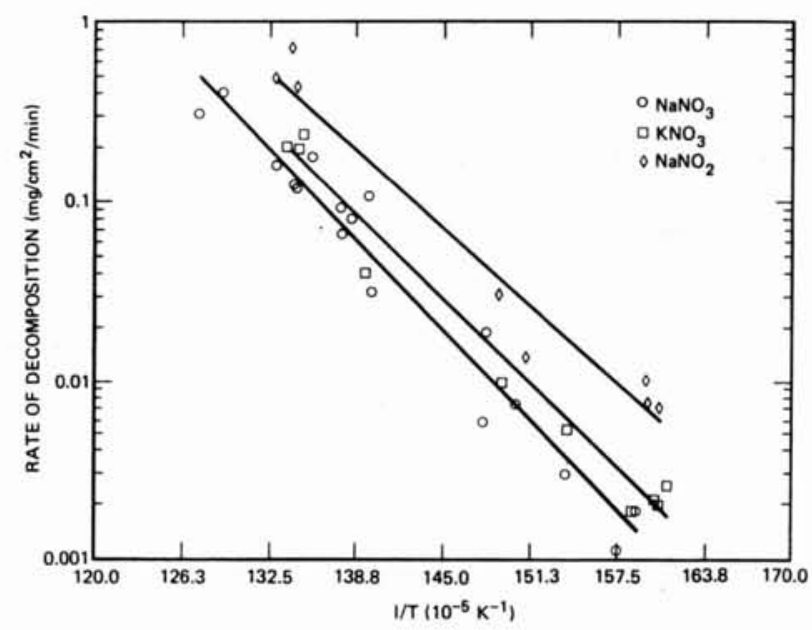

Figure 8.2. Rates of Weight Loss vs Inverse Temperature of $\mathrm{NaNO}_{3}$, $\mathrm{KNO}_{3}$, and $\mathrm{NaNO}_{2}$ in a Vacuum

\subsection{Results and Discussion}

The nitrate and nitrite samples were completely decomposed and vaporized within 100 minutes at $480^{\circ} \mathrm{C}$. Salt vaporized and condensed in cooler areas outside the furnace. In contrast to previous work by Freeman (Reference 8.7 ) the weight loss profile did not arrest at a weight corresponding to 100 percent oxide formation. These results indicate that decomposition, vaporization of the nitrates and nitrites, and vaporization of the decomposition products occur simultaneously.

The intrinsic gaseous decomposition products from $\mathrm{NaNO}_{2}$ are $\mathrm{N}_{2}$ and $\mathrm{NO}$. The nitrates evolve $\mathrm{N}_{2}$, $\mathrm{NO}$, and $\mathrm{O}_{2}$ as they decompose. Nitrogen dioxide was not observed although it has been reported in the literature (References 8.9, 8.13). It is believed the $\mathrm{NO}_{2}$ that was observed (References $8.7,8.13$ ) was actually oxidized NO. However, the procedure in this work differed from Freeman's because the decomposition was studied in a vacuum. The gases were observed as they evolved with no interaction (such as $\mathrm{NO}+1 / 2 \mathrm{O}_{2} \rightarrow \mathrm{NO}_{2}$ ). Although the absolute amounts of each gas could only be estimated, the fraction of $\mathrm{NO}$ compared to $\mathrm{N}_{2}$ arising from $\mathrm{NaNO}_{2}$ and the nitrates was significant.

\subsection{Conclusion}

The rates of weight loss in a vacuum increased with temperature in this order: $\mathrm{NaNO}_{3}, \mathrm{KNO}_{3}, \mathrm{NaNO}_{2}$. The salts' rates of decomposition differed by less than a factor of 10 at any given temperature. The activation enthalpies of the three salts ranged from $32-36 \mathrm{Kcal} \mathrm{mole}^{-1}$. These activation energies are lower than those reported for either decomposition or vaporization (refer to Table 8.IV). These rates are a combination of several processes. 
TABLE 8.IV

ACTIVATION ENERGIES OF $\mathrm{NaNO}_{3}, \mathrm{KNO}_{3}$ AND $\mathrm{NaNO}_{2}$

\begin{tabular}{lclc}
\hline Salt & Activation Energies & \multicolumn{1}{c}{ Process } & Reference \\
\hline $\mathrm{NaNO}_{3}$ & $44 \mathrm{Kcal} \mathrm{mole}^{-1}$ & Decomposition in Air & 8.7 \\
$\mathrm{NaNO}_{3}$ & 41 & Vaporization & 8.9 \\
$\mathrm{NaNO}_{3}$ & 36 & Decomposition in Vacuum & This Work \\
$\mathrm{KNO}_{3}$ & 65 & Decomposition in Air & 8.8 \\
$\mathrm{KNO}_{3}$ & 42 & Vaporization & 8.10 \\
$\mathrm{KNO}_{3}$ & 35 & Decomposition in Vacuum & This Work \\
$\mathrm{NaNO}_{2}$ & 43 & Decomposition in Air & 8.7 \\
$\mathrm{NaNO}_{2}$ & 32 & Decomposition in Vacuum & This Work \\
\hline
\end{tabular}

\subsection{References}

8.1 L. N. Tallerico, "A Description and Assessment of Large Solar Power Systems Technology," Sandia Laboratories, Livermore, SAND79-8015, 1979.

8.2 L. Radosevich, "Thermal Energy Storage for Advanced Solar Central Receiver Power Systems," Sandia Laboratories, Livermore, SAND78-8821, 1978.

8.3 A. Borucka, "Survey and Selection of Inorganic Salts for Application to Thermal Energy Storage," Borucka Research Co., Livingston, NJ, 1975.

8.4 H. P. Voznick and V. W. Uh1, Chem. Eng. 70, 135 (1963).

8.5 B. W. Watt and D. H. Kerridge, Chem. in Brit. 15, 78 (1979).

8.6 J. Alexander and S. G. Hindin, Ind. Eng. Chem 39, 1044 (1947).

8.7 E. S. Freeman, J. Phys. Chem. 60, 1487 (1956).

8.8 E. S. Freeeman, J. Amer. Chem. Soc. 79, 838 (1957).

8.9 N. V. Bagaratiyan, M. K. Il'in, and 0. T. Nikitin, Mosc. Univ. Chem. Bul1. 32, 10 (1977).

8.10 N. V. Bagaratiyan and 0. T. Nikitin, Mosc. Univ. Chem. Bul1. 32, 8 (1977). 


\title{
9.0 PRESSURE-TEMPERATURE-COMPOSITION RELATIONSHIPS FOR HEATED DRAWSALT SYSTEMS
}

\author{
R. W. Mar and C. M. Kramer
}

\subsection{Introduction}

Nitrate salts have been proposed for use in solar thermal energy systems as a heat transfer fluid and thermal energy storage medium. The salt composition with the greatest industrial use is a ternary mixture of 40 percent $\mathrm{NaNO}_{2}$, 7 percent $\mathrm{NaNO}_{3}$ and 53 percent $\mathrm{KNO}_{3}$ by weight. This mixture is marketed by Coastal Chemical under the trade name HITEC, and by Park Chemical Company under the trade name PARTHERM 290. Studies have shown the ternary composition to be unsuitable for use in large solar power systems. Interest has therefore centered on drawsalt (Reference 9.1), which is nominally an equimolar mixture of $\mathrm{NaNO}_{3}$ and $\mathrm{KNO}_{3}$. For applications calling for the use of copious quantities of salt, a significant cost savings can be realized by using a mixture containing an excess of $\mathrm{NaNO}_{3}$, the less costly component. $\mathrm{A} \mathrm{NaNO}_{3}-r i c h$ mixture containing 60 percent $\mathrm{NaNO}_{3}$ and 40 percent $\mathrm{KNO}_{3}$ by weight is commercially marketed by Park Chemical Company under the trade name PARTHERM 430. This study examined the behavior of the PARTHERM 430 composition. The relationships between pressure, temperature, and composition (nitrite to nitrate ratio) were analyzed under several different conditions pertinent to large solar power systems.

In preliminary design studies (References $9.1,9.2$ ), the salts have been allowed to communicate freely with the atmosphere. However, it is well known that nitrates interact with $\mathrm{H}_{2} \mathrm{O}$ and $\mathrm{CO}_{2}$ to form hydroxides and carbonates. With extended periods of operation significant fluid degradation may result. One alternate design approach is to force the system to "breathe" through a scrubbing system. The use of an inert atmosphere cover gas has also been proposed to inhibit deleterious interactions. In both cases, the system operates as a fixed pressure system. Another solution is to completely seal the salt from the atmosphere. In this case the system operates as a fixedvolume system.

Upon heating, partial decomposition of the nitrate salt is inevitable. Starting with a pure nitrate composition, a mixture of nitrate and nitrite will eventuate. The ultimate salt composition (nitrate-to-nitrite ratio) depends upon the pressure and composition of the cover gas and the temperature. The relationships between pressure, temperature, and salt composition under the two conditions of fixed volume and fixed pressure are examined here. 


\subsection{Background}

The nitrates of sodium, potassium, and their mixtures melt without undergoing significant decomposition (Reference 9.3). Continued heating to higher temperatures causes the nitrate to decompose by a variety of reaction paths (References 9.4-9.8). The principal decomposition reaction is

$$
2 \mathrm{MNO}_{3} \rightarrow 2 \mathrm{MNO}_{2}+\mathrm{O}_{2}
$$

where $\mathrm{M}$ is $\mathrm{Na}, \mathrm{K}$, or a mixture thereof. Buchler and Stauffer (Reference 9.9) showed the principal gaseous decomposition product for $\mathrm{NaNO}_{3}$ to be oxygen. Freeman's studies of $\mathrm{NaNO}_{3}$ and $\mathrm{KNO}_{3}$ also pointed to oxygen as the primary reaction product, with nitrogen appearing at temperatures greater than $700^{\circ} \mathrm{C}$ (References 9.3, 9.4).

Other secondary decomposition reactions have been observed or hypothesized including direct vaporization to form complex nitrate gas species (References 9.9-9.11), and the formation of oxides in the melt with the release of $\mathrm{N}_{2}$ and $\mathrm{NO}_{2}$ (Reference 9.12). These reactions are favored by high temperature $\left(>700^{\circ} \mathrm{C}\right)$ and continual gas product removal, as under evacuated conditions. Neither of these conditions should exist in an operating solar-energy power plant. It has al so been suggested that secondary decomposition reactions are more directly a result of corrosion reactions with containment materials (Reference 9.13). Therefore, it is assumed in this study that secondary decomposition reactions are unimportant and that Reaction (1) is a complete and adequate representation of the chemistry taking place within a sealed container.

It is informative to apply the phase rule to the problem at hand. Upon heating a mass of nitrate salt, a portion of it decomposes to form oxygen and nitrite according to Reaction (1). The nitrite is incorporated into the liquid phase, forming a liquid solution with the remaining nitrate. There are thus two phases present in a sealed system: the gas phase and the liquid solution; and there are also two components: nitrate and nitrite. From the phase rule

$$
F=C-P+2
$$

for $P$ phases, $C$ components, and $F$ degrees of freedom, it is seen that there are two degrees of freedom. Therefore, one cannot define a unique pressure by specifying a temperature alone; a singular pressure is defined only if an additional degree of freedom is defined. This extra degree of freedom was specified in this study by two methods. In one, volume constraints were imposed. In other words, the starting volume fraction of the salt and the container volume were specified. In the second method, we considered the pressure to be fixed along with the temperature, thereby fixing the salt composition. 


\subsection{Sealed Containment Systems}

\subsubsection{Mathematical Analysis}

Initially, one is given a container of volume $\mathrm{V}_{T}$ containing a given amount of salt. The initial conditions are specified by one parameter, $\alpha$, where $\alpha$ is the initial salt volume fraction. Upon heating, the nitrate salt partially decomposes, and the salt reaches a final composition of $\mathrm{X}_{\mathrm{NO}} \mathrm{z}$ and $\mathrm{X}_{\mathrm{NO}_{3}}$, mole fractions of nitrite and nitrate, respectively. The system pressure is at $\mathrm{P}_{2}$.

The basic working relationship for this analysis is

$$
\Delta G_{T}^{0}=-R T \ln \left(\frac{P_{0_{2}^{1 / 2}}^{1 / 2} X_{N_{2}-}}{X_{N_{0}}}\right)
$$

which is derived from a thermodynamic analysis of Reaction (1) assuming ideal solution behavior. The strategy is to modify Eq. (3) so the only variables are the final nitrite concentration, $\mathrm{X}_{\mathrm{NO}_{2}}$, the initial salt volume fraction, $\alpha$, and the temperature, T. From such an expression one can solve for $\mathrm{X}_{\mathrm{N} \mathrm{O}_{2}}$, given $\alpha$ and $T$.

Assuming ideal-gas conditions exist, one can express the oxygen pressure $\mathrm{P}_{2}$ as

$$
P_{0_{2}}=\frac{\mathrm{N}_{0_{2}}{ }^{R T}}{V_{g}}
$$

where $\mathrm{N}_{2}$ is the number of moles of oxygen in the gas phase, and $\mathrm{V}_{\mathrm{g}}$ is the volume of the gas phase. The gas volume is calculated from

$$
V_{g}=V_{T}-V_{S}
$$

where $V_{T}$ is the constant total volume of the system, and $V_{S}$ is the volume of the molten salt. $V_{T}$ can be expressed as a function of parameters defining the initial system:

$$
v_{T}=\frac{\left(\mathrm{N}_{\mathrm{NO}}^{\mathrm{i}}\right)\left(\mathrm{w}_{\mathrm{NO}}{ }_{3}\right)}{\alpha \rho_{\mathrm{S}}}
$$

where $\mathrm{N}_{\mathrm{NO}}^{i}$ is the initial number of moles of nitrate, $\mathrm{W}_{\mathrm{NO}} \overline{3}$ is the molecular weight, and $\rho_{S}$ is the room-temperature density of the salt in solid form. The density of a molten mixture of nitrate-nitrite is commonly expressed in the form 


$$
\rho_{\ell}=a+b T+c X_{N O}
$$

where $\rho_{\ell}$ is the molten salt density expressed in units of $\mathrm{g} / \mathrm{cm}^{3}$ and $a, b$, and $c$ are constants (Reference 9.14). The molten salt volume $V_{S}$ can thus be represented as

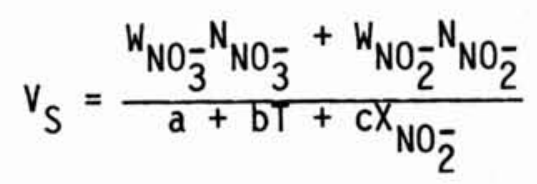

where $\mathrm{W}_{\mathrm{NO}_{3}}$ and $\mathrm{W}_{\mathrm{NO}_{2}}$ are the molecular weights of the nitrate and nitrite mixture, respectively; and $\mathrm{N}_{\mathrm{NO}_{3}}$ and $\mathrm{N}_{\mathrm{NO}}-$ are the moles of nitrate and nitrite. Expressing $\mathrm{N}_{\mathrm{NO}}$ and
requires that
$\mathrm{N}_{\mathrm{NO}_{3}}=\mathrm{N}_{\mathrm{NO}_{3}^{-}}^{i}-\mathrm{N}_{\mathrm{NO}_{2}}$

and

$$
2 \mathrm{~N}_{0_{2}}=\mathrm{N}_{\mathrm{N} O}-
$$

But since

$$
x_{\mathrm{NO}_{2}^{-}}=\frac{\mathrm{N}_{\mathrm{NO}_{2}}}{\mathrm{~N}_{\mathrm{NO}_{3}}+\mathrm{N}_{\mathrm{NO}_{2}}}
$$

it follows that

$$
\mathrm{X}_{\mathrm{NO}_{2}^{-}}=\frac{\mathrm{N}_{\mathrm{NO}-}}{\mathrm{N}_{\mathrm{NO}-\overline{3}}^{i}}
$$

and therefore,

$$
\mathrm{N}_{\mathrm{NO}-}=\mathrm{N}_{\mathrm{NO}_{3}^{-}}^{\mathrm{i}} \mathrm{X}_{\mathrm{NO}}-
$$

Similarly, for $\mathrm{N}_{\mathrm{NO}_{3}}$ one has

$$
\mathrm{N}_{\mathrm{NO}}-\mathrm{N}_{\mathrm{NO}}^{-}\left(1-\mathrm{X}_{\mathrm{NO}}{ }_{2}^{-}\right)
$$

Substituting terms into Eq. (4) and simplifying leads to the following: 


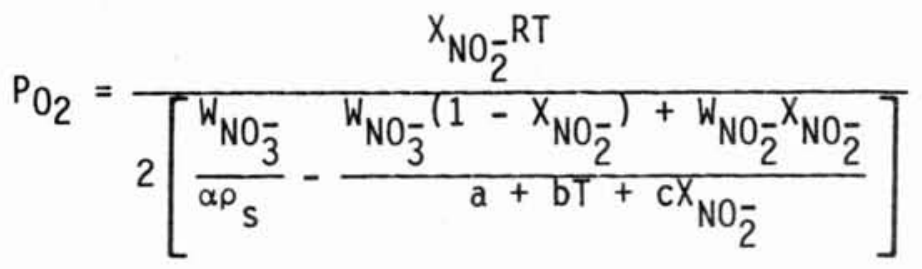

Substitution into Eq. (3) gives

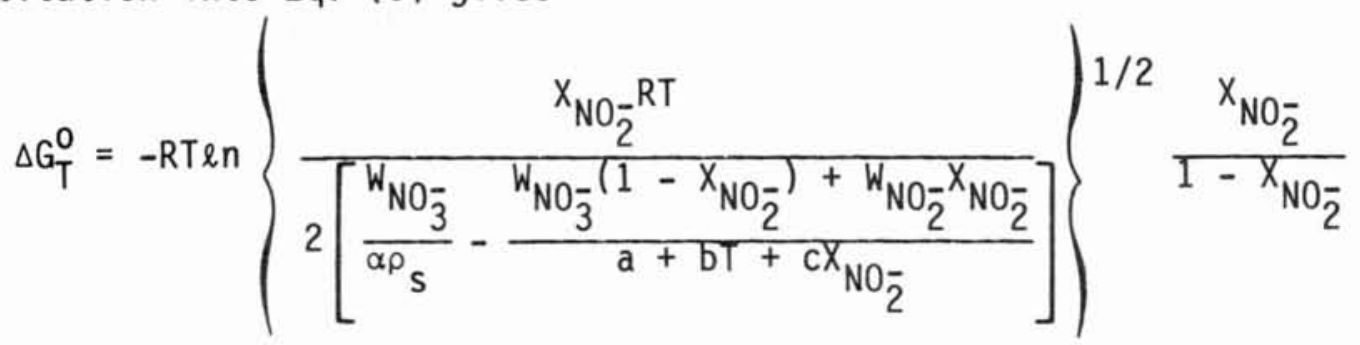

In the ahalysis to follow, values for $T$ and $\alpha$ were selected, the free energy change $\triangle G O$ was calculated from thermochemical data, and Eq. (15) solved numerically for $\mathrm{X}_{\mathrm{NO}}$. Knowing $\mathrm{X}_{\mathrm{NO}}$ z allows one to calculate the oxygen pressure by Eq. (14). In this manner families of pressure-temperature curves have been generated for varying initial salt volume fractions. Compositiontemperature curves have been calculated as well.

\subsubsection{Calculated Relationships}

In order to perform the calculations described above values were needed for the free energy change, for the room-temperature salt density, and for the fluid salt density as a function of temperature and nitrite concentration. The standard-state free energy change for the nitrate decomposition, Reaction (1), where $\mathrm{M}$ is $\mathrm{Na}_{0} .64^{\mathrm{K}} 0.36$, was taken to be

$$
\left.\Delta \mathrm{G}_{\mathrm{T}}^{0} \text { (cal } / \text { mole nitrate }\right)=25.3 \mathrm{~T}(\mathrm{~K})-27540
$$

based upon data reported by Martin Marietta (Reference 9.1). The roomtemperature salt density was taken to be $2.198 \mathrm{~g} / \mathrm{cm}^{3}$, which was estimated by a linear combination of properties for $\mathrm{NaNO}_{3}$ and $\mathrm{KNO}_{3}$. The fluid salt density was similarly estimated from data presented by Krebz et al. (Reference 9.14) for $\mathrm{NaNO}_{3}$ and $\mathrm{KNO}_{3}$ :

$$
\rho_{\ell}\left(\mathrm{g} / \mathrm{cm}^{3}\right)=2.2775-(6.58) 10^{-4} T(K)-(.108) \mathrm{X}_{\mathrm{NO}_{2}}
$$

where $\mathrm{X}_{\mathrm{N} O}{ }_{2}$ is the mole fraction of nitrite present.

The calculated behavior for Partherm 430 is shown in Figures 9.1 and 9.2. Pressure-temperature and composition-temperature curves are given for initial salt volume fractions from 0.1 to 0.7 . The calculations were 1 imited to an upper temperature of $1000 \mathrm{~K}$ because above this temperature the assumption that the nitrate/nitrite reaction is the only important reaction is invalid. The pressures and nitrite concentrations are seen to increase monotonically with temperature. The temperature dependence approximately follows an Arrhenius relation, where the $\log$ of the pressure and log of the nitrite concentration are both proportional to the inverse of temperature. 


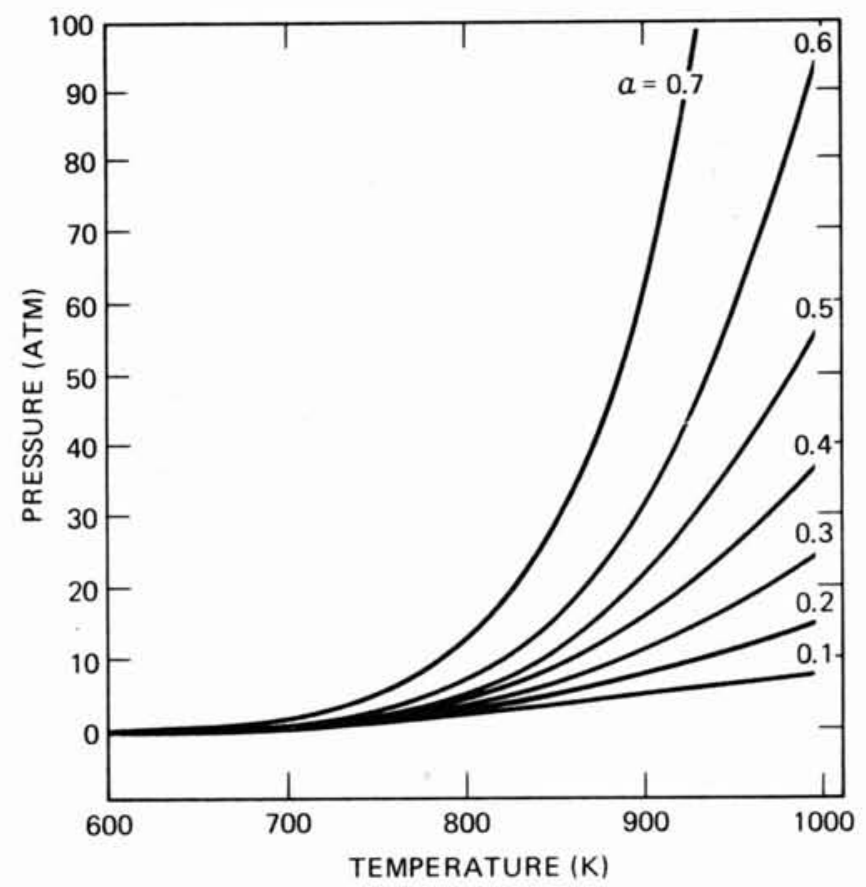

Figure 9.1. Pressure-Temperature Behavior of Partherm 430 for Initial Salt Volume Fractions of 0.1 to 0.7

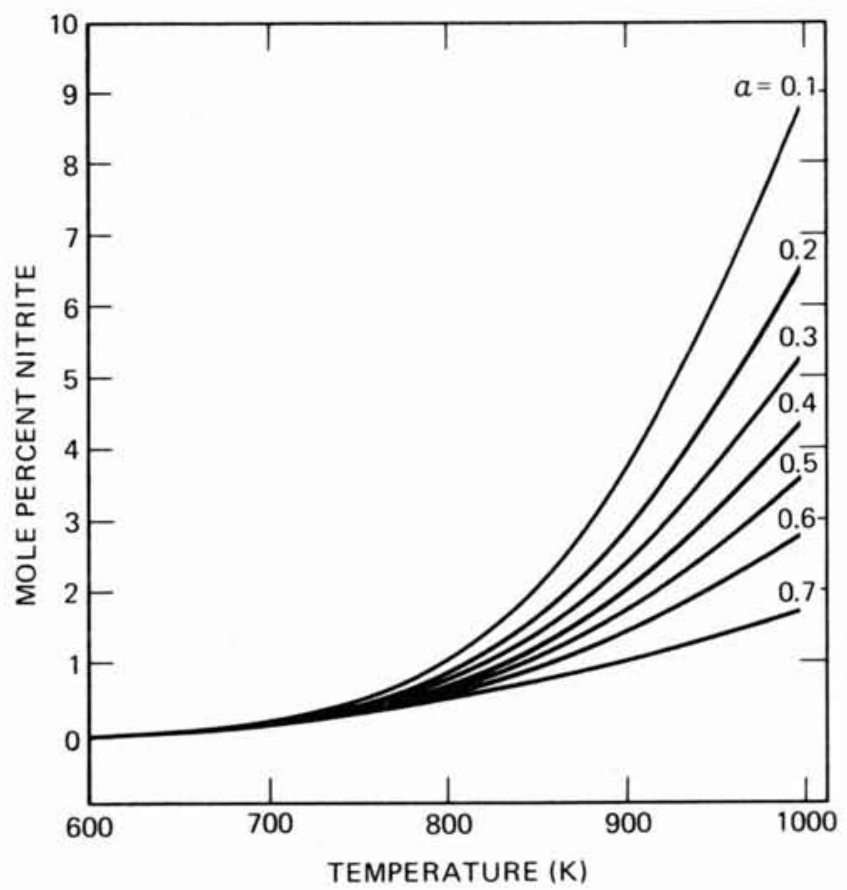

Figure 9.2. Composition-Temperature Behavior of Partherm 430 for Initial Salt Volume Fractions of 0.1 to 0.7 
As the system approaches overflow conditions--that is, when the salt volume approaches that of the container, thereby causing the ullage gas volume to approach zero--deviations from Arrhenius behavior are found. To illustrate these characteristics, Figure 9.3 shows the behavior of a system initially filled to a volume fraction, $\alpha$, of 0.8 . It is seen that the pressure increases monotonically with temperature and that the increase is greater than predicted by an Arrhenius relationship. Overflow conditions are reached at approximately $516^{\circ} \mathrm{C}$. The nitrite level is seen to reach a maximum before attaining overflow. This result is a consequence of two competing processes.

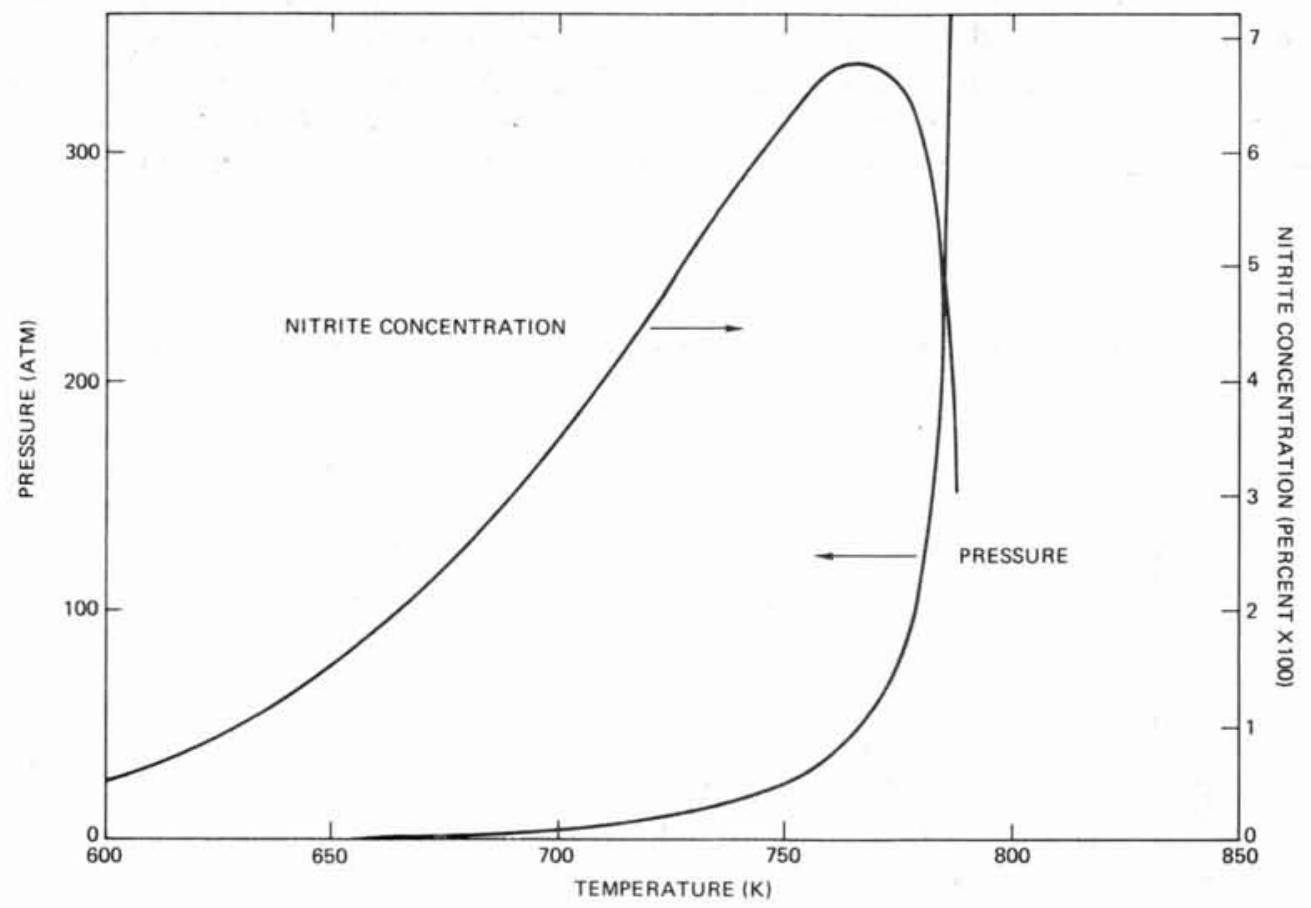

Figure 9.3. Behavior of a System of $\mathrm{NaNO}_{3} / \mathrm{KNO}_{3}$ Initially Filled to a Volume Fraction, $\alpha$, of 0.8

At higher temperatures a greater amount of nitrate decomposes and the nitrite level increases. However, the salt also expands, reducing the gas volume and thereby reducing the amount of oxygen decomposition product that can be accommodated. We note though that under realistic conditions (reasonable initial salt fills) overflow conditions are never reached. Initial salt fill volume fractions $\alpha$ are generally less than 0.5 .

\subsubsection{Experimental Observations}

Two experiments were conducted to verify the validity of the calculations and assumptions described above. Drawsalt of the Partherm 430 composition (60 percent $\mathrm{NaNO}_{3}-40$ percent $\mathrm{KNO}_{3}$ by weight) was prepared from reagent grade 
$\mathrm{NaNO}_{3}$ and $\mathrm{KNO}_{3}$. The salt was placed in closed-end alumina tubes that were sealed by means of compression 0-ring fittings and evacuated. The tube containers were instrumented to measure the pressure continuously. Two experiments were conducted; one with an initial salt volume fraction loading of $\alpha=0.06$, and another with $\alpha=0.17$. The tube containers were placed in a furnace with the compression fitting placed outside of the furnace. The experimental configuration was designed so $\sim 90$ percent of the container volume was held at the salt temperature. Therefore, a direct comparison between the experimental results and the calculations discussed in this study, which assumed the gas and salt temperatures were the same, is valid. The temperature for both experiments was $590^{\circ} \mathrm{C}$.

Of particular interest was the end pressure attained. The results are shown on Figure 9.4 where the two experimental data points appear on a plot of pressure versus initial salt volume. Also shown on Figure 9.4 are several calculated isotherms for comparison. It can be seen that there is excellent agreement between the experimentally measured pressures and those calculated.

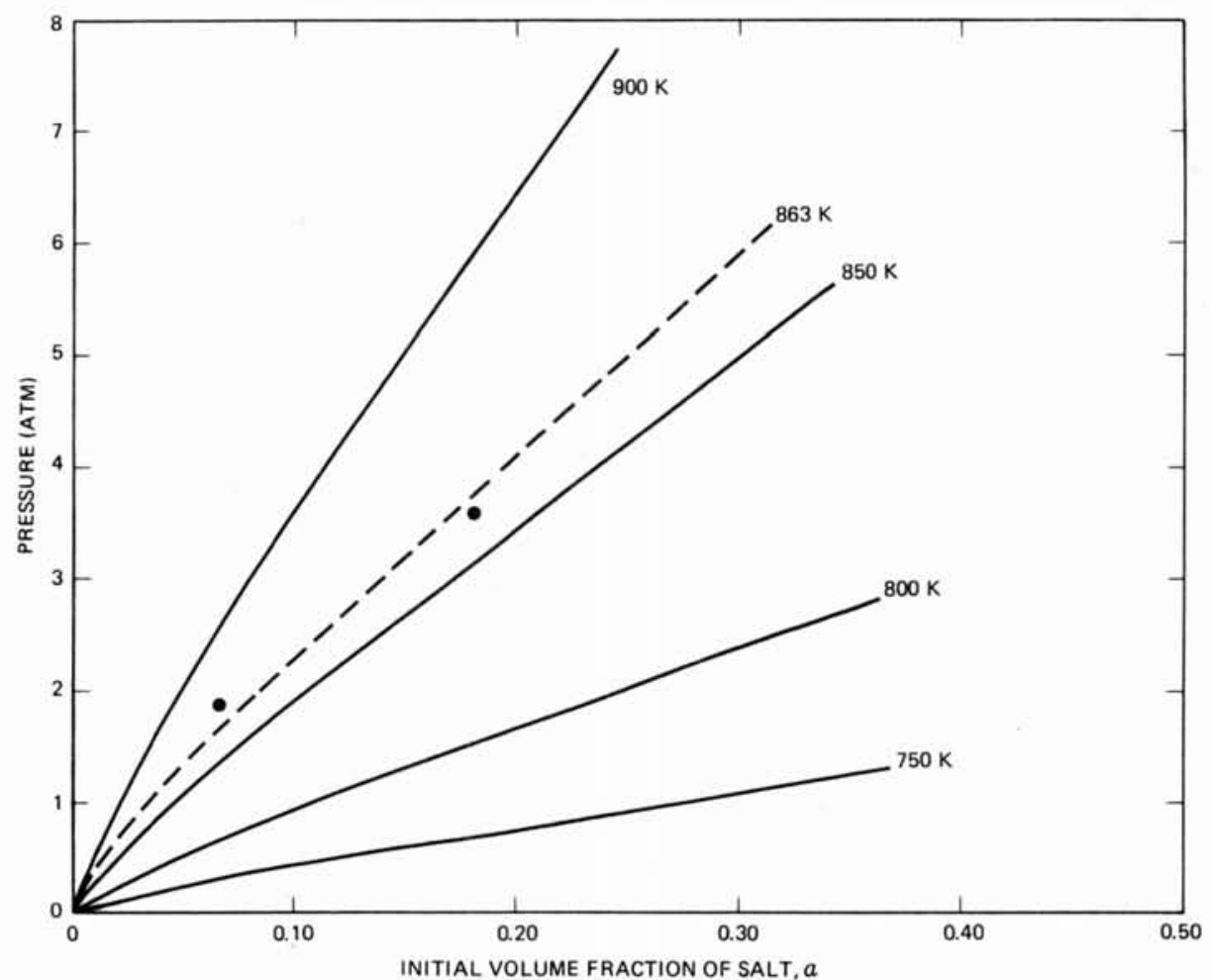

Figure 9.4. Calculated Isotherms for Partherm 430 As a Function of $\mathrm{PO}_{2}$ and Initial Volume Fraction of Salt, $\alpha$. •, experimental results obtained at $863 \mathrm{~K}$. 


\subsection{Open Containment Systems}

In an open system the nitrate salt is exposed to a constant total pressure of one atmosphere, but the oxygen partial pressure, while constant, may vary from system to system. If the oxygen partial pressure and temperature are specified, one can calculate a unique salt composition (nitrite-to-nitrate ratio) using Eqs. (3) and (4). Accordingly, composition-temperature curves have been calculated and plotted in Figure 9.5 for four different oxygen pressures: $1.0,0.2,0.01$, and $0.001 \mathrm{~atm}$. The 0.2 -atm. curve is obviously important because it represents the behavior of a system open to the air. The effect of an inert cover gas is to reduce the oxygen partial pressure; the exact level depends upon design features and operational parameters such as cover gas purity, flow rate, and system tightness. The curves for 0.01 and $0.001 \mathrm{~atm}$. are reasonable representations of open systems with control by inert atmosphere flooding.

Referring to Figure 9.5, it is evident that as temperature increases, the nitrite concentration rises. A temperature change of 100 degrees can cause as much as an order of magnitude change in the nitrite to nitrate ratio. It is al so clear from Figure 9.5 that increasing the partial pressure of oxygen suppresses nitrite formation, in accordance with the Le Chatlier principle applied to Reaction (1). Decreasing the oxygen partial pressure by an order of magnitude causes approximately a factor of two increase in the nitrite-tonitrate ratio.

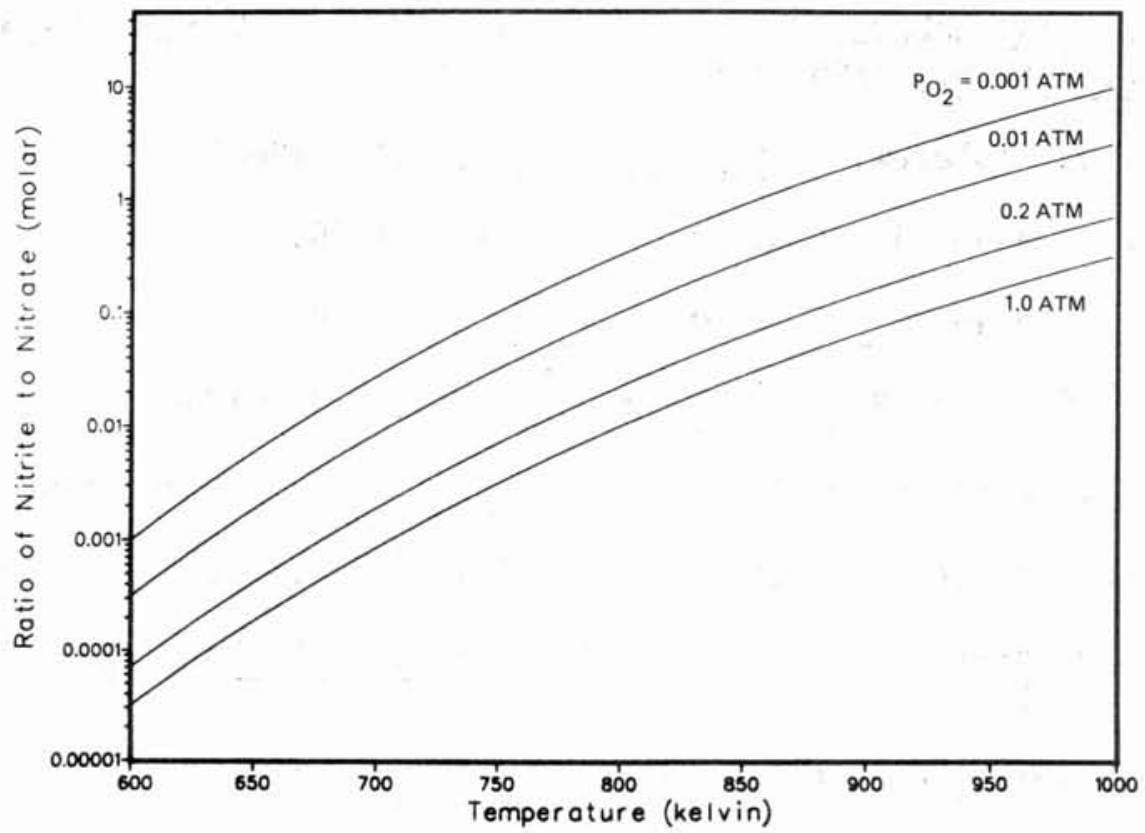

Figure 9.5. Calculated Composition-Temperature Curves for Four Different 0xygen Pressures 


\subsection{Summary}

Pressure-temperature-composition relationships for heated drawsalt of the Partherm 430 composition ( 60 percent $\mathrm{NaNO}_{3}-40$ percent $\mathrm{KNO}_{3}$ by weight) have been calculated for two system designs: a fixed-volume (sealed) system, and a fixed-pressure (breathing or inert cover gas) system. In the analysis the following assumptions were made: (1) the only reaction of importance is nitrate-nitrite-oxygen equilibrium, (2) the liquid solution behaves ideally, and (3) equilibrium conditions are obtained. For the sealed system, pressuretemperature and composition-temperature curves were generated for various initial salt volume fractions ranging from $\alpha=0.1$ to 0.7 ( refer to Figures 9.1 and 9.2). The validity of the assumptions and calculations was verified by comparing the pressures obtained in two experiments (conducted at $590^{\circ} \mathrm{C}$ and with initial salt volume fill fractions of 0.06 and 0.17 ) with calculated values. For open systems, composition-temperature curves ( $r$ efer to Figure 9.5) were generated for various oxygen partial pressures.

\subsection{References}

9.1 T. R. Tracey, "Conceptual Design of Advanced Central Receiver Power System, Phase I," Martin Marietta, final report for DOE contract EG-77-C-03-1724.

9.2 L. N. Tallerico, "A Description and Assessment of Large Solar Power Systems Technology," Sandia Laboratories, Livermore, SAND79-8015, August 1979.

9.3 E. A. Bordyushkova, D. I. Protsenko, and L. N. Venerovskaya, J. Appl . Chem., USSR 40, 1396 (1967).

9.4 R. F. Barthol emew, J. Phys. Chem. 70, 3442 (1966).

9.5 E. S. Freeman, J. Phys. Chem. 60, 1487 (1956).

9.6 E. S. Freeman, J. Am. Chem. Soc. 79, 838 (1957).

9.7 G. D. Sirotkin, Russ. J. Inorg. Chem. $\underline{4}, 1180$ (1959).

9.8 B. D. Bond and P. W. M. Jacob, J. Chem. Soc. A, 1265 (1966).

9.9 A. Buchler and J. L. Stauffer, J. Phys. Chem. 70, 4092 (1966).

9.10 N. V. Bagaratian and 0. T. Nikitin, Vestaik Moskovskogo Univ. Khimiay 32, 388 (1977).

9.11 C. J. Hardy and B. 0. Field, J. Chem. Soc. 11, 1963).

9.12 C. M. Kramer, Sandia National Laboratories, Livermore, private communication. 
9.13 D. A. Nissen, Sandia National Laboratories, Livermore, private communication.

9.14 U. Krebs, H. F. Siegenthaler, and R. P. T. Tomkins, J. Phys. and Chem. Ref. Data 1, 581 (1972). 


\title{
10.0 VISCOSITY, SURFACE TENSION, AND DENSITY OF $(\mathrm{K}, \mathrm{Na}) \mathrm{NO}_{3} \mathrm{FROM} 300 \mathrm{TO} 600^{\circ} \mathrm{C}$
}

\author{
D. A. Nissen
}

\subsection{Introduction}

The equimolar molten salt mixture $\mathrm{NaNO}_{3}-\mathrm{KNO}_{3}$ is being proposed as a heat-transfer fluid and thermal-energy storage medium for various solar energy applications. In these applications the maximum operating temperature will be in the $500-600^{\circ} \mathrm{C}$ range. Industrial experience and previous experimental investigations on this molten salt mixture have generally been confined to temperatures below $450^{\circ} \mathrm{C}$. In order to provide data to solve various specific design problems associated with the use of these molten nitrate salts as heat transfer fluids, it is important that we know how the physical properties of these salts are affected by temperature and composition of the liquid and gas phases. It is the purpose of this report to present and comment on the viscosity, surface tension, and density data that have been measured over the $300-600^{\circ} \mathrm{C}$ temperature range.

\subsection{Apparatus and Experimental Technique}

The thermophysical property data for the equimolar $\mathrm{NaNO}_{3}-\mathrm{KNO}_{3}$ mixture were taken by an instrument designed and built by the author at SNLL (Reference 10.10). This instrument is based on the principle of a damped, onedimensional, harmonic oscillator, i.e., the motion of a body suspended from a spring and oscillating in a fluid. A description of the theoretical principles that govern the operation of this instrument, the details of construction, and its operation and response are discussed el sewhere (Reference 10.1). Only an abbreviated description of the various modes of operation of this instrument will be given here.

The heart of the apparatus is a quartz spring oscillator, an electromagnet for remotely starting the spring oscillating, a position transducer for remote readout of the spring extension (linear variable differential transformer-LVDT), and a gold plate suspended in a liquid whose viscosity is being measured (Figure 10.1). It is the viscous drag exerted on this plate by the liquid that causes damping of the oscillatory motion of the quartz spring. 


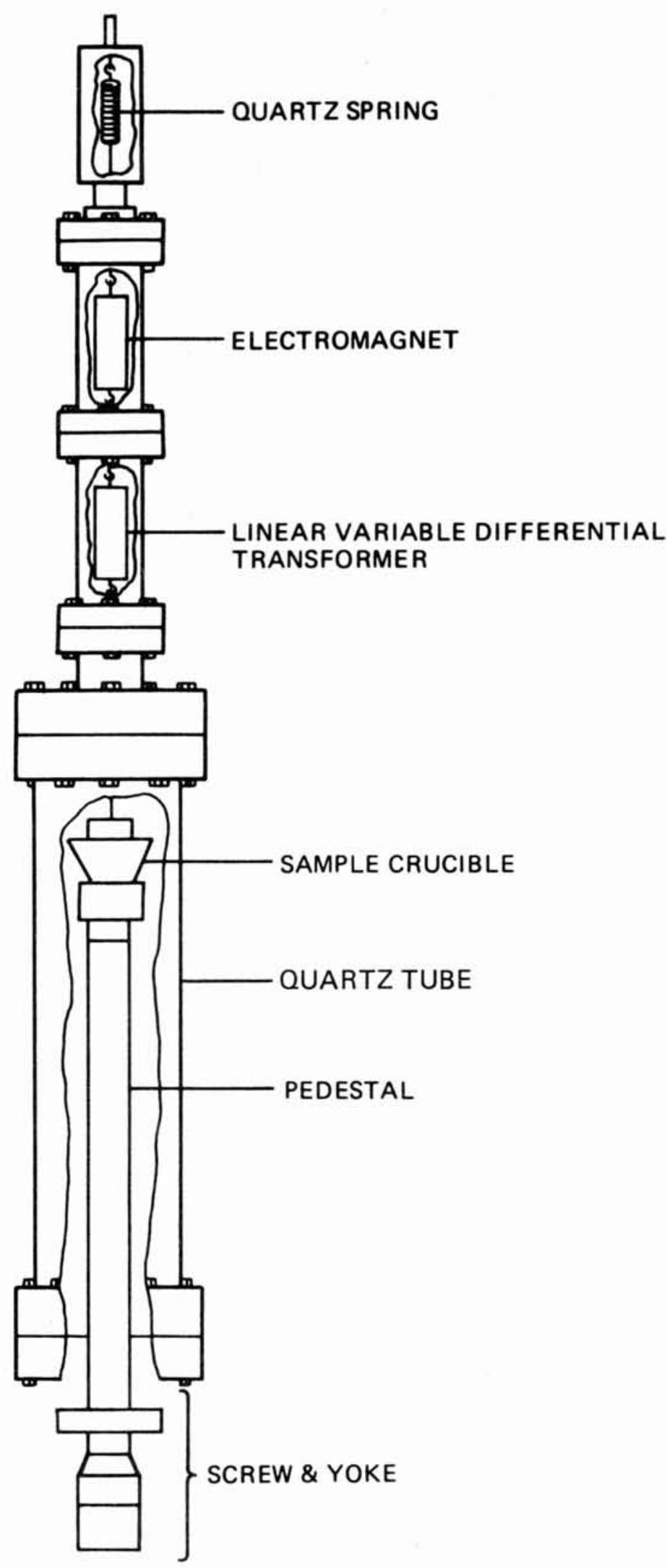

Figure 10.1. Cutaway View of Apparatus to Measure Viscosity, Surface Tension, and Density 
The liquid being studied is contained in a gold crucible mounted on a pedestal fastened to a screw and yoke arrangement.* This is attached to the bottom flange of an intermediate quartz tube. The pedestal and screw are connected by a machined stainless steel rod that passes through a compression fitting designed to maintain the integrity of the atmosphere within the viscometer. This arrangement permits the crucible and its contents to be raised or lowered smoothly and slowly about $4 \mathrm{~cm}$. It is the ability to lower the crucible that is central to the surface tension measurement, as will be clear from later discussion.

A thermocouple sheathed in stainless steel is fed through a fitting in the bottom flange and bent to allow its tip to be immersed in the liquid. In this way the temperature of the liquid can be monitored continuously. A gold sheath on the tip of the thermocouple prevents any reaction between it and the liquid. The bottom flange also has a tube welded into it for admitting gas into the heated zone.

A clam-shell-type furnace, mounted on the supporting structure, is fastened around the quartz tube to heat the contents of the crucible (Figure 10.2). This furnace and its associated controller are capable of maintaining the temperature of the crucible contents to within $+0.5^{\circ} \mathrm{C}$ of the set point. The vertical temperature gradient over the $5 \mathrm{~cm}$ height of the crucible is $<1^{\circ} \mathrm{C}$.

\subsubsection{Viscosity}

It is possible to show (Reference 10.2) that for a damped harmonic oscillator the ratio of any arbitrary zeroth oscillation to the nth successive one is given by

$$
\begin{aligned}
y_{0} / y_{n} & =e^{2 \pi n p} \\
& =e^{n \delta}
\end{aligned}
$$

where $\mathrm{p}$ is a constant. The quantity $\delta$, known as the logarithmic decrement, is given by

$$
\delta=\frac{1}{n} \text { ln } y_{0} / y_{n}
$$

and is therefore a measure of the rate of damping of the oscillations of the spring. Solomons and White (Reference 10.3) have shown that $\delta$ is directly related to the viscosity of the damping medium by the equation

$$
\sqrt{n \rho}=D \delta-E
$$

where $n$ and $\rho$ are the viscosity and density of the liquid being studied. Both $D$ and $E$ are instrument constants:

*For simplicity only the screw is shown in Figure 10.1; however, Figure 10.2 shows the yoke clearly. 


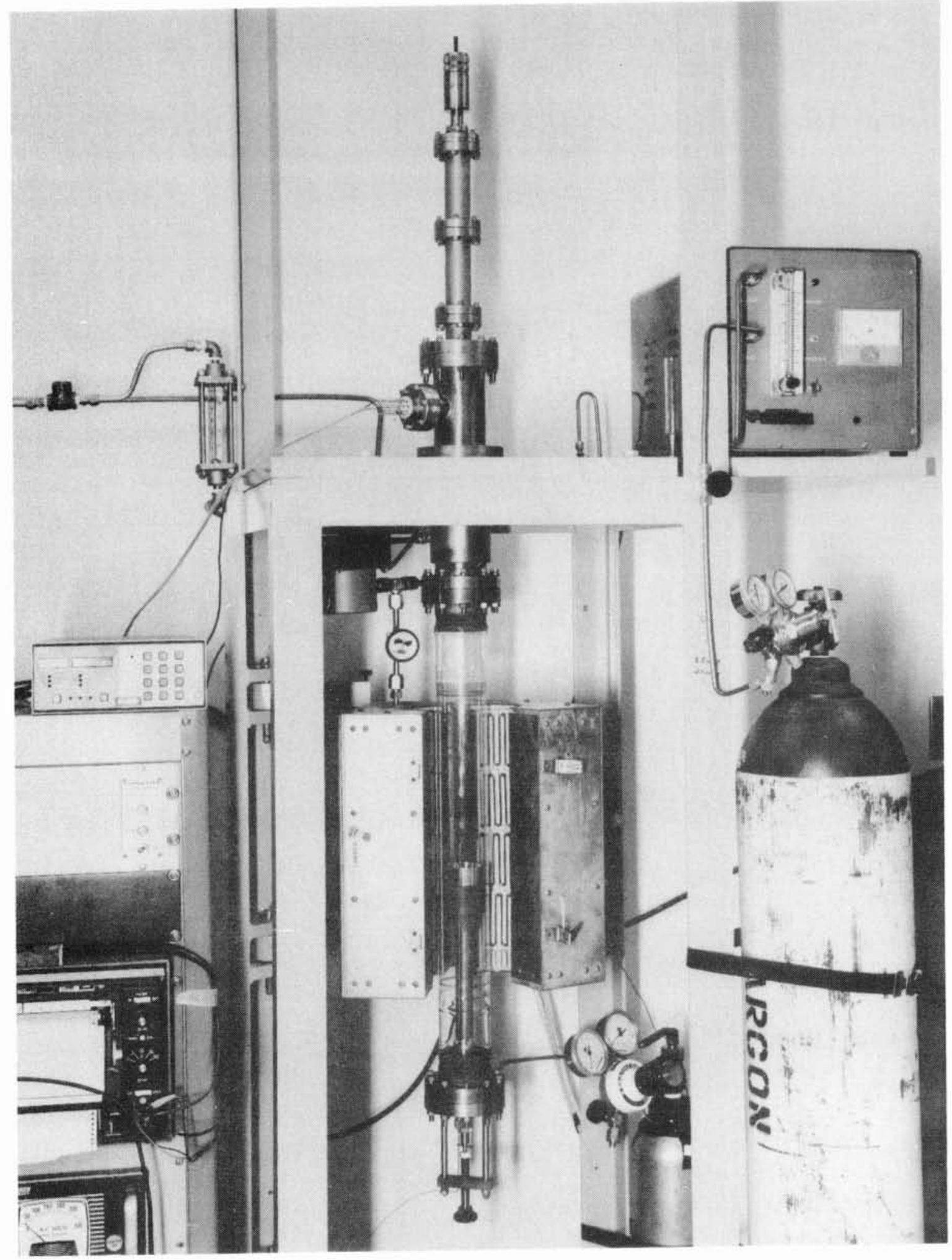

Figure 10.2. Photograph of Apparatus to Measure Viscosity, Surface Tension, and Density 
The constants $\mathrm{D}$ and $\mathrm{E}$ were evaluated by measuring $\delta$ for molten $\mathrm{KNO}_{3}$, whose viscosity and density are well known (Reference 10.4), and for a set of specially prepared organic liquids whose viscosity and density are accurately known. These liquids, supplied by Cannon Instrument Co., have a viscosity range of $1.5-5.0 \mathrm{cP}$.

Figure 10.3 shows the relationship between the quantity $\sqrt{n \rho}$ and the experimentally measured values of the logarithmic decrement for these materials. The equation

$$
\sqrt{n p}=70.00 \delta+0.040
$$

was obtained from a least-squares fit of the data. Each data point in Figure $10-3$ is the average of 10 measurements. The average standard deviation is 0.25 percent.

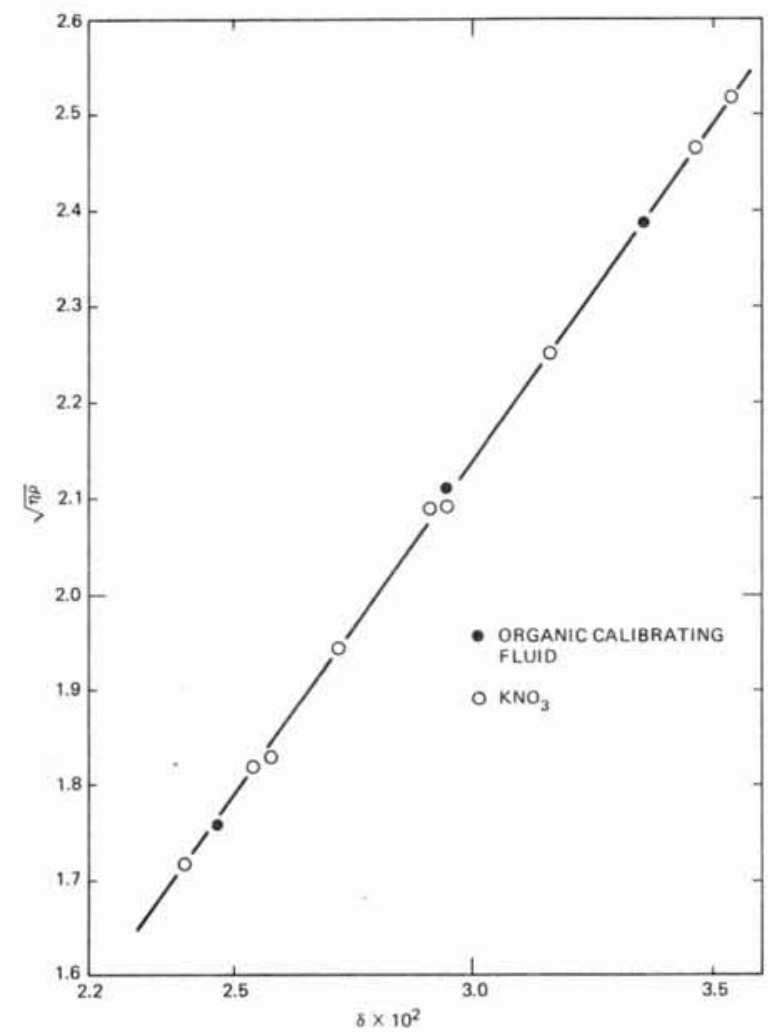

Figure 10.3. Calibration Plot for Viscosity

\subsubsection{Surface Tension}

In addition to functioning as a viscometer, the apparatus can be converted to an instrument for measuring surface tension with a few minor modifications (Reference 10.1). 
By slowly and continuously separating the liquid and the plate immersed in it, and measuring the maximum force exerted on the plate (which occurs just before the column of liquid supported by the plate breaks), the surface tension of the liquid can be determined through the formula

$$
\gamma=\frac{F}{P \cos \theta}
$$

where $\gamma$ is the surface tension, $F$ is the maximum force exerted on the plate (which is detected as an apparent increase in the weight of the plate), $P$ is the perimeter of the plate, and $\theta$ is the wetting angle (generally assumed to be zero if the liquid wets the plate). The gold plate in these experiments was $1.609 \mathrm{~cm}$ wide and $0.0262 \mathrm{~cm}$ thick.

\subsubsection{Density}

The apparatus can also function as an Archimedean densitometer (Reference 10.1). The loss in weight $(\Delta w)$ of a solid of known volume (V) is related to the density of the liquid $(\rho)$ in which it is immersed by

$$
\rho=\frac{\Delta W}{V}
$$

Therefore, the density of a liquid is given simply by the difference in LVDT reading, converted to weight, with and without liquid surrounding the solid, divided by its volume. For increased accuracy of the density measurements the thin plate was replaced by a larger volume bob. The bob presently used is made of gold-plated zirconium and is in the form of a right circular cylinder with a tapered top and bottom to permit drainage. A small post with a hole drilled through it extends from the top taper to provide a means of attaching the bob to the LVDT.

For measurements of density using Archimedes' method it is necessary that the volume of the immersed body be accurately known. This was determined by immersing the bob in several liquids of known density. The volume of the bob was determined to be $1.3518 \pm 0.0005 \mathrm{~cm}^{3}$ (Reference 10.1 ).

\subsection{Results and Discussion}

The thermophysical properties that we determined for the equimolar $\mathrm{NaNO}_{3}-\mathrm{KNO}_{3}$ mixture are presented and discussed in this section. These data cover the $300-600^{\circ} \mathrm{C}$ range and were taken in argon and in oxygen to determine what effect, if any, the composition of the atmosphere might have. It was found that, with the exception of the density, the thermophysical properties are unaffected by atmospheric composition. This statement must be treated with some caution, however, since extended exposure of the melt to an argon atmosphere at $600^{\circ} \mathrm{C}$ will result in the production of increasingly large quantities of nitrite. This is a consequence of the thermal decomposition of nitrate,

$$
\mathrm{NO}_{3}^{-}+\mathrm{NO}_{2}^{-}+(1 / 2) \mathrm{O}_{2}
$$


So that the dependence of the thermophysical properties on nitrite concentration may be more fully characterized, the $\mathrm{MNO}_{3} / \mathrm{MNO}_{2}$ system ( $\mathrm{M}$ being $\mathrm{Na}$ or $\mathrm{K}$ ) is presently being studied in detail.

Where they are available, literature values are compared with the results from this work. The $\mathrm{NaNO}_{3}$ and $\mathrm{KNO}_{3}$ in these experiments were recrystallized from distilled water at least once and vacuum dried at $150^{\circ} \mathrm{C}$ before use.

\subsubsection{Surface Tension}

The surface tension of the equimolar $\mathrm{NaNO}_{3}-\mathrm{KNO}_{3}$ mixture is given in Table 10.I and Figure 10.4. Over the $300-600^{\circ} \mathrm{C}$ range in both argon and oxygen these data can be satisfactorily represented by the equation

$$
\gamma(\text { dynes } / \mathrm{cm})=133.12-6.25 \times 10^{-2} \mathrm{~T}\left({ }^{\circ} \mathrm{C}\right)
$$

with an uncertainty of \pm 0.5 percent.

TABLE $10 . \mathrm{I}$

SURFACE TENSION OF EQUIMOLAR $\mathrm{NaNO}_{3}-\mathrm{KNO}_{3}$

\begin{tabular}{lccc}
\hline $\begin{array}{c}T \\
\left({ }^{\circ} \mathrm{C}\right)\end{array}$ & $\begin{array}{c}\gamma(\text { Expt) } \\
\text { (dynes/cm) }\end{array}$ & $\begin{array}{c}\gamma(\text { Ref. 10.4) } \\
(\text { dynes } / \mathrm{cm})\end{array}$ & $\begin{array}{c}\gamma(\text { Ref. 10.5) } \\
(\text { dynes } / \mathrm{cm})\end{array}$ \\
\hline \hline 257 & 117.1 & 120.0 & 117.9 \\
267 & 116.5 & 119.2 & 117.0 \\
280 & 115.6 & 118.2 & 115.7 \\
307 & 114.4 & 116.3 & - \\
350 & 111.3 & 113.0 & - \\
400 & 108.1 & 109.7 & - \\
450 & 105.0 & - & - \\
500 & 101.7 & - & - \\
547 & 109.0 & - & - \\
594 & 96.0 & - & \\
\hline
\end{tabular}

The excellent agreement between our data and that of Krivovyazov, Table 10.I and Figure 10.4, suggests that the data of Reference 10.4 are incorrect. The agreement between these two sets of data is particularly impressive since Krivovyazov's data were obtained by a different method than ours, maximum bubble pressure vs plate detachment. A more complete discussion of the different methods is given in Reference 10.1.

The close agreement between the surface tension values measured in oxygen and argon (Figure 10.4) implies that the presence of small concentrations of nitrite (< 7 wt\%) has little effect on the surface tension of the nitrites. This result would be expected since the nitrates have a lower surface tension than the corresponding nitrites and thus would tend to concentrate at the surface (Reference 10.5). 


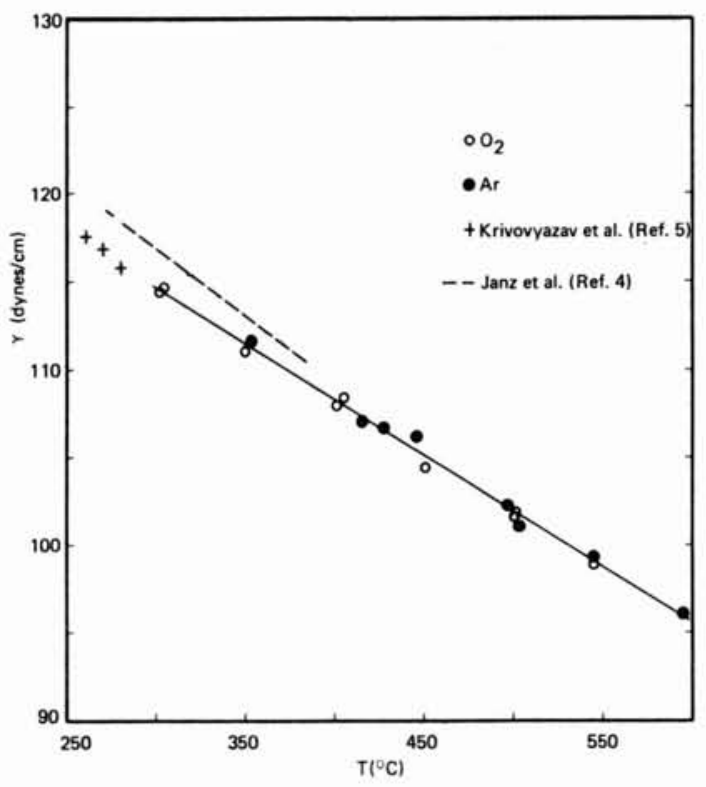

Figure 10.4. Surface Tension of 50:50 Molar Mixture of $\mathrm{NaNO}_{3}$ and $\mathrm{KNO}_{3}$ vs Temperature

\section{3 .2 Density}

The density of the equimolar $\mathrm{NaNO}_{3}-\mathrm{KNO}_{3}$ mixture in argon or oxygen is presented in Table 10.II and Figure 10.5. The first set of data can be represented by the equation

$$
\rho\left(\mathrm{g} / \mathrm{cm}^{3}\right)=2.100-6.56 \times 10^{-4} \mathrm{~T}\left({ }^{\circ} \mathrm{C}\right)
$$

with an uncertainty of \pm 0.5 percent from $300-600^{\circ} \mathrm{C}$. We have found, however, that if the melt is held for 72 hours at $600^{\circ} \mathrm{C}$ in an argon atmosphere there is a decrease in the density. The new values of the density are given by

$$
\rho^{\prime}=2.074-6.36 \times 10^{-4} \mathrm{~T}\left({ }^{\circ} \mathrm{C}\right)
$$

This decrease in density is attributed to the presence of $\approx 7$ wt\% nitrite in the melt which results from the thermal decomposition of nitrate, Eq. (6).

\subsubsection{Viscosity}

The viscosity of the equimolar $\mathrm{NaNO}_{3}-\mathrm{KNO}_{3}$ mixture between 300 and $600^{\circ} \mathrm{C}$, in argon and oxygen, is shown in Figure 10.6. The results can be represented by the equation

$$
\eta(C P)=22.714-.120 \mathrm{~T}+2.281 \times 10^{-4} \mathrm{~T}^{2}-1.474 \times 10^{-7} \mathrm{~T}^{3}\left({ }^{\circ} \mathrm{C}\right)
$$

For comparison, values of the viscosity from Reference 10.4 are included. To facilitate comparison the solid line in Figure 10.6 is drawn through the literature data. It can be seen that agreement between the two sets of values is quite good. 
TABLE 10.II

DENSITY OF EQUIMOLAR $\mathrm{NaNO}_{3}-\mathrm{KNO}_{3}$

\begin{tabular}{lcc}
\hline$T\left({ }^{\circ} \mathrm{C}\right)$ & $\rho($ Expt $)\left(\mathrm{g} / \mathrm{cm}^{3}\right)$ & $\rho($ Ref. $10-4)\left(\mathrm{g} / \mathrm{cm}^{3}\right)$ \\
\hline \hline 298 & 1.905 & $1.900^{\star}$ \\
347 & 1.873 & 1.872 \\
400 & 1.836 & 1.835 \\
442 & 1.810 & 1.805 \\
498 & 1.774 & - \\
555 & 1.735 & - \\
595 & 1.709 & - \\
& ---72 hours at $600^{\circ} \mathrm{C}$ in argon --- \\
607 & 1.686 & - \\
506 & 1.757 & 1.831 \\
406 & 1.813 & $1.900^{\star}$ \\
298 & 1.877 & \\
& & \\
\hline \multirow{2}{*}{ *Extrapolated. } & \\
\hline
\end{tabular}

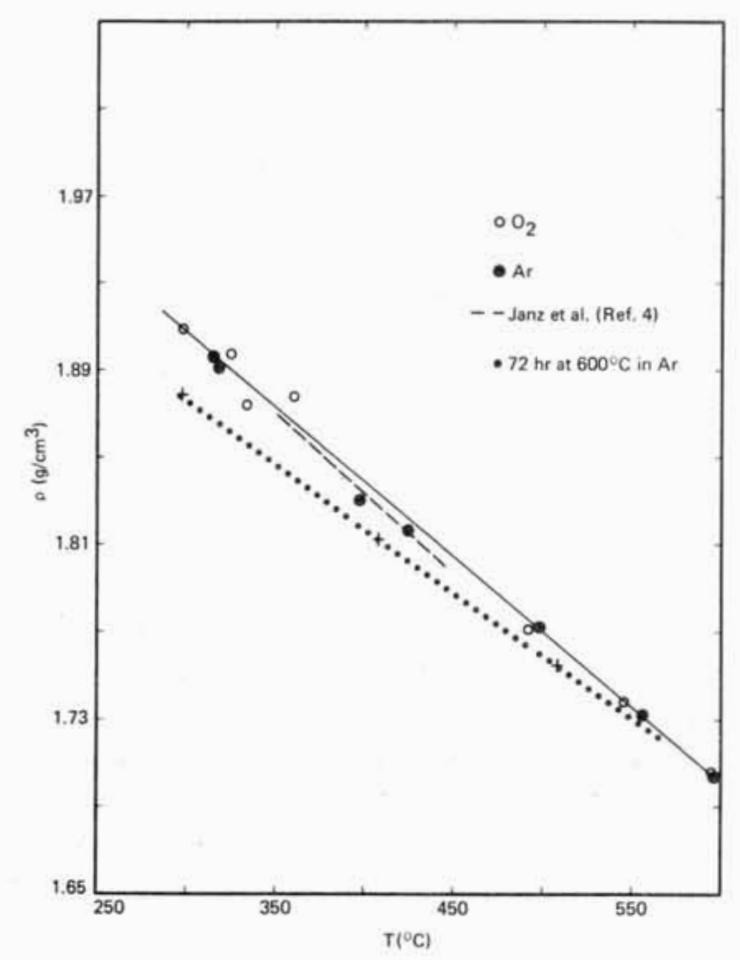

Figure 10.5. Density of 50:50 Molar Mixture of $\mathrm{NaNO}_{3}$ and $\mathrm{KNO}_{3}$ vs Temperature 


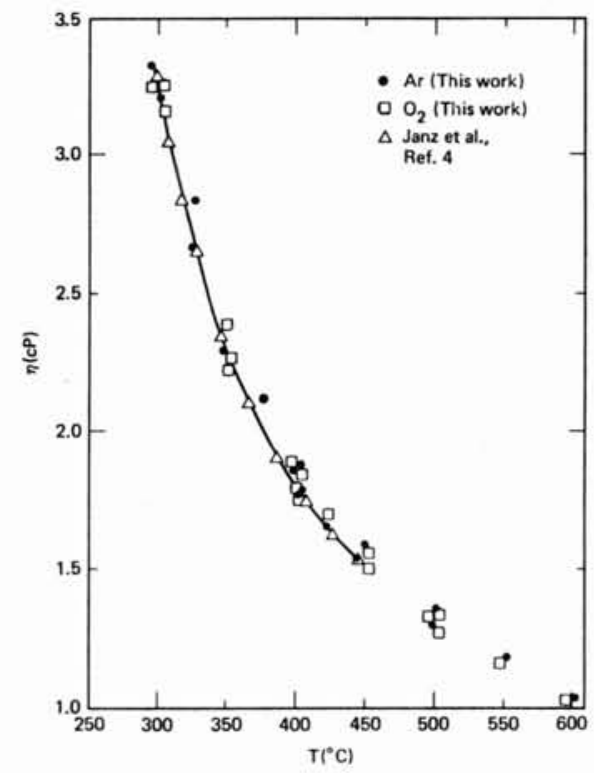

Figure 10.6. Viscosity of 50:50 Molar Mixture of $\mathrm{NaNO}_{3}$ and $\mathrm{KNO}_{3}$ vs Temperature

If we make the assumption that for ideal or near-ideal solutions the temperature dependence of the viscosity may be written in the form (Reference 10.7).

$$
n=n_{0} \exp \left(-E_{n} / R T\right)
$$

where $E_{n}$ is the activation energy for viscous flow and $R$ and $T$ have their usual meanings, $\ell n n$ then should depend linearly on the reciprocal of the absolute temperature. In Figure 10.7 our viscosity data and the recommended literature values are plotted as en $n$ against $1 / T$. Rather than a single straight line the data are seen to fall on a smooth curve that is asymptotic to a straight line at both the low and high temperature limits. The change in slope appears to be in the vicinity of $385^{\circ} \mathrm{C}$. Above this temperature $E_{\eta}$, calculated from the limiting slope, is $3.2 \mathrm{kcal} / \mathrm{mole}$ while below it $E_{\eta}=4.6 \mathrm{kcal} / \mathrm{mole}$.

It is possible that the change in slope of this curve at $385^{\circ} \mathrm{C}$ is caused by the presence of nitrite in the melt arising from the thermal decomposition of nitrate, Eq. (6). However, if this were the case one would expect to see different values of the viscosity in oxygen and argon; this was not observed. A pronounced curvature of that part of the plot above $385^{\circ} \mathrm{C}$ would also be expected as a consequence of the increased production of nitrite at the higher temperatures; this was also not observed. Therefore, the presence of small amounts of nitrite appears to have negligible effect on the viscosity of nitrate melts. 


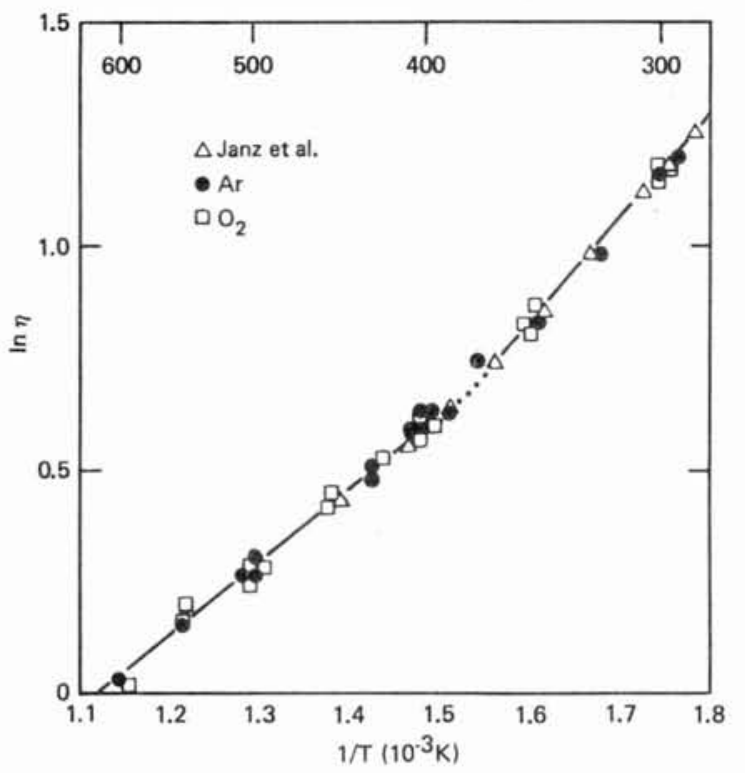

Figure 10.7. The en $n$ of 50:50 Molar Mixture of $\mathrm{NaNO}_{3}$ and $\mathrm{KNO}_{3}$ vs Temperature

In general, for low viscosity liquids the temperature dependence of the viscosity is best given by Eq. (11) (References $10.8,10.9$ ). For a number of liquids, however, behavior similar to that shown in Figure 10.7 has been observed (Reference 10.8). Two examples of this are illustrated in Figure 10.8 where values of $\ell n n$ vs $1 / T$ are plotted for methylene iodide $\left(\mathrm{CH}_{2} \mathrm{I}_{2}\right)$ and water $\left(\mathrm{H}_{2} \mathrm{O}\right)$ (References $10.10,10.11$ ). Spectroscopic evidence suggests that rotation of the $\mathrm{CH}_{2} \mathrm{I}_{2}$ molecules is restricted because of steric hindrance (Reference 10.12). Hydrogen bonding plays a similar role in $\mathrm{H}_{2} \mathrm{O}$. The conclusion these data suggest is that in those instances where molecular rotation is restricted because of either steric hindrance or strong intermolecular attraction (e.g., hydrogen bonding) the temperature dependence of the viscosity cannot be adequately described by a single value of $E_{n}$. This conclusion has been supported by molecular volume calculations (Reference 10.8) that show where the molecules are free to rotate about at least two axes, Eq. (11) is obeyed over the entire liquid range. However, the onset of non-Arrhenius viscosity behavior occurs at that temperature where rotation about two axes becomes restricted. That is, a molecule whose rotation is restricted is less able to translate freely than one whose rotation is free because it is more difficult for the restricted molecule to rotate into a favorable orientation for moving past its neighbors.

A corollary is that spherical molecules should obey Eq. (11). Figure 10.9 shows a plot of $\ell n n$ vs $1 / T$ for the equimolar mixture $\mathrm{NaCl}-\mathrm{KCl}$ (Reference 10.13), that is composed of spherically symmetric ions (Reference 10.14). It can be readily seen that Eq. (11) is obeyed over the entire $170^{\circ} \mathrm{C}$ temperature range for which data are available $\left(727-897^{\circ} \mathrm{C}\right)$. 


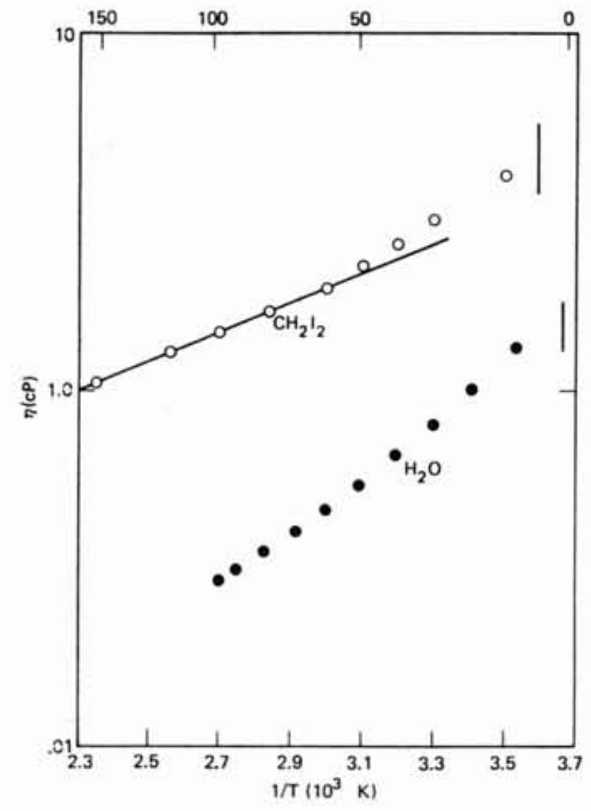

Figure 10.8. The en $n$ of $\mathrm{CH}_{2} \mathrm{I}_{2}$ and $\mathrm{H}_{2} \mathrm{O}$ vs $1 / \mathrm{T}$. The vertical lines designate the melting points of $\mathrm{CH}_{2} \mathrm{I}_{2}$ and $\mathrm{H}_{2} \mathrm{O}$.

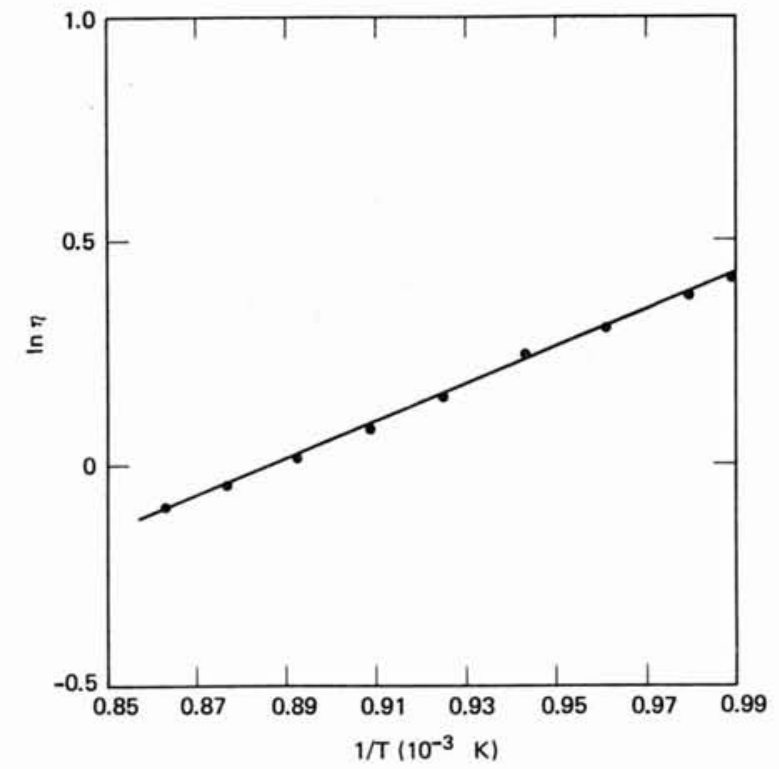

Figure 10.9. The $\mathrm{en} n$ of a Mixture of $\mathrm{NaCl}$ and $\mathrm{KCl}$ vs $1 / \mathrm{T}$ 
In contrast to the spherically symmetric chloride ion, the nitrate ion is a planar species of finite thickness and a star-shaped symmetry (Reference 10.15). It is inferred, therefore, that because of the nonspherical symmetry of the nitrate ion, rotation is restricted at temperatures below $385^{\circ} \mathrm{C}$, with a consequent increase in $E_{\eta}$.

While the change in activation energy for the viscous flow of $\mathrm{NaNO}_{3}-\mathrm{KNO}_{3}$ could be explained by changes in the rotational modes of the nitrate ion with temperature, it could also occur from loosening of the melt structure or a change in the molecular packing.

The discontinuity in viscosity observed in the nitrate melt should correspond to a thermodynamic transition of the second or third order (Reference 10.8), i.e., $\mathrm{dC}_{\mathrm{p}} / \mathrm{dT}=0$ in the former case, and $\mathrm{d}^{2} \mathrm{C}_{\mathrm{p}} / \mathrm{dT}^{2}\langle 0$ or $>0$ in the latter. Experiments are now being done to confirm this discontinuity (Reference 10.16).

\subsection{Summary}

We have determined the viscosity, surface tension, and density for the equimolar mixture $\mathrm{NaNO}_{3}-\mathrm{KNO}_{3}$ in both argon and oxygen. Both the surface tension and viscosity of this salt mixture are unaffected by small concentrations of nitrite ( $7 \mathrm{wt} \%)$ formed by thermal decomposition of nitrate in an argon atmosphere, while the density was lowered slightly. The viscosity showed a change in activation energy at $385^{\circ} \mathrm{C}$ that has been attributed to a freeing of one of the rotational modes of the nitrate ion as the temperature increased above this value.

\subsection{References}

10.1 D. A. Nissen, "A Single Apparatus for the Precise Measurement of the Physical Properties of Liquid at Elevated Temperature and Pressure," Sandia National Laboratories, Livermore, SAND80-8034, October 1980.

10.2 C. R. Wylie, Advanced Engineering Math (McGraw-Hill Book Co., New York, 1960), p. 205.

10.3 C. Solomons and M. S. White, Trans. Faraday Soc. 65, 305 (1969).

10.4. G. J. Janz, U. Krebs, H. E. Siegenthaler, and R. P. T. Tomkins, J. Phys. Chem. Ref. Data 1, 587 (1972).

10.5 E. L. Krivovyazov, I. D. Sokolova, and H. K. Voskresenskaya, Russ. J. Appl. Chem. 36, 2458 (1963).

10.6 H. Bloom, F. G. Davis and D. W. James, Trans. Faraday Soc. 56, 117a (1960). 
10.7 W. Brockner, K. Tørklep, and H. A. Øye, Ber. Bunsenges. Phys. Chem. 83,12 (1979).

10.8 D. B. Davies and J. Matheson, J. Chem. Phys. 45, 1000 (1966).

10.9 D. Dumas, B. Fjeld, K. Grotheim, and H. A. Øye, Acta. Chem. Scand. 27, 31a (1973).

$10.10 \mathrm{~J}$. Timmermans, Physico-Chemical Constants of Pure Organic Compounds (Elsevier, New York, 1950).

10.11 Handbook of Chemistry \& Physics, 26th edition, edited by C. D. Hodgman, (Chemical Rubber Co., Cleveland, Ohio, 1942), p. 1638.

10.12 W. J. Jones and H. Sheppard, "Report Conf. Hydrocarbon Research Group," Inst. of Petroleum, London, p. 181, 1962.

10.13 G. J. Janz, R. P. T. Tomkins, C. B. Allen, J. R. Downey, G. L. Gardner, U. Krebs, and S. K. Singer, J. Phys. Chem. Ref. Data 4 , 871 (1975).

10.14 A. Timedei and G. J. Janz, Trans. Faraday Soc. 64, 202 (1968).

10.15 G. J. Janz and D. W. James, J. Chem. Phys. 35, 739 (1961).

10.16 R. W. Carling, Sandia National Laboratories, Livermore, private communication. 


\subsection{HEAT CAPACITIES OF $\mathrm{NaNO}_{3}, \mathrm{KNO}_{3}$, AND $(\mathrm{Na}, \mathrm{K}) \mathrm{NO}_{3}$}

R. W. Carling

\subsection{Introduction}

Some current designs of solar central receivers employ molten nitrate salts as the heat transfer and storage medium. The salt of most interest is a $50 / 50$ molar mixture of $\mathrm{NaNO}_{3}$ and $\mathrm{KNO}_{3}$, often referred to as drawsalt. Work has focused on this salt mixture because it has good physical and chemical properties relative to other salt mixtures over the temperature range of a central receiver $\left(350\right.$ to $\left.600^{\circ} \mathrm{C}\right)$. Some of these properties are low cost, chemically stable, non-corrosive, low melting point, and high heat capacity. Although many of the physical and chemical properties of $\mathrm{NaNO}_{3} / \mathrm{KNO}_{3}$ are known at low temperatures, there are relatively little data available in the temperature range of interest. The property of interest in this paper is the heat capacity. The heat capacity is an important parameter for the designers and engineers of the heat transfer and storage systems. Data are available up to $500^{\circ} \mathrm{C}$, but not beyond (Reference 11.1 ). While it is often assumed that the heat capacity of a molten salt does not change with temperature, the heat capacity of molten $\mathrm{NaNO}_{3} / \mathrm{KNO}_{3}$ decreases by about 10 percent from 240 to $500^{\circ} \mathrm{C}$ (Reference 11.1 ). The main thrust of this work was to extend the heat capacity to $600^{\circ} \mathrm{C}$.

The heat capacities of $\mathrm{NaNO}_{3}$ and $\mathrm{KNO}_{3}$ were also measured in this study. The reasons for this work were twofold. First, since the heat capacities of $\mathrm{NaNO}_{3}$ and $\mathrm{KNO}_{3}$ have been measured previously (References 11.1-11.12), the previous work would provide a means for measuring the accuracy of the work reported here. Secondly, the validity of the additive rule was determined. One can calculate a heat capacity by adding the heat capacities of $\mathrm{NaNO}_{3}$ and $\mathrm{KNO}_{3}$

in the appropriate proportions of the mixture (Reference 11.2). If the experimentally derived heat capacity and that obtained by adding the Cp's of the components agree, then the heat capacity of any mixture of $\mathrm{KNO}_{3}$ and $\mathrm{NaNO}_{3}$ could be determined simply. 


\subsection{Experimental}

Heat capacity measurements were made with a Perkin-Elmer differential scanning calorimeter, DSC-2. All measurements were made with the samples sealed in gold or stainless steel capsules. Sapphire was used as the heat capacity reference material. Heat capacity measurements were made at a heating rate of 10 degrees/min with range settings of 1.25 to $5.00 \mathrm{~J} / \mathrm{min}$. The salts were reagent grade material, recrystallized from water and dried at $150^{\circ} \mathrm{C}$ for at least 48 hours in vacuum. The salts, prepared in this manner, were stored over $\mathrm{CaSO}_{4}$ until use.

Control and operation of the DSC were through a Hewlett Packard 9825 desk-top calculator. Measurements were typically taken over temperature ranges of 100 degrees. The temperature ranges were overlapped and scanned several times. The heat capacity results are, therefore, the average of several measurements at each temperature. Accuracies in the solid regions were estimated to be two percent as compared to previous heat capacity results.

A major problem developed in the liquid region of each salt. The gold sample pans cracked and then leaked salt inside the DSC sample pan holder. The gold pans cracked adjacent to the hermetic seals and it is thought to be due to either residual $\mathrm{H}_{2} \mathrm{O}$ vapor and/or $\mathrm{O}_{2}$ being generated as the salt decomposed to nitrite and oxygen. The stainless steel pans did not work any better. The stainless steel pans were closed without the Viton 0-rings and hence leaked for lack of proper sealing. The 0-rings were omitted because Viton will not take the temperatures over which the measurements were to be made.

\subsection{Results and Discussion}

The heat capacity results for $\mathrm{NaNO}_{3}, \mathrm{KNO}_{3}$, and $(\mathrm{Na}, \mathrm{K}) \mathrm{NO}_{3}$ are illustrated in Figures 11.1 to 11.3 and tabulated in Table 11 .I. The results do not extend to the $600^{\circ} \mathrm{C}$ upper limit as desired. The upper temperature was limited due to salt leakage from the sample pans as described in Section 11.2. The heat capacity results of the solids agree well with previous investigations (References $11.3,11.5-11.7)$. Comparisons of the results are not shown in the figures to avoid confusion. It can also be seen in Table 11.I that the additivity rule for the heat capacities holds for $\mathrm{NaNO}_{3}$ and $\mathrm{KNO}_{3}$

(Reference 11.2).

Temperatures and enthalpies and entropies of transition and fusion of $\mathrm{NaNO}_{3}, \mathrm{KNO}_{3}$, and $(\mathrm{Na}, \mathrm{K}) \mathrm{NO}_{3}$ are presented in Table $11 . \mathrm{II}$. As can be seen the values in this work agree well with previous investigations. These results are presented to further support the accuracy of the technique up to the melting points. However, the accuracy of the heat capacity results obtained above the melting are in doubt. The heat capacity values have considerably more scatter in the liquid region than in the solid region. Although the results from this work tend to agree reasonably well with a few previous 


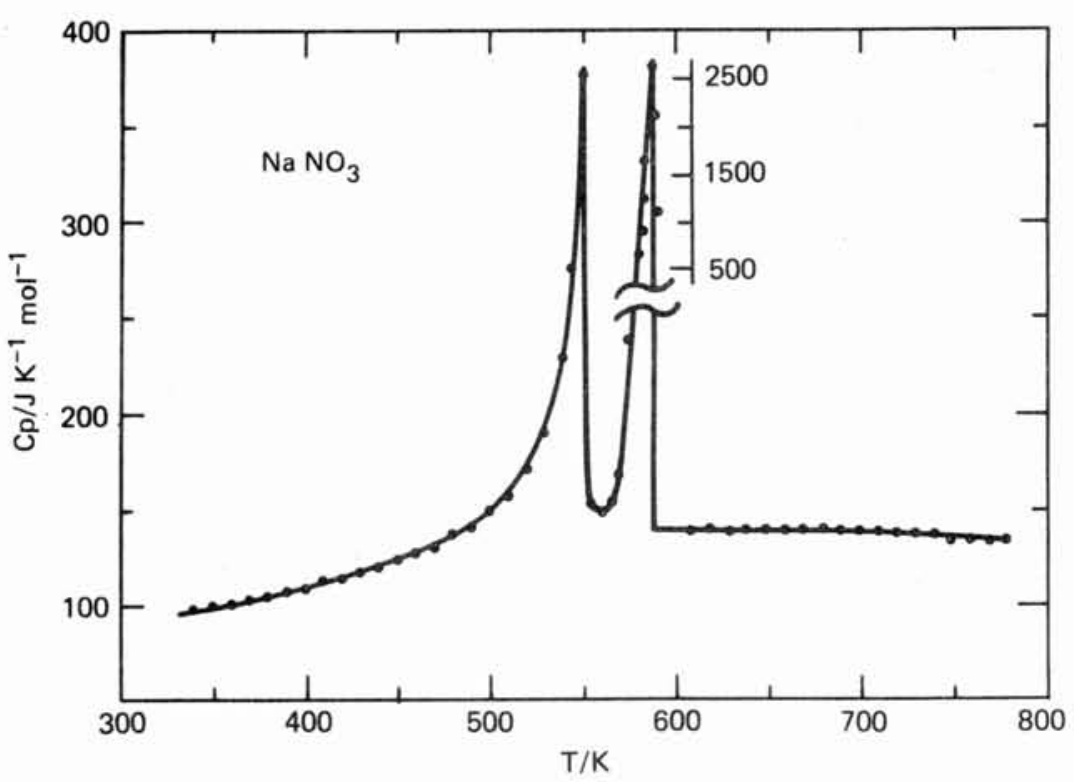

Figure 11.1. Heat Capacity vs Temperature for $\mathrm{NaNO}_{3}$

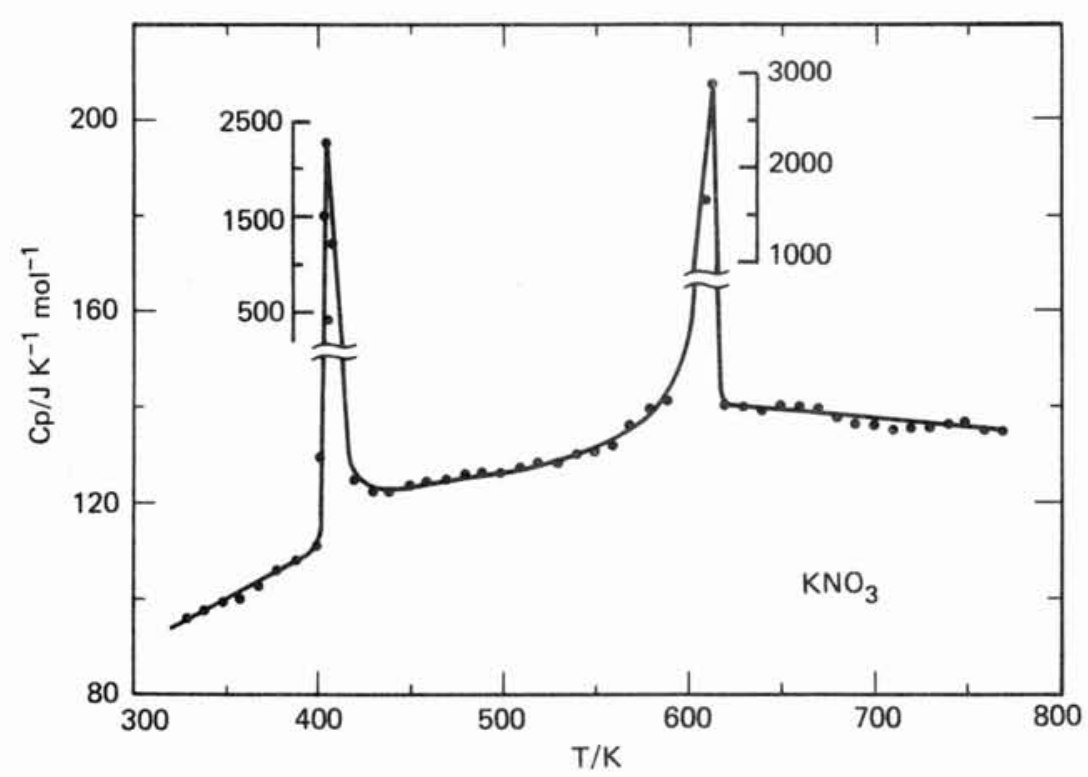

Figure 11.2. Heat Capacity vs Temperature for $\mathrm{KNO}_{3}$ 


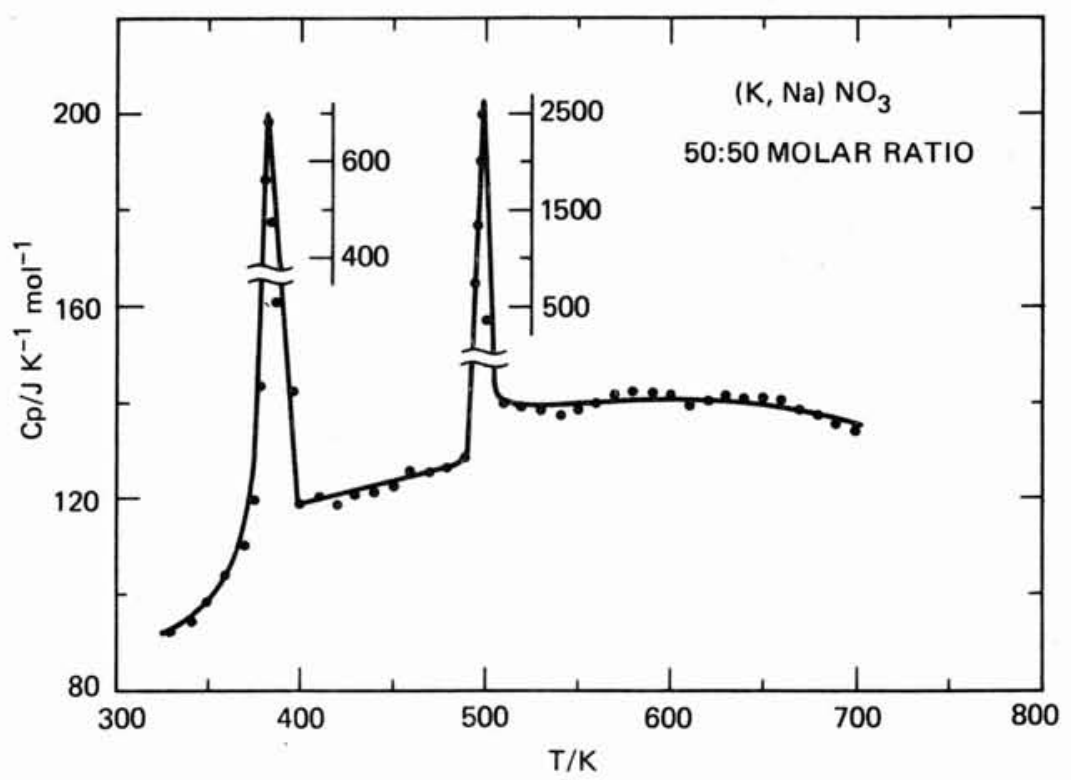

Figure 11.3. Heat Capacity vs Temperature for a 50:50 Molar Mixture of $\mathrm{NaNO}_{3}$ and $\mathrm{KNO}_{3}$

TABLE 11.I

HEAT CAPACITIES OF $\mathrm{NaNO}_{3}, \mathrm{KNO}_{3}$, AND $(\mathrm{Na}, \mathrm{K}) \mathrm{NO}_{3}$

\begin{tabular}{|c|c|c|c|}
\hline \multirow{2}{*}{$\begin{array}{c}\mathrm{T} \\
\left({ }^{\circ} \mathrm{C}\right) \\
\end{array}$} & \multicolumn{3}{|c|}{$\left(\mathrm{J} \mathrm{K}^{\mathrm{C}} \mathrm{1}_{\mathrm{mol}}-1\right)$} \\
\hline & $\mathrm{NaNO}_{3}$ & $\mathrm{KNO}_{3}$ & $(\mathrm{Na}, \mathrm{K}) \mathrm{NO}_{3}$ \\
\hline $\begin{array}{r}27 \\
52 \\
77 \\
102 \\
127\end{array}$ & $\begin{array}{r}92.2 \\
96.3 \\
100.7 \\
105.6 \\
111.3\end{array}$ & $\begin{array}{r}95.6 \\
96.6 \\
98.8 \\
105.1 \\
111.3\end{array}$ & $\begin{array}{l}104.7 \\
109.4 \\
110.9\end{array}$ \\
\hline $\begin{array}{l}152 \\
177 \\
202 \\
227 \\
252\end{array}$ & $\begin{array}{l}118.0 \\
125.6 \\
134.6 \\
150.1 \\
182.2\end{array}$ & $\begin{array}{l}124.2 \\
124.3 \\
125.5 \\
126.7 \\
128.6\end{array}$ & $\begin{array}{c}119.9 \\
122.7 \\
126.1 \\
a \\
138.9\end{array}$ \\
\hline $\begin{array}{l}277 \\
302 \\
327 \\
352 \\
377\end{array}$ & $\begin{array}{c}a \\
a \\
140.0 \\
140.6 \\
141.2\end{array}$ & $\begin{array}{c}131.7 \\
138.4 \\
a \\
140.6 \\
139.1\end{array}$ & $\begin{array}{l}137.0 \\
141.5 \\
141.9 \\
139.9 \\
141.2\end{array}$ \\
\hline $\begin{array}{l}402 \\
427 \\
452 \\
477 \\
502\end{array}$ & $\begin{array}{l}141.4 \\
140.8 \\
139.5 \\
137.3\end{array}$ & $\begin{array}{l}138.1 \\
137.3 \\
136.4 \\
135.1 \\
133.1\end{array}$ & $\begin{array}{l}137.6 \\
134.6\end{array}$ \\
\hline 527 & & 130.1 & \\
\hline
\end{tabular}

asolid-solid transition or melting region. 
investigations they are in serious disagreement with some very recent publications (References $11.11,11.12$ ). The discrepancies of the pure liquid components will be discussed separately from the mixture.

TABLE 11.II

SUMMARY OF TRANSITION AND MELTING IN $\mathrm{NaNO}_{3}, \mathrm{KNO}_{3}$, and $(\mathrm{Na}, \mathrm{K}) \mathrm{NO}_{3}$

\begin{tabular}{|c|c|c|c|c|c|c|c|}
\hline Compound & $\begin{array}{c}T_{\mathrm{t}} \\
\left({ }^{\circ} \mathrm{C}\right) \\
\end{array}$ & $\begin{array}{c}\mathrm{T}_{\mathrm{m}} \\
\left({ }^{\circ} \mathrm{C}\right) \\
\end{array}$ & $\begin{array}{c}\Delta \mathrm{H}_{\mathrm{t}} \\
\left(\mathrm{kJ} \mathrm{mol}^{-1}\right)\end{array}$ & $\begin{array}{c}\Delta H_{\mathrm{m}} \\
\left(\mathrm{kJ} \mathrm{mol}^{-1}\right)\end{array}$ & $\begin{array}{c}\Delta \mathrm{S}_{\mathrm{t}} \\
\left(\mathrm{J} \mathrm{K}^{-1} \mathrm{~mol}^{-1}\right)\end{array}$ & $\begin{array}{c}\Delta S_{\mathrm{m}} \\
\left(\mathrm{J} \mathrm{K}^{-1} \mathrm{~mol}^{-1}\right) \\
\end{array}$ & Reference \\
\hline \multirow[t]{11}{*}{$\mathrm{NaNO}_{3}$} & 277 & 310 & 4.42 & $\begin{array}{l}15.1 \\
15.1\end{array}$ & \multirow[t]{2}{*}{8.43} & \multirow[t]{2}{*}{26.0} & \multirow{11}{*}{$\begin{array}{c}\text { This Work } \\
11.13 \\
11.14 \\
11.15 \\
11.16 \\
11.9 \\
11.17 \\
11.4 \\
11.18 \\
11.19 \\
11.6 \\
11.20 \\
11.21 \\
11.22\end{array}$} \\
\hline & \multirow[t]{7}{*}{276} & & 4.3 & & & & \\
\hline & & 306 & & $\begin{array}{l}15.1 \\
15.6\end{array}$ & & \multirow{6}{*}{26.8} & \\
\hline & & 306 & & $\begin{array}{l}15.0 \\
15.0\end{array}$ & & & \\
\hline & & & & 15.1 & & & \\
\hline & & 333 & & 15.4 & & & \\
\hline & & & & 14.9 & & & \\
\hline & & & & 14.7 & & & \\
\hline & \multirow[t]{3}{*}{276} & 306 & 3.95 & 14.6 & 5.27 & \multirow[t]{3}{*}{25.2} & \\
\hline & & & & 15.9 & & & \\
\hline & & 310 & & 15.5 & & & \\
\hline \multirow{8}{*}{$\mathrm{KNO}_{3}$} & 133 & 339 & 5.64 & 10.5 & 13.8 & 17.2 & \multirow{8}{*}{$\begin{array}{c}\text { This work } \\
11.23 \\
11.10 \\
11.16 \\
11.22 \\
11.4 \\
11.7 \\
11.14\end{array}$} \\
\hline & & 337 & & 10.0 & & 16.4 & \\
\hline & 128 & 334 & 5.10 & 9.6 & & \multirow{6}{*}{16.7} & \\
\hline & & 334 & & 10.0 & & & \\
\hline & & 337 & & 10.1 & & & \\
\hline & & 308 & & 10.7 & & & \\
\hline & 129 & & 5.42 & & & & \\
\hline & 130 & & 5.02 & & & & \\
\hline$(\mathrm{Na}, \mathrm{K}) \mathrm{NO}_{3}$ & 110 & $\begin{array}{l}221 \\
222\end{array}$ & 3.5 & $\begin{array}{l}10.2 \\
13.4\end{array}$ & 9.2 & 20.5 & This work \\
\hline
\end{tabular}

11.3.1 $\mathrm{NaNO}_{3}$ and $\mathrm{KNO}_{3}$ (Liquid)

Some of the literature-derived heat capacity values for liquid $\mathrm{NaNO}_{3}$ and $\mathrm{KNO}_{3}$ are in serious disagreement with this work. The results obtained in this work indicate a decrease in heat capacity as the temperatures increase above the melting point. The heat capacities measured were in the range of 130 to $140 \mathrm{~J} \mathrm{~K}^{-1} \mathrm{~mol}^{-1}$ at temperatures up to 200 degrees past the melting points. Two previous investigations support these results for $\mathrm{KNO}_{3}$ (References 11.1 , 11.4). Other investigations suggest that the heat capacity results from this work are too low. They suggest heat capacities of about 150 to $160 \mathrm{~J} \mathrm{~K}^{-1} \mathrm{~mol}-1$ at temperatures slightly above the melting point (References $11.1,11.4,11.6$ ). A decreasing heat capacity in the liquid region is also supported by one other investigator (Reference 11.6). However, two very recent publications put the heat capacities of $\mathrm{NaNO}_{3}$ at 160 to $180 \mathrm{~J} \mathrm{~K}^{-1} \mathrm{~mol}^{-1}$ (Reference 11.12) and $212 \mathrm{~J} \mathrm{~K}^{-1} \mathrm{~mol}^{-1}$ (Reference 11.11 ), and $\mathrm{KNO}_{3}$ at 180 to $210 \mathrm{~J} \mathrm{~K}^{-1} \mathrm{~mol}^{-1}$

(Reference 11.12) and $233 \mathrm{~J} \mathrm{~K}^{-1} \mathrm{~mol}^{-1}$ (Reference 11.11) just above the melting points. Further, one (Reference 11.12) suggests an increasing heat capacity with temperature. Unfortunately, at this point it is difficult to rationalize any set of results as better than another. Each of the techniques used have serious drawbacks. The results from this work up to the melting point would suggest accuracies of two-to-three percent in the heat capacity measurements. 
The increased scatter and the experimental difficulties due to leaking sample pans obviously decreases the accuracy of the heat capacities in the liquid region. Therefore, the heat capacities in this work may be too low as a result of the experimental difficulties described above. However, previously reported heat capacity values were measured at the melting point and not into the liquid region. If the salt had not completely melted heat capacity values much too high could be measured. The conclusion at this stage is that the heat capacities of each salt are in the range of 140 to $160 \mathrm{~J} \mathrm{~K}-1 \mathrm{~mol}-1$ at temperatures up to 50 degrees beyond the melting point. Also, the heat capacities certainly decrease but probably do not change much in the liquid region until the salts begin to decompose (Reference 11.24).

\subsection{2 ( $\mathrm{Na}, \mathrm{K}) \mathrm{NO}_{3}$ (Liquid)}

There are only two previous investigations on the heat capacity of the $50 / 50$ molar mixture. One shows the heat capacity decreasing with temperature from $167.3 \mathrm{~J} \mathrm{~K}^{-1} \mathrm{~mol}^{-1}$ at $237^{\circ} \mathrm{C}$ to $138.6 \mathrm{~J} \mathrm{~K}^{-1} \mathrm{~mol}-1$ at $497^{\circ} \mathrm{C}$ (Reference 11.1 ). The other gives a value of $142 \mathrm{~J} \mathrm{~K}^{-1} \mathrm{~mol}^{-1}$ just above the melting point $\left(221^{\circ} \mathrm{C}\right.$ ) (Reference 11.11 ). This latter result is about 35 percent lower than their results for pure $\mathrm{NaNO}_{3}$ and $\mathrm{KNO}_{3}$ as liquids. It is difficult to reconcile such a difference. Again, the techniques for measuring heat capacities in the temperature range of interest have serious drawbacks as described above. At this point it is not possible to arrive at recommended values for the heat capacity of the liquid.

\subsection{Summary}

The heat capacities of $\mathrm{NaNO}_{3}, \mathrm{KNO}_{3}$, and $(\mathrm{Na}, \mathrm{K}) \mathrm{NO}_{3}$ have been measured well into the liquid range of each salt. The heat capacity results in the solid agree very well with previous investigations as do the transition and melting points. However, serious experimental difficulties were encountered in the liquid regions of the salts. Methods to resolve the experimental difficulties are being explored. Future experiments will clarify the disparate heat capacity results obtained to date.

\subsection{References}

11.1 G. J. Janz, C. B. Allen, N. P. Bansal, R. M. Murphy, and

R. P. T. Tompkins, "Physical Properties Data Compilations Relevant to Energy Storage, II. Molten Salts: Data on Single- and Multi-Component Salt Systems," NSRDS-NBS 61, April 1979.

11.2 T. B. Douglas, ASME Trans. 79, 23 (1957).

11.3 V. C. Reinsborough and F. E. W. Wetmore, Aust. J. Chem. 20, 1 (1967).

11.4 H. M. Goodwin and H. T. Kalmus, Phys. Rev. 28, 1 (1909). 
11.5 J. C. Southard and R. A. Nelson, J. Am. Chem. Soc. 55, 4865 (1933).

11.6 A. Mustajoki, Ann. Acad. Scient. Fenn. A VI, 5 (1957).

11.7 A. Mustajoki, ibid. 99 (1962).

11.8 V. A. Sokolov, V. A. Palkin, and N. E. Shmidt, Invest. Sektora Fiz.Khim. Anal., Inst. Obshchei i Neorg. Khim., Akad. Nauk S.S.S.R. 25, 134 (1954) CA 49:14463.

11.9 V. A. Sokolov and N. E. Schmidt, ibid. 26, 123 (1955). CA 50:3060.

11.10 V. A. Sokolov and N. E. Schmidt, ibid. 27, 217 (1956). CA 50:15200.

11.11 P. Nguyen-Duy and E. A. Dancy, Thermochim. Acta 39, 95 (1980).

11.12 T. Asahina, M. Kosaka, and H. Taoda (Gov. Ind. Res. Inst., Najoya, Japan), Nagoya Kogyo Gijutsu Shikensho Hokoku 29, 25 (1980).

11.13 M. G. Lowings, K. G. McCurdy, and L. G. Hepler, Thermochim. Acta 23, 365 (1978).

11.14 C. N. R. Rao, B. Prakash, and M. Naturajan, "Crystal Structure Transformations in Inorganic Nitrites, Nitrates, and Carbonates," NSRDS-NBS 53, May 1975.

11.15 D. I. Marchidan and C. Telea, Rev. Roumaine Chim. 13, 1291 (1968).

11.16 P. Franzosini and C. Sinistri, Ricerca Sci. 33, 411 (1963).

11.17 H. C. Ko, T. Hu, J. G. Spencer, C. Y. Huang, and L. G. Hepler, J. Chem. Eng. Data 8,364 (1963).

11.18 T. Hu, H. C. Ko, and L. G. Hepler, J. Phys. Chem. 68, 387 (1964).

11.19 G. J. Janz and T. R. Kozlowski, J. Phys. Chem. 67, 2857 (1963).

11.20 E. R. Van Artsdalen, J. Phys. Chem. 60, 173 (1956).

11.21 D. M. Speros and R. L. Woodhouse, J. Phys. Chem. 67, 2164 (1963).

11.22 0. J. Kleppa and F. G. McCarty, J. Chem. Eng. Data 8, 331 (1963).

11.23 R. P. Clark, J. Chem. Eng. Data 18, 67 (1973).

11.24 0. Kubaschewski and C. B. Alcock, Metallurgical Thermochemistry (Pergamon Press, New York, 1979). 


\title{
12.0 PHASE DIAGRAMS OF $\mathrm{NaNO}_{3}-\mathrm{Na}_{2} \mathrm{CO}_{3}$ AND $\mathrm{KNO}_{3}-\mathrm{K}_{2} \mathrm{CO}_{3}$
}

\author{
M. M. Karnowsky, R. M. Biefeld, and N. J. Norem
}

\subsection{Introduction}

The determination of the phase diagrams of the $\mathrm{NaNO}_{3}-\mathrm{Na}_{2} \mathrm{CO}_{3}$ and $\mathrm{KNO}_{3}-\mathrm{K}_{2} \mathrm{CO}_{3}$ systems is a result of concern over possible degradation to the mixed salt, $\mathrm{NaNO}_{3}-\mathrm{KNO}_{3}$, from environmental exposure in solar central receiver applications. The $\mathrm{NaNO}_{3}-\mathrm{KNO}_{3}$ system, proposed for thermal transport and energy storage, may be subjected to absorption of water or $\mathrm{CO}_{2}$ under operating conditions. This work addresses the effects of $\mathrm{CO}_{2}$ addition on the assumption that a carbonate will be formed. Phase diagrams between $\mathrm{NaNO}_{3}-\mathrm{Na}_{2} \mathrm{CO}_{3}$ and $\mathrm{KNO}_{3}-\mathrm{K}_{2} \mathrm{CO}_{3}$ can show possible effects of the carbonate formation on the original nitrate mixture.

A literature survey indicated that the only reported phase diagrams of the $\mathrm{NaNO}_{3}-\mathrm{Na}_{2} \mathrm{CO}_{3}$ and $\mathrm{KNO}_{3}-\mathrm{K}_{2} \mathrm{CO}_{3}$ systems were the work of Amadori

(Reference 12.1) in 1913. These diagrams are reproduced in Figures 12.1 and 12.2. Amadori's work extended only from $100 \mathrm{~m} / 0 \mathrm{NaNO}_{3}$ to $70 \mathrm{~m} / \mathrm{o} \mathrm{NaNO} 3$ $\left(30 \mathrm{~m} / \mathrm{o} \mathrm{Na}_{2} \mathrm{CO}_{3}\right)$, and $100 \mathrm{~m} / \mathrm{o} \mathrm{KNO}_{3}$ to $50 \mathrm{~m} / \mathrm{o} \mathrm{KNO}_{3}\left(50 \mathrm{~m} / \mathrm{o} \mathrm{K}_{2} \mathrm{CO}_{3}\right)$. The work did not include a discussion of the polymorphic forms of any of the end members.

Since the published data on the nitrate-carbonate phase equilibria were inadequate, the equilibrium phase diagrams were determined.

\subsection{Experimental}

Reagent grade chemicals were used and the analyses of the chemicals are given in Table 12.I.

The nitrates and carbonates of the sodium system and separately, for the potassium system were mixed to provide a series of compositions ranging from $100 \mathrm{~m} / \mathrm{o} \mathrm{MNO}_{3}$ to $0 \mathrm{~m} / \mathrm{o} \mathrm{MNO}_{3}$ where $\mathrm{M}$ is sodium or potassium in $5 \mathrm{~m} / \mathrm{o}$ increments. The mixtures were contained in nickel crucibles and were then analyzed by differential thermal analysis (DTA) for determination of the phase diagrams. The techniques applied in this work are those commonly used in phase-diagram determinations for metal systems, where the samples typically are heated to a temperature above the liquidus and then cooled slowly. In addition, elevated temperature $\mathrm{X}$-ray diffraction and thermogravimetric analyses were performed as 


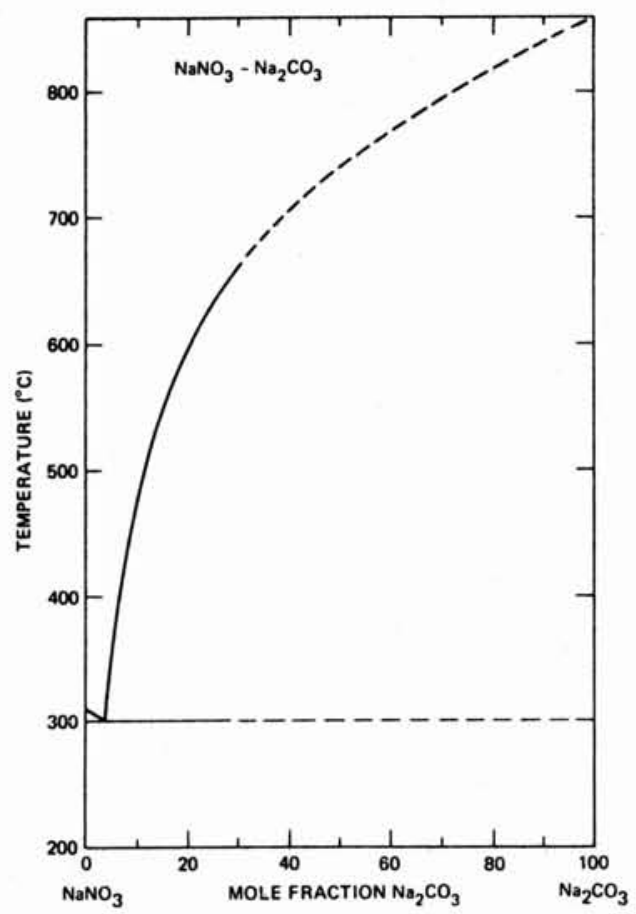

Figure 12.1. Phase Diagram of $\mathrm{NaNO}_{3}-\mathrm{Na}_{2} \mathrm{CO}_{3}$ System (Ref. 12.1)

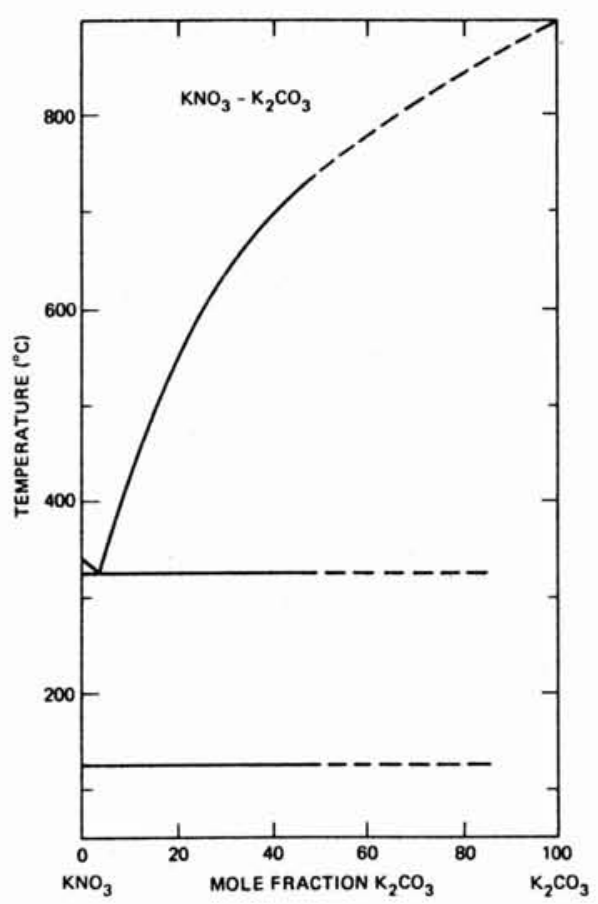

Figure 12.2. Phase Diagram of $\mathrm{KNO}_{3}-\mathrm{K}_{2} \mathrm{CO}_{3}$ System (Ref. 12.1) 
TABLE $12 . \mathrm{I}$

CHEMICAL ANALYSIS OF STARTING MATERIALS

\begin{tabular}{rrrrr}
\hline Element & $\begin{array}{c}\mathrm{NaNO}_{3} \\
(\mathrm{ppm})\end{array}$ & $\begin{array}{c}\mathrm{Na}_{2} \mathrm{CO}_{3} \\
(\mathrm{ppm})\end{array}$ & $\begin{array}{c}\mathrm{KNO}_{3} \\
(\mathrm{ppm})\end{array}$ & $\begin{array}{r}\mathrm{K}_{2} \mathrm{CO}_{3} \\
(\mathrm{ppm})\end{array}$ \\
\hline \hline $\mathrm{Na}$ & - & - & 1000 & 50 \\
$\mathrm{~K}$ & 80 & 60 & - & - \\
$\mathrm{Li}$ & 150 & 25 & 15 & 25 \\
$\mathrm{Ag}$ & 150 & $\mathrm{ND}$ & $\mathrm{ND}$ & 120 \\
$\mathrm{Al}$ & 120 & 50 & 40 & 30 \\
$\mathrm{Ca}$ & 150 & 150 & 100 & 100 \\
$\mathrm{Mg}$ & 30 & 40 & 200 & 12 \\
$\mathrm{Fe}$ & $\mathrm{ND}$ & $\mathrm{ND}$ & 40 & $\mathrm{ND}$ \\
$\mathrm{Si}$ & 50 & 25 & 50 & 25 \\
$\mathrm{Cu}$ & 12 & 12 & 12 & 15 \\
& & & & \\
\hline ND: not detected. & & & & \\
\hline
\end{tabular}

necessary to confirm the phase diagram postulated from the DTA measurements. Details of the experimental technique can be found el sewhere (Reference 12.2).

\subsection{Results and Discussion}

\subsection{1 $\mathrm{NaNO}_{3}-\mathrm{Na}_{2} \mathrm{CO}_{3}$}

The phase diagram determined in this work is given in Figure 12.3. The diagram indicates almost no interaction between $\mathrm{NaNO}_{3}$ and $\mathrm{Na}_{2} \mathrm{CO}_{3}$ with the exception of slight mutual solubilities in each of the polymorphic phases of $\mathrm{NaNO}_{3}$ and $\mathrm{Na}_{2} \mathrm{CO}_{3}$.

The reactions may be tabulated as follows:

$$
\text { cooling }
$$

1. liquid $\ddagger \mathrm{\beta}-\mathrm{NaNO}_{3}(\mathrm{~S})+\gamma-\mathrm{Na}_{2} \mathrm{CO}_{3}(\mathrm{~S}) \odot 293^{\circ} \mathrm{C}$

$$
\text { cooling }
$$

2. $\delta-\mathrm{Na}_{2} \mathrm{CO}_{3}(\mathrm{~S}) \neq \gamma-\mathrm{Na}_{2} \mathrm{CO}_{3}(\mathrm{~S})+1$ iquid $\odot 351^{\circ} \mathrm{C}$

$$
\text { cooling }
$$

3. $\varepsilon-\mathrm{Na}_{2} \mathrm{CO}_{3}(\mathrm{~S}) \rightleftarrows \delta-\mathrm{Na}_{2} \mathrm{CO}_{3}(\mathrm{~S})+1$ iquid $0470^{\circ} \mathrm{C}$

High-temperature X-ray diffraction on samples of near-50 m/o Na2 $\mathrm{CO}_{3}$ composition indicated only the terminal components. 


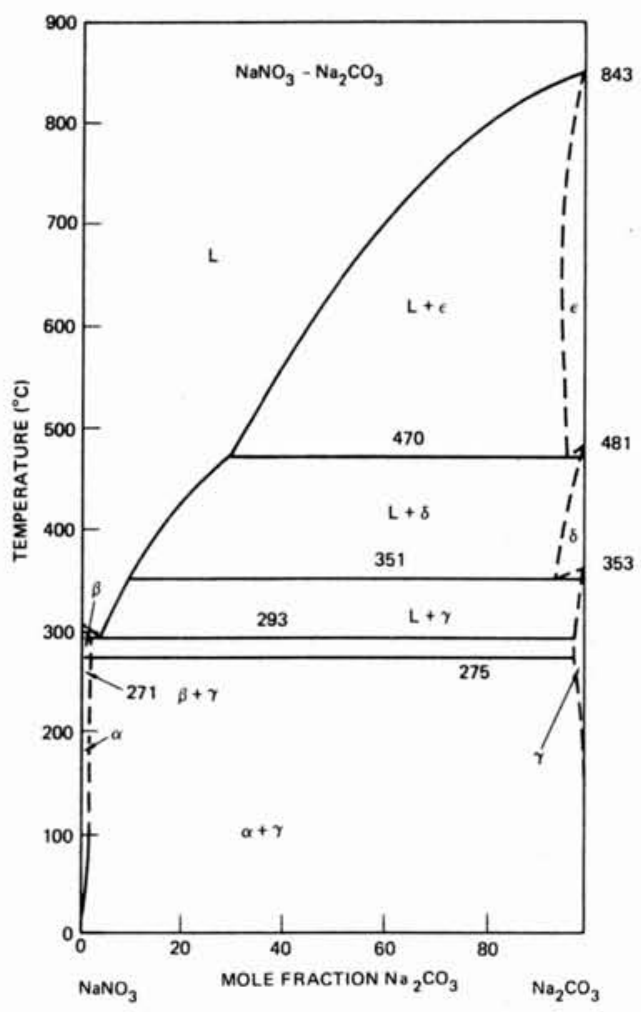

Figure 12.3. Phase Diagram of $\mathrm{NaNO}_{3}-\mathrm{Na}_{2} \mathrm{CO}_{3}$ System (this work)

The possibility exists that decomposition occurs on melting and that the cooling curves are influenced by decomposition products 1 ike $\mathrm{Na}_{2} \mathrm{O}$ and $\mathrm{NaNO}_{2}$. To explore that possibility thermogravimetric analyses were performed on pure $\mathrm{Na}_{2} \mathrm{CO}_{3}$ and a $44.5 \mathrm{~m} / 0 \mathrm{NaNO}_{3}-55.5 \mathrm{~m} / 0 \mathrm{Na}_{2} \mathrm{CO}_{3}$ mixture under a $\mathrm{CO}_{2}$ atmosphere. The results indicated that $\mathrm{Na}_{2} \mathrm{CO}_{3}$ began to decompose after melting at $\sim 850^{\circ} \mathrm{C}$; the mixture of $\mathrm{Na}_{2} \mathrm{CO}_{3}$ and $\mathrm{NaNO}_{3}$ began to decompose at $600^{\circ} \mathrm{C}$ (Reference 12.3). Stern (Reference 12.4) reported that $\mathrm{NaNO}_{3}$ melts without decomposition at $306^{\circ} \mathrm{C}$ and begins a slow decomposition near $600^{\circ} \mathrm{C}$ in accord with the results in this work. It is possible that some contamination of the samples occurred by virtue of decomposition of the components. However, it is felt that contamination is minimal and has little effect upon the equilibrium diagram.

\subsubsection{The $\mathrm{KNO}_{3}-\mathrm{K}_{2} \mathrm{CO}_{3}$ Phase Diagram}

The phase diagram for this system is shown in Figure 12.4. Like the $\mathrm{NaNO}_{3}-\mathrm{Na}_{2} \mathrm{CO}_{3}$ system, the outstanding feature is the absence of interactions with the terminal components. Only the eutectic at $315^{\circ} \mathrm{C}$ shows any interaction. All the other events are related to the solid state polymorphic changes in the individual components. High-temperature $X$-ray diffraction results at 80 and $90 \mathrm{~m} / 0 \mathrm{~K}_{2} \mathrm{CO}_{3}$ were used to establish the solid solution limits on the carbonate side. In the main, the reactions with the $\mathrm{KNO}_{3}-\mathrm{K}_{2} \mathrm{CO}_{3}$ system are very similar to those of the $\mathrm{NaNO}_{3}-\mathrm{Na}_{2} \mathrm{CO}_{3}$ system. 


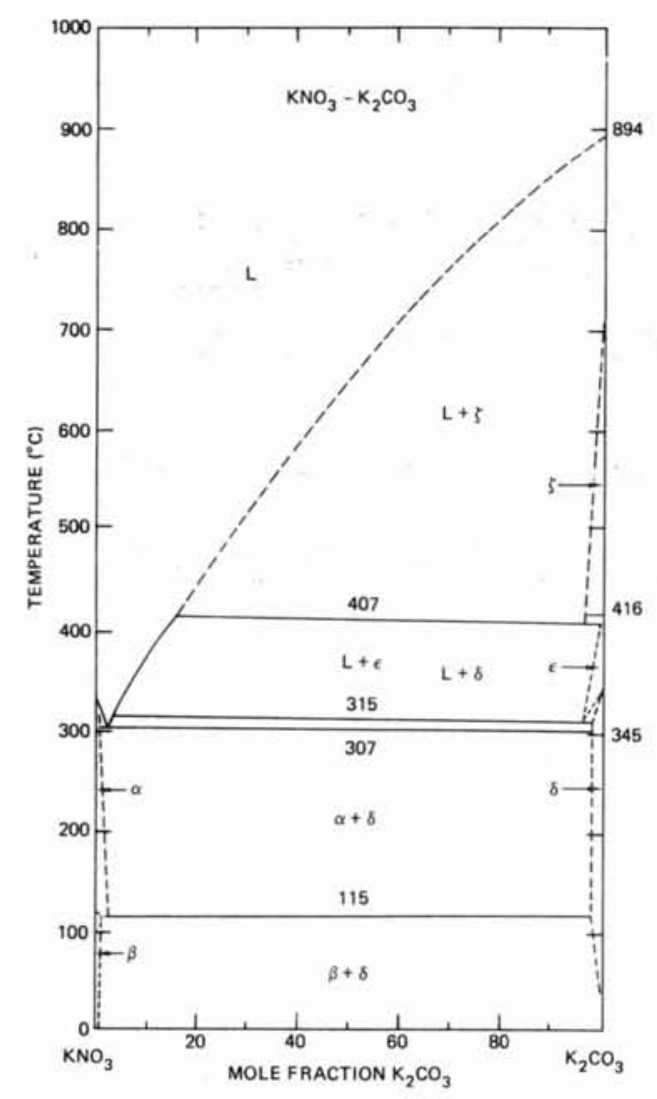

Figure 12.4. Phase Diagram of $\mathrm{KNO}_{3}-\mathrm{K}_{2} \mathrm{CO}_{3}$ System (this work)

\subsection{Summary}

It is concluded that:

1. Because there are no substantial interactions between $\mathrm{NaNO}_{3}$ and $\mathrm{Na}_{2} \mathrm{CO}_{3}$ and between $\mathrm{KNO}_{3}$ and $\mathrm{K}_{2} \mathrm{CO}_{3}$ in those systems, no major effects on the thermal behavior of the $\mathrm{NaNO}_{3}-\mathrm{KNO}_{3}$ system due to $\mathrm{CO}_{2}$ contamination are foreseen.

2. With only a small temperature increment above the liquidus in the $\mathrm{NaNO}_{3} / \mathrm{Na}_{2} \mathrm{CO}_{3}$ and $\mathrm{KNO}_{3} / \mathrm{K}_{2} \mathrm{CO}_{3}$ phase diagrams, the liquid can dissolve relatively large amounts of $\mathrm{Na}_{2} \mathrm{CO}_{3}$ and $\mathrm{K}_{2} \mathrm{CO}_{3}$. 


\subsection{References}

12.1 M. Amadori, Atti Reale Accad. Lincei Sez II 22, 336 (1913). Also referenced as: M. Amadori, Rendiconti 22, 191 332-337 (1913).

12.2 M. M. Karnowsky, R. P. Clark, and R. M. Biefeld, J. Solid State Chem. 19,281 (1976).

12.3 D. A. Powers, private communication, 1979.

12.4 K. H. Stern, J. Phys. Chem. Ref. Data 1, 747 (1972). 


\subsection{REVIEW OF INDUSTRIAL USE}

R. W. Carling and R. W. Mar

\subsection{Introduction}

It is often stated that the supporting base for the industrial use of molten nitrate salt is weak. This limited industrial experience, is to some extent, a misconception. Molten nitrate salts have been used for decades in the chemicals and metals industries as heat transfer fluids and as heat treating media. However, little has been documented and virtually all of the industrial processes using flowing salts are at temperatures of $450^{\circ} \mathrm{C}$ and below. In addition almost all of the flowing salt systems are operated isothermally.

Heat transfer applications include extracting heat from exothermic reactions and providing heat to drive endothermic reactions. Prime examples of the former are found in the maleic and phthalic anhydride production processes. Concentrators or evaporators are examples of nitrate salts used to provide heat.

Even though the industrial experience in molten salt use is limited as far as its relevance to solar thermal power applications, it is useful to know and document what information there is. To this end, we have contacted various industrial users of nitrate salt, made several plant visits, and talked to production managers or others with firsthand knowledge of molten salt usage. The information derived to date is summarized in this report.

\subsection{Plant Visits}

Four sites have been visited that use molten nitrate salts in their industrial process. They are: (1) $\mathrm{NaNO}_{3}$ production, 01 in Chemical Corporation, Lake Charles, Louisiana, (2) caustic concentration, 0lin Chemical Corporation, Charleston, Tennessee, (3) phthalic anhydride production, Monsanto, Texas City, Texas, and (4) carbon black production, Intenco, Inc., Houston, Texas. A brief summary of the plant characteristics are presented in Table 13.I. 
TABLE 13.I

SUMMARY OF MOLTEN SALT USAGE AT PLANTS VISITED

\begin{tabular}{|c|c|c|c|c|c|}
\hline Plant & Salt & $\begin{array}{c}\text { Maximum } \\
\text { Temp }\left({ }^{\circ} \mathrm{C}\right) \\
\end{array}$ & $\begin{array}{c}\text { Construction } \\
\text { Material } \\
\end{array}$ & $\begin{array}{l}\text { Thermal } \\
\text { Cycling }\end{array}$ & $\begin{array}{l}\text { Years of } \\
\text { Operation }\end{array}$ \\
\hline $\begin{array}{l}\text { 0lin Chem. } \\
\mathrm{NaNO}_{3} \text { production } \\
\text { Lake Charles, LA }\end{array}$ & $\mathrm{NaNO}_{3}$ & 450 & $\begin{array}{l}\text { Mild Steel } \\
\text { 304L } \\
347\end{array}$ & no & 30 \\
\hline $\begin{array}{l}01 \text { in Chem. } \\
\text { caustic conc. } \\
\text { Charleston, TN }\end{array}$ & HITEC & 425 & $\begin{array}{l}\text { Mild Steel } \\
\text { IN600 }\end{array}$ & no & 7 \\
\hline $\begin{array}{l}\text { Intenco } \\
\text { tire pyrolysis } \\
\text { Houston, TX }\end{array}$ & HITEC & 550 & 304 & no & $1-1 / 2$ \\
\hline $\begin{array}{l}\text { Monsanto } \\
\text { phthalic anhydride } \\
\text { Texas City, TX }\end{array}$ & HITEC & 480 & Mild Steel & no & 9 \\
\hline
\end{tabular}

\subsection{1 $\mathrm{NaNO}_{3}$ Production}

01 in Chemical Corporation is the only domestic producer of $\mathrm{NaNO}_{3}$. The production plant, in Lake Charles, Louisiana, has a capacity of about 114 million $\mathrm{kg}$ per year, and has been in operation since $1949 . \mathrm{NaNO}_{3}$ is prepared synthetically by mixing $\mathrm{HNO}_{3}$ with either $\mathrm{NaOH}$ or $\mathrm{Na}_{2} \mathrm{CO}_{3}$. The sodium source may be either $\mathrm{NaOH}$ or $\mathrm{Na}_{2} \mathrm{CO}_{3}$. After mixing the reactants a solution of $\mathrm{NaNO}_{3}$ is left that must be dried. As anhydrous, molten $\mathrm{NaNO}_{3}$ is prepared it is recirculated to flash the $\mathrm{H}_{2} \mathrm{O}$ off the incoming salt solution. The maximum temperature of the salt during this process is about $450^{\circ} \mathrm{C}$. The molten, anhydrous salt is fed to a prill tower. The salt flow through the system is controlled by the amount being prilled. Salt not prilled returns to the melting pot to dry the incoming salt solution. There is about $55,000 \mathrm{~kg}$ of recirculating salt.

The entire system is insulated. Stainless steel 0-rings are used in the flanges. The system runs 24 hours a day and does not shut down except due to mechanical failures. The plant averages about one day of down time per month due to mechanical failures. No problems have ever been attributed to the molten salt system.

The plant safety record has been flawless. New employees go through a vigorous safety indoctrination before working in the plant. Salt is stored in bags or goes directly into a hopper for transport. 


\subsubsection{Caustic Concentration}

01 in Chemical Corporation has a caustic soda production plant in Charleston, Tennessee. Capacity of the plant is about $15,000 \mathrm{~kg}$ per year of caustic soda. The plant has been operating since 1973 and uses HITEC as the heat transfer medium. The 70 percent solution of caustic is dried in a tube-in-shell heat exchanger. The caustic solution flows through Inconel 600 tubes in the heat exchanger as molten salt (at $400^{\circ} \mathrm{C}$ ) flows countercurrently outside of the tubes. The temperature within the heat exchanger remains constant and the process runs 24 hours a day.

Salt inventory is about $12,000 \mathrm{~kg}$. The melting point of the salt is measured once a week. If the melting point of the salt begins to go up a drum (about $182 \mathrm{~kg}$ ) of salt is added. About one drum per month is added. However, the additional salt is required primarily to replace salt lost due to leaks, rather than salt lost due to decomposition or degradation. The entire inventory of salt has not been changed since 1973 . The salt has a $\mathrm{N}_{2}$ blanket but the system is not sealed. Flow is controlled by an orifice on the discharge side of the heat exchanger.

Routine maintenance of the system occurs about every 18 months. However, the system is down about one or two times a month due to problems on the caustic side of the process. Few, if any, problems have occurred on the salt side. The molten salt pump has been repaired once since 1973.

The plant has had no safety accidents or fires attributable to salt.

\subsubsection{Phthalic Anhydride Production}

Phthalic anhydride is produced in the petrochemical industry by the oxidation of either naphthalene or orthoxylene. These reactions are catalyzed, exothermic gas phase reactions. Typically, a tubular catalytic reactor is used. Tubes are filled with catalyst pellets and are placed in a shell and tube reactor heat exchanger. The reactants (naphthalene or orthoxylene and air) enter the tube from the bottom and gaseous phthalic anhydride exists at the top. The heat of reaction is removed by a counter current flow of salt exterior to the tubes. Temperatures in the reactor do not exceed $480^{\circ} \mathrm{C}$. The hot salt exiting the chemical reactor is diverted to a steam generator, where another shell and tube heat exchanger is used to generate steam, thereby cooling off the salt.

The phthalic anhydride plant at Texas City operated by Monsanto uses HITEC. The total salt capacity is about $57,000 \mathrm{~kg}$. A nitrogen cover gas is used to mitigate salt decomposition. The amount of salt is monitored periodically and additional HITEC is added when the salt level in the holding tank falls below a specified level. Salt make-up requirements are about 140 to $180 \mathrm{~kg} /$ year. It is felt that the bulk of the salt loss is due to physical loss (e.g., leakage through valve seals and fittings) rather than thermal decomposition. The maximum salt temperature is $480^{\circ} \mathrm{C}$. Mild steel was the material of construction throughout. The salt loop has a trouble free history. No breaks in operation can be attributed to molten salt problems. Potential problems with the steam generator (poor water quality and associated corrosion) were a key concern in the plant. 


\subsubsection{Carbon Black Production}

A procedure for the production of carbon black from used rubber tires has been developed by Intenco, Inc. In this process, molten salt is used to provide the heat for pyrolysis. The heart of the salt loop is a $14,000 \mathrm{~kg}$ capacity molten salt system, designed and marketed by American Hydrotherm. Salt is pumped out of the holding tank to two reactors. Maximum salt temperatures are about $550^{\circ} \mathrm{C}$ and flow rates of up to $150 \mathrm{gal} / \mathrm{min}$ are used. The salt composition is HITEC, and the containment, reactor and piping material is 304 stainless. The system has been in existence for approximately three years, and the total cumulative time of operation is estimated to be about 10,000 hours. When operational, the process is run 24 hours a day under nearly isothermal conditions. 
UNL IMITED RELEASE

INITIAL DISTRIBUTION:

Division of Thermal and Mechanical Energy Storage Systems

MS 6B025 Room 1G-100

Forrestal Building

U.S. Department of Energy

Washington, D. C. 20585

Attn: M. Gurevich

J. H. Swisher

J. Strauch

Division of Solar Thermal Energy Systems

U.S. Department of Energy

600 E Street N.W., Room 419

Washington, D.C. 20585

Attn: W. Auer

G. W. Braun

K. Cherian

M. U. Gutstein

J. E. Rannels

Albuquerque Operations office

Special Programs Division

U.S. Department of Energy

P. 0. Box 5400

Albuquerque, NM 87115

Attn: J. Morley

D. Schueler

San Francisco Operations Office

U.S. Department of Energy

1333 Broadway

0akland, CA 94612

Attn: D. Elliott

R. Hughey

L. Prince

C. M. Kramer

Code 6130

Naval Research Lab

Washington, D. C. 20375

Dr. Robert A. Osteryoung

Department of Chemistry

State University of New York at Buffalo

Buffalo, NY 14214

Prof. Harald A. Oye

Institutt for uorganisk kjemi

Norges tekniske hogskole

Universitetet $i$ Trondheim

N-7034 Trondheim - NTH, NORWAY 
John Neill

Advanced Energy Concepts

Suite I

11722 Sorrento Valley Rd.

San Diego, CA 92121

Aerospace Corporation

2350 El Segundo Blvd.

E1 Segundo, CA 90009

Attn: P. Mathur

L. R. Sitney

Babcock and Wilcox Company

P. 0. Box 351

Barberton, $\mathrm{OH} 44203$

Attn: William F. Clancey

Murray Wiener, Power Generation Group

Bill Oberjohn

Babcock and Wilcox

Box 835

Alliance, $\mathrm{OH} \quad 44601$

Dr. C. A. Bolthrunis

Badger Energy, Inc.

One Broadway

Cambridge, MA 02142

Robert L. Lessley

Bechtel

50 Beale

San Francisco, CA 94119

James P. Maddox

Biphase Energy Systems

2800 Airport Ave.

Santa Monica, CA 90405

Charles Grosskreutz

Black \& Veatch

P. 0. Box 845

Kansas City, M0 64114

William D. Beveriy

Boeing Engineering and Construction Co.

P. 0. Box 3707

Seattle, WA 98124

George H. Rowe

Combustion Engineering

1000 Prospect Hill Road

Windsor, CT 06095 
Pierre Spiteri

EDF

Les Renaidierz

Ecuelles, France

Sydney H. White

EIC Labs., Inc.

55 Chapel Street

Newton, MA 02158

EPRI

P. 0. Box 10412

3412 Hillview Ave.

Palo Alto, CA 94303

Attn: J. Bigger

T. R. Schneider

Donald C. Erickson

Energy Concepts Co.

627 Ridgely

Annapolis, MD 21401

T. V. Narayanan

Foster Wheeler

12 Peach Tree Hill Road

Livingston, NJ 07039

Donald J. Spellman

Gas Cooled Reactor Assoc.

3344 N. Torrey Pines Road

La Jolla, CA 92137

General Atomic Co.

P. 0. Box 81608

San Diego, CA 92138

Attn: Thomas H. Van Hagan

Daniel L. Vrable

Fred $\mathrm{F}$. Witt

General Electric

3172 Porter Drive

Palo Alto, CA 94304

Soeren S. Nielsen

Gould, Inc.

40 Gould Center

Rolling Meadows, IL 60008

Alan Snelson

ITT Research Institute

10 W 35 Street

Chicago, IL 60616 
JPL

4800 Oak Grove Dr.

Pasadena, CA 91103

Attn: J. Becker

R. Manvi

J. Sheldon

v. Truscello

Skip Gross

MSA Research

Evans City, PA 16033

Martin Marietta Corporation

Box 179

Denver, CO 80201

Attn: Charles N. Bolton Russell A. Chihoski David W. Neiswander Tom Tracey

McDonnell Douglas

5301 Bolsa Ave.

Huntington Beach, CA 92647

Attn: Donald L. Endicott

George F. Greenwald

Russell T. Neher

J. H. DeVan

Oak Ridge National Laboratory

Oak Ridge, TN 37830

01 in Corporation

275 Winchester Ave.

New Haven, CT 06511

Attn: Louis C. Fiorucci

Stephen L. Goldstein

Joe K. Mensah

01 in Corporation

120 Long Ridge Road

Stamford, CT 06904

Attn: Norman Christopher

Gerald A. Habib

Robert E. Smith

Pacific Gas and Electric

3400 Crow Canyon Road

San Ramon, CA 94583

Attn: Helena T. Rowl and

Harold E. Seielstand

Jay Raggio

Dr. R. W. Foreman

Park Chemical Company

8074 Military Avenue

Detroit, MI 48204 
Richard D. Smith

Rocket Research Company

York Center

Redmond, WA 98052

Robert J. Walter

Rocketdyne

6633 Canoga Ave.

Canoga Park, CA 91360

Rockwell International/ETEC

8900 De Soto Ave.

Canoga Park, CA 91304

Attn: Jerry B. Brukiewa, ETEC

A. Z. Frangos

Rick L. Howerton, ETEC

Ted Johnson, ESG

SERI

1536 Cole Blvd.

Golden, CO 80401

Attn: B. Butler

B. P. Gupta

J. Lefferdo

R. G. Nix

R. Ortiz (Library)

P. A. Roberts

P. Russell

K. Touryan

C. Wyman

George Yenetchi

Solar Thermal Systems

Division of Exxon Enterprises Inc.

P. 0. Box 592

Florham Park, NJ 07932

Kenneth Ladd

Southwestern Public Service Co.

P. 0. Box 1261

Amarillo, TX 79170

Donald J. Liffengren

Stearns-Roger

4500 S. Cherry Creek Drive

Denver, CO 80217

Robert M. N. Killen

United Engineers and Construction

Suite 300

3344 N. Torrey Pines CT.

La Jolla, CA 92137 
John B. Mulligan

United Engineers and Construction

30 S. 17th Street

Philadelphia, PA 19103

Niven D. Morgan, Jr.

Vertac Chemical Corporation

Suite 241

3000 Knight 0 ffice $\mathrm{Place}$

Shreveport, LA 71105

Stuart A. Shiels

Westinghouse Electric Corporation

Advanced Reactors Division

Box 158

Madison, PA 15663

C. Winter, 400

A. Narath, 4000

J. H. Scott, 4700

B. W. Marshal1, 4713

R. P. Stromberg, 4714

G. E. Brandvold, 4720; Attn: J. V. Otts, 4721

J. F. Banas, 4722

J. A. Leonard, 4725

J. K. Galt, 5000

J. E. Schirber, 5150

R. M. Biefeld, 5154

G. D. Stucky, 5154

R. S. Claassen, 5800

R. G. Kepler, 5810

M. J. Davis, 5830

M. M. Karnowsky, 5832

J. W. Mumford, 5832

R. W. Rohde, 5832

N. J. Magnani, 5840; Attn: D. W. Schaefer, 5841

T. B. Cook, 8000

W. E. Alzheimer, 8120; Attn: R. J. Gallagher, 8124

A. N. B1 ackwe11, 8200

B. F. Murphey, 8300

D. M. Schuster, 8310

R. W. Bradshaw, 8313

R. W. Mar, 8313

D. A. Nissen, 8313

S. H. Goods, 8316

J. C. Swearengen, 8316

R. Rinne, 8320; Attn:

L. Gutierrez, 8400

R. Baroody, 8410

C. S. Selvage, 8420

R. C. Wayne, 8450

P. J. Eicker, 8451

A. C. Skinrood, 8452

R. W. Carling, 8453 (25) 
L. G. Radosevich, 8453

W. G. Wilson, 8453

C. M. Tapp, 8460

Publications Division, 8265, for TIC (27)

Publications Division, 8265/Technical Library Processes and Systems Division, 3141

Technical Library Processes and Systems Division, 3141 (2)

Education Division, 8214-2 (3) 


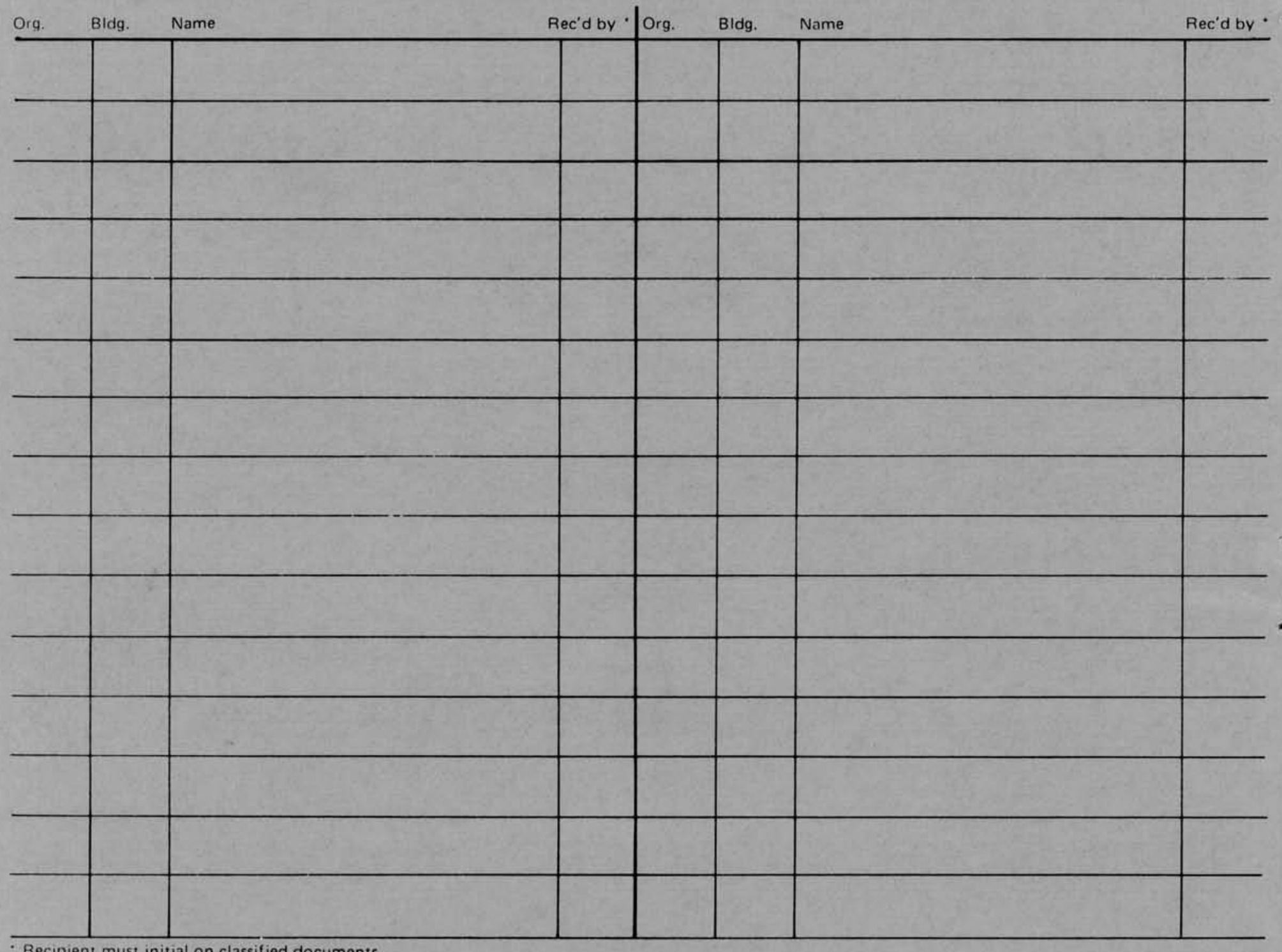

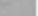

